\title{
STEAM GENERATOR SECONDARY PH DURING A STEAM GENERATOR TUBE RUPTURE
}

by

EGG-NE--10046

DE92 012219

\author{
J. P. Adams \\ E. S. Peterson
}

Published December 1991

Idaho National Engineering Laboratory

EG\&G Idaho, Inc.

Idaho Falls, ID 83415

Prepared for the

U.S. Nuclear Regulatory Commission

Washington, D.C. 20555

Under DOE Contract No. DE-AC07-76ID01570 


\section{ABSTRACT}

The Nuclear Regulatory Commission requires utilities to determine the response of a pressurized water reactor to a steam generator tube rupture (SGTR) as part of the safety analysis for the plant. The SGTR analysis includes assumptions regarding the partitioning of iodine between liquid and vapor in the steam generator secondary. Experimental studies have determined that the partitioning of iodine in water is very sensitive to the $\mathrm{pH}$. Based on this experimental evidence, the NRC requested the INEL to perform an analytical assessment of secondary coolant system (SCS) pH during an SGTR. Design basis thermal and hydraulic calculations were used together with industry standard chemistry guidelines to determine the SCS chemical concentrations during an SGTR. These were used as input to the Facility for Analysis of Chemical Thermodynamics computer system to calculate the equilibrium $\mathrm{pH}$ in the SCS at various discrete times during an SGTR. The results of this analysis indicate that the SCS pH decreases from the initial value of 8.8 to approximately 6.5 by the end of the transient, independent of PWR design. 


\section{SUMMARY}

The concern regarding the consequences of a steam generator tube rupture (SGTR) in a pressurized water reactor (PWR) is dominated by the possibility that radioactive iodine, present in the reactor coolant system (RCS) and transported with the break flow to the secondary coolant system (SCS), can be released directly to the environment. In the majority of SGTRs, both actual and postulated, this occurs via steam transport from the SCS when either the atmospheric dump valves or steam relief valves cycle open. Thus, the iodine concentration in the SCS vapor spaces needs to be determined in order to assess the environmental consequences of an SGTR.

The iodine concentration in the SCS vapor spaces depends on the mass of iodine which has flowed into the SCS liquid via the break flow plus the partitioning of the iodine from the liquid into the vapor. In previous studies, the mass transfer of iodine from the fuel to the RCS to the SCS has been investigated. Iodine partitioning in the SCS has been experimentally investigated and determined to be very sensitive to SCS coolant $\mathrm{pH}$. This report documents the results of an analytical assessment of the response of the SCS $\mathrm{pH}$ to a design basis SGTR.

The study was conducted in two parts. First, design basis thermal and hydraulic analyses were used together with chemistry control guidelines to determine the time variant chemical concentrations in the SCS. Second, these chemical concentrations were used as input to calculate the equilibrium coolant PH during an SGTR.

Simplifying assumptions were used to reduce the total number of individual analyses while allowing the results to be as generally applicable as possible. These assumptions were: 1) the makeup system is, in general, capable of maintaining RCS mass inventory during the 30 min transient; 2) the chemical concentration (of any chemical used in this analysis) in the makeup system is constant during the transient; 3) the concentration of any chemical in either the RCS, SCS, or makeup system is independent of the concentration 
of any other chemical - that is, the concentrations of the various chemicals can be determined individually; 4) mixing of chemicals in the RCS and SCS during an SGTR is both instantaneous and complete; 5) the effect of the initial SCS boron concentration can be ignored; and 6) the affected steam generator is isolated at transient initiation. Applying these assumptions, a total of 10 individual analyses were performed which apply directly to a total of 59 (out of 74) operating PWRs.

The SCS pH was calculated for each of these ten cases using the EQUILIBRIUM computer code in the Facility for Analysis of Chemical Thermodynamics (FACT) computer system. EQUILIBRIUM is used to calculate the equilibrium speciation of a mixture of chemicals by minimization of the system Gibbs free energy. This methodology was applied at discrete times during the transients to calculate the equilibrium $\mathrm{pH}$ in the SCS coolant. In general, the $\mathrm{pH}$ was calculated for each of the ten cases at the end of the transient (assumed to be 30 min after tube rupture). In two cases, a pH time history was also calculated.

The results of this study indicate that the SCS PH during an SGTR is dominated by the boric acid which is disolved in the RCS coolant and flows with the RCS coolant through the break. The pH decreases from the initial value of 8.8 to less than 7 within the first $600 \mathrm{~s}$ of the transient. By the end of the transient, the $\mathrm{pH}$ is approximately 6.5, independent of PWR design. 


\section{ACKNOWLEDGMENTS}

The authors would like to thank Gary Brobst, GEBCO Engineering, for his assistance in interpreting the EPRI chemistry guidelines. In addition, Chris Bale, Art Pelton, and Paul Talley, Ecole Polytechnique, and William Thompson, Royal Military College of Canada provided invaluable assistance in understanding and applying the models within the FACT computer system to this study' as well as in researching the data for the various morpholine phases and developing the user data base. 


\section{CONTENTS}

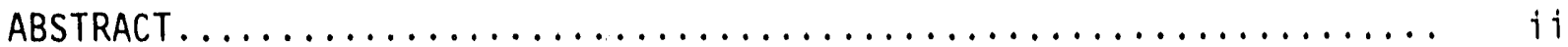

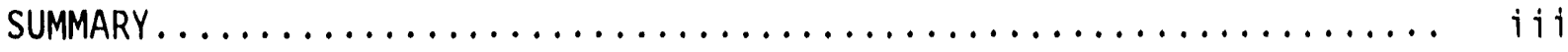

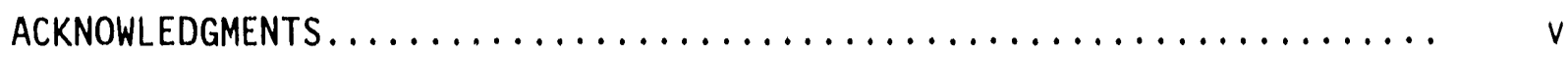

INTRODUCTION. . . . . . . . . . . .

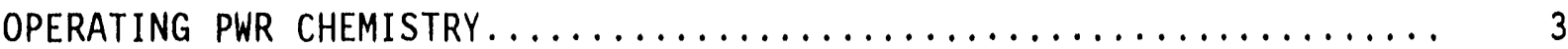

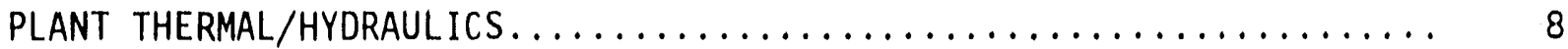

CHEMICAL ANALYSIS...................................... 10

Validation Calculations............................ 12

Steam Generator Calculations......................... 14

Discussion....................................... 16

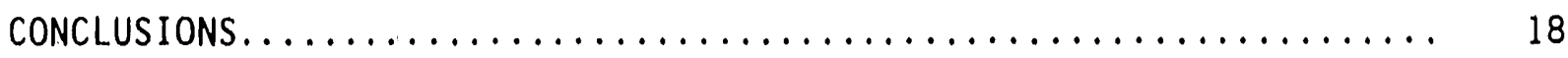

REFERENCES....................................... 30

APPENDIX A: CHEMCAL................................ A-1

APPENDIX B: ESTIMATED THERMODYNAMIC PROPERTIES OF MORPHOLINE AND.... BTHE AQUEOUS MORPHOLINIUM ION

APPENDIX C: WESTINGHOUSE SGTR PROCEDURE.................... C-1

\section{TABLES}

1. Initial condition chemistry for Westinghouse and CE plants.... 19

2. Initial condition chemistry for B\&W plants............... 20

3. Design thermal and hydraulic data used in the

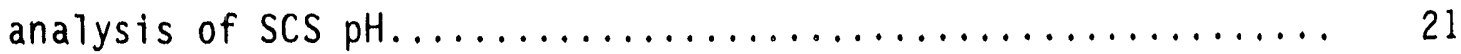

4. Validation calculations using EPRI data................. 22

5. Validation calculations using operating PWR sample data....... 23

6. Steam generator $\mathrm{pH}$ calculations performed using the utility supplied data 1800 seconds after tube rupture......... 24

7. Scs pH time profiles for selected plant designs at $298 \mathrm{~K}$ and $0.1 \mathrm{MPa}$ temperature and pressure, $\mathrm{pH}^{\prime} \mathrm{s}$ are FACT calculated. 25

8. Sensitivity of $\mathrm{pH}$ to temperature under saturated conditions.... 26

9. $\quad \mathrm{PC}_{1}$ measured during $\mathrm{ORNL}$ experiments.................. 27

A-1. Source code listing for the computer program CHEMCAL.......... A-6

C-1. Typical SGTR Sequence of Events....................... C-8 


\section{FIGURES}

1. FACT system output for EPRI validation calculations......... 28

2. FACT system output for the $W 4-1.51 / D$ system at ful1........ 29 power, and 1800 seconds after tube rupture

A-1a: Westinghouse $4-100 p 51 / 0 \mathrm{~S} / \mathrm{G}$ high boron case................ A

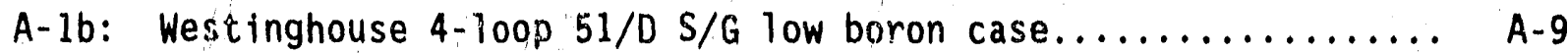

A-1C: Westinghouse $4-100 p 51 / D S / G$ high lithium case............ A-10

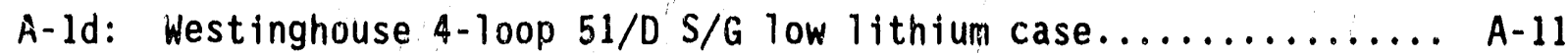

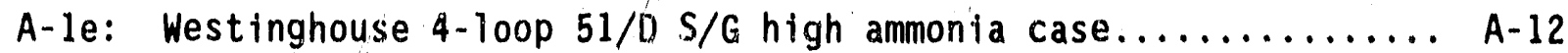

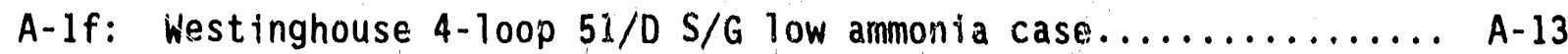

A-1g: Westinghouse 4-10op $51 / 0 \mathrm{~S} / \mathrm{G}$ morphol ine case............... A-14

A-2a: Westinghouse $4-1$ oop $44 \mathrm{~S} / \mathrm{G}$ high boron case............... A-15

A-2b: Westinghouse $4-1$ oop $44 \mathrm{~S} / \mathrm{G}$ low boron case...................

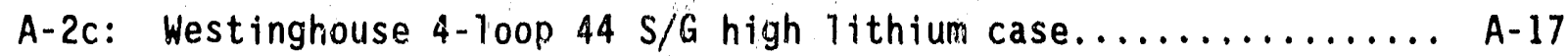

A-2d: Westinghouse $4-100 p 44 \mathrm{~S} / \mathrm{G}$ low lithium case................ A-18

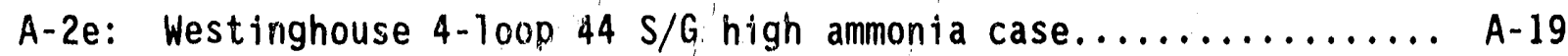

A-2f: Westinghouse 4 -loop $44 \mathrm{~S} / \mathrm{G}$ low ammonia case...................

A-2g: Westinghouse $4-100 p 44 \mathrm{~S} / \mathrm{G}$ morphol ine case..................

A-3a: Westinghouse $4-1$ loop $E S / G$ high boron case.............. A-22

A-3b: Westinghouse $4-100 p$ E $S / G$ low boron case.................. A-23

A-3c: Westinghouse 4-10op E $S / G$ high lithium case.............. A-24

A-3d: Westinghouse 4-10op E $S / G$ low lithium case.............. A-25

A-3e: Westinghouse 4-10op E $S / G$ high ammonia case............. A-26

A-3f: Westinghouse $4-1$ oop $E S / G$ low ammonia case.............. A-27

A-3g: Westinghouse 4-loop $E S / G$ morpholine case.............. A-28

A-4a: Westinghouse $4-1$ loop $F S / G$ high boron case.............. A-29

$A-4 b$ : Westinghouse $4-100 p \mathrm{~F} S / G$ low boron case............... A-30

$A-4 c$ : Westinghouse $4-100 p F S / G$ high 1 ithium case............. A-31

A-4d: Westinghouse $4-100 p \mathrm{~F} S / G$ low 1 ithium case.............. A-32

A-4e: Westinghouse $4-100 p F S / G$ high ammonia case............. A 33

$A-4 f:$ Westinghouse $4-100 p F S / G$ low ammonia case.............. A-34

$A-4 \mathrm{~g}$ : Westinghouse $4-100 \mathrm{p} F \mathrm{~S} / \mathrm{G}$ morpholine case................ $A-35$

A-5a: Westinghouse $3-100 p 51 \mathrm{~S} / \mathrm{G}$ high boron case.............. A-36 
A-5b: Westinghouse $3-100 p 51 \mathrm{~S} / \mathrm{G}$ low boron case.............. A-37

A-5c: Westinghouse $3-100$ p $51 \mathrm{~S} / \mathrm{G}$ high 1 ithium case............. A-38

A-5d: Westinghouse $3-100 p 51 \mathrm{~S} / \mathrm{G}$ low lithium case.............. A-39

A-5e: Westinghouse $3-100 p 51 \mathrm{~S} / \mathrm{G}$ high ammonia case............. A-40

A-5f: Westinghouse 3-10op $51 \mathrm{~S} / \mathrm{G}$ low ammonia case.............. A-41

A-5g: Westinghouse $3-100 p 51 \mathrm{~S} / \mathrm{G}$ morpholine case............... A-42

A-6a: Westinghouse 2-10op $51 \mathrm{~S} / \mathrm{G}$ high boron case.............. A-43

A-6b: Westinghouse 2-10op $51 \mathrm{~S} / \mathrm{G}$ low boron case............... A-44

A-6c: Westinghouse 2-10op $51 \mathrm{~S} / \mathrm{G}$ high lithium case............. A-45

A-6d: Westinghouse 2-10op $51 \mathrm{~S} / \mathrm{G}$ low lithium case............... A-46

A-6e: Westinghouse 2-10op $51 \mathrm{~S} / \mathrm{G}$ high ammonia case............. A-47

A-6f: Westinghouse 2-100p $51 \mathrm{~S} / \mathrm{G}$ low ammonia case.............. A-48

A-6g: Westinghouse 2-100p $51 \mathrm{~S} / \mathrm{G}$ morpholine case................ A-49

A-7a: C.E. 2700 MWt Plant high boron case.................... A-50

A-7b: C.E. 2700 MWt P1ant low boron case.................... A-51

A-7c: C.E. 2700 MWt P1ant high lithium case.................. A-52

A-7d: C.E. 2700 MWt Plant low lithium case.................. A-53

A-7e: C.E. 2700 MWt Plant high ammonia case.................. A-54

A-7f: C.E. 2700 MWt Plant low ammonia case................... A-55

A-7g: C.E. 2700 MWt Plant morphol ine case................... A-56

A-8a: C.E. System 80 Plants high boron case................. A-57

A-8b: C.E. System 80 Plants low boron case.................. A-58

A-8C: C.E. System 80 Plants high lithium case................ A-59

A-8d: C.E. System 80 Plants low lithium case.................. A-60

A-8e: C.E. System 80 Plants high ammonia case................. A-61

A-8f: C.E. System 80 Plants low ammonia case.................. A-62

A-8g: C.E. System 80 Plants morpholine case................. A-63

A-9a: C.E. Mod. System 80 Plants high boron case............... A-64

A-9b: C.E. Mod. System 80 Plants low boron case............... A-65

A-9C: C.E. Mod. System 80 Plants high 1ithium case.............. A-66

A-9d: C.E. Mod. System 80 Plants low lithium case.............. A-67

A-9e: C.E. Mod. System $80 \mathrm{Plants}$ high ammonia case.............. A-68

A-9f: C.E. Mod. System 80 P1 ants low ammonia case.............. A-69

A-9g: C.E. Mod. System 80 Plants morphol ine case............. A-70

A-10a: Babcock and Wilcox Plants high boron case................ A-64 
A-10b: Babcock and Wilcox Plants low boron case.............. A-65

A-10c: Babcock and Wilcox Plants high lithium case............. A-66

A-10d: Babcock and Wilcox Plants low lithium case.............. A-67

A-10e: Babcock and Wilcox Plants high ammonia case............. A-68

A-10g: Babcock and Wilcox Plants morphol ine case.............. A-70 


\title{
STEAM GENERATOR SECONDARY PH DURING A STEAM GENERATOR TUBE RUPTURE
}

\author{
INTRODUCTION
}

In pressurized water reactors, (PWRs), water in the reactor coolant system (RCS) is pressurized to prevent it from boiling. This high-pressure water is circulated through heat exchanger tubes in steam generators where heat is transferred to the lower pressure secondary coolant system (SCS), producing steam which is used to generate electrical power. The tubes represent a large fraction of the RCS boundary and rupture of these tubes can result in a direct release of radioactivity to the environment (containment bypass) through either the atmospheric dump valves or secondary relief valves. Since this coolant typically contains radioactive materials, a steam generator tube rupture (SGTR) has been designated as a design basis accident for PWRs and must be analyzed as part of the plants Final Safety Analys is Report (FSAR).

The principal radiological concern during an SGTR results from the presence of radioactive iodine in the RCS coolant. The iodine, a fission product which is present in irradiated fuel, is found in the RCS coolant either as a product of the fissioning of tramp uranium on the fuel element surface or from the fuel itself, being released through tiny holes in the cladding of otherwise undamaged fuel rods. Recent studies have been conducted to determine the amount of radioactive iodine which is expected to be present in the RCS coolant during an SGTR ${ }^{1,2}$. The previous studies were restricted to the determination of iodine concentrations in the RCS resulting from iodine spiking in conjunction with an SGTR.

During an SGTR, radioactive iodine is transported by the break flow from the RCS into the SCS where it is mixed with the other chemicals in the steam generator. If the steam generator secondary is completely filled with water, as a result of the break flow, the iodine may be transported, again with 
water, and released to the environment. However, in the majority of SGTR transients (both postulated and actual), the steam generator is not completely filled and only steam is released to the environment. Therefore, the iodine concentration in the steam must be determined in order to estimate the environmental consequences (i.e. iodine source term to the environment) due to an SGTR.

Previous studies have been made of iodine partitioning between liquid and steam in a closed system ${ }^{3,4}$. The sensitivity of lodine partitioning to several parameters was studied under a wide variety of conditions. One of the most important parameters was determined to be the $\mathrm{pH}$ of the coolant. Acidic conditions favor the formation of volatile iodine species and alkaline conditions favor the formation of non-volatile iodine species. Thus, an estimate of the coolant $\mathrm{pH}$ during an SGTR is required for the determination of the environmental release of radioactive iodine. The objective of this study was the determination of secondary $\mathrm{pH}$ during an SGTR.

The remainder of this report is divided into four sections. "Operating PWR Chemistry" includes a discussion of typical RCS, SCS, and makeup system chemistries during nominal PWR power operations. "Plant Thermal/Hydraulics" summarizes the grouping of PWRs into a manageable number of designs with common RCS mass, SCS mass, and break flow characteristics. "Chemical Analysis" presents the final results of this study, the determination of SCS $\mathrm{pH}$ during an SGTR. The final section presents the conclusions of this study. There are, in addition, three appendices: Appendix $A$ contains a discussion of the computer program CHEMCAL which was used to calculate the concentrations of the various chemical species expected to be present in the SCS; Appendix B contains a discussion of the morpholine thermodynamic data base used in the analysis of SCS pH; and Appendix C contains a discussion of a typical SGTR recovery procedure and the effects of the simplifying assumptions used in this analysis on the final results. 


\section{OPERATING PWR CHEMISTRY}

Since the first commercial PWR at Shippingport, PA was constructed, corrosion has emerged as one of the most troublesome phenomena associated with the production of electricity using nuciear fuel. As the construction materials in the RCS corrode, microscopic particles spall off the walls, are circulated though the reactor core where they are activated by neutron absorption, and then are deposited in the RCS piping, causing "hot spots." These hot spots are a source of great concern since they can cause excessive worker irradiation, especially during maintenance activities. Much research has been conducted to understand and prevent RCS corrosion using various chemical inhibitors.

Corrosion on the secondary side is, if anything, even more difficult to control because chemical contaminants which cause the corrosion tend to be locally concentrated (e.g. In the tube support plate crevices) during the boiling process in the steam generator secondaries. Indeed, it is most often this corrosion (SCS corrosion) rather than RCS corrosion that causes SGTRS when the tube wall has been weakened sufficiently that the RCS-SCS pressure differential can rupture the tube(s). Various steam generator tube corrosion mechanisms have been identified (e.g. chlorine stress corrosion cracking of stainless stee1, phosphate attack in tube sheet crevices, fast linear generation of magnetite leading to tube denting, etc), usually after they have caused tube corrosion in operating plants. In each case, SCS chenistry control procedures were revised to counteract the newly discovered corrosion mechanism.

The Electric Power Research Institute (EPRI) has conducted a number of corrosion studies for the materials found in PWRs. As a result of these studies, ERPI has issued and then periodically updated RCS and SCS chemistry control guidelines which, in their best judgement based on extensive corrosion experimental data, minimize material corrosion during the various plant states (shutdown, cold layup, hot layup, power operations, etc.). These guidelines are universally used by all U.S. PWR operators as the basis for their RCS and 
SCS chemistry controls. " The latest versions of these guidelines ${ }^{5,6}$ were used in this study to provide the boundary conditions for the analysis of secordary pH during an SGTR. In all cases, the nominal chemistry concentration ranges that are recommended during normal full power operations were used.

The principal chemical additives to the RCS are boric acid and lithium hydroxide. Boric acid is added as one part of the reactor kinetics control system. Use of this adjustable neutron poison allows more fissile material to be loaded into the core during refueling. Boric acid is also maintained in the RCS makeup system, again for the purpose of controlling reactivity, this time in the event of an off nominal transient. The RCS materials of cunstruction, including both structural and core materials, tend to corrode more rapidly under acidic conditions. Therefore, lithium hydroxide is added to the coolant to maintain an alkaline $\mathrm{pH}$ and minimize corrosion.

Chemistry control guidelines for the RCS are independent of reactor design. There are, however, some differences based on the length of the fuel cycle. For reactors using a 12 month fuel cycle, the boron (introduced as boric acid) concentration is varied from 1200 parts per million (ppm) (beginning of core life [BOL]) to $0 \mathrm{ppm}$ (end of core life [EOL]). However, for plants with an extended 18 month fuel cycle, the BOL boron concentration is increased to $1400 \mathrm{ppm}$. The EOL boron concentration remains the same as for those plants with a 12 month fuel cycle. For this study, the boron concentration was varied between 0 and $1400 \mathrm{ppm}$, representing the larger boron concentration range. Primary coolant $\mathrm{pH}$ is maintained between 6.9 and 7.4 throughout core life by the addition of lithium hydroxide with a lithium concentration ranging from $2.3 \mathrm{ppm}$ (BOL) to $0.2 \mathrm{ppm}$ (EOL). This was the range used in this study. Because of the RCS coolant $\mathrm{pH}$ guideline, the higher concentrations of lithium and boron were used in conjunction with each other, as well as the lower concentrations of both species. There is an additional

Private communication with Frank Witt (USNRC-NRR) on January 29, 1991. 
source of lithium in the RCS, namely activation of ${ }^{10} \mathrm{~B}$ via the neutron-alpha reaction, ${ }^{10} B(n, \alpha){ }^{7} \mathrm{~L} i$. The total amount of 1 ithium which may be in the RCS due to this reaction depends on core 1 ife and ranges from 0 at $B O L$ to concentrations approaching the ppm level at EOL. ${ }^{b}$

Control of chemistry on the secondary side is more complex, primarily because of different steam generator designs. Therefore, additional guidance was obtained on the interpretation of the applicable EPRI guidelincs. ${ }^{c}$ There are four principal additives for chemistry control in the steam generator secondary sides. The principal pH control additive is ammonia. Ammonia is compatible with the secondary plant construction materials and provides an adequate protection against corrosion in the absence of impurity ingress. However, ammonia is very volatile and only minimal residuals remain on the steam generator heat transfer surfaces and in crevices during power operation. This means that non-volatile contaminants (such as chlorine and sodium) can concentrate in tube crevices and create an unbuffered corrosive environment. Morpholine and other additives are used to provide the buffering in the crevices.

Morpholire is less volatile than ammonia and as such reduces ernsioncorrosion in two-phase regions and provides a higher liquid phase pH in wet steam regions. The addition of morpholine has significantly reduced the erosion/corrosion of carbon steel components, especially in the steam/condensate piping outside the steam generator. ${ }^{7}$ Additionally, the use of morpholine has resulted in much lower accumulations of sludge in the steam generators than would have been expected if ammonia alone had been used. ${ }^{8}$ Morpholine is currently considered acceptable as an SCS pH control additive for both recirculating and once-through steam generators.

b Personal communication from K. I. Parczewski, December 16, 1991.

c Private communication with Gary Brobst (GEBCO Engineering, Inc.) on February 8, 1991. 
With the popularity of all-volatile steam generator chemistry continl in the 1960s, a new tube deyradation mechanism was discovered. Under certain conditions, the carbon steel tube support plates were subjected to fast linear growth of magnetite in the tube-support plate crevices. Tiie magnetite presses on the outside of the tubes, compressing them inward until they crack, a phenomenon called "denting." To counteract this denting, small concentrations of boric acid are maintained in the SCS. ${ }^{9}$ This treatment has also been sirown to mitigate caustic ilitergranular attack of inconel Alloy 600 tubes. ${ }^{10}$

Finally, hydrazine is added, in some plants, both as a pH control additive and to "scavenge" any oxygen introduced into the system with the feedwater.

Westinghouse and Combustion Engineering (CE) design plants contain recirculating steam generators, which are essentially a boiling pot of water with liquid separators on the steam exit to dry the saturated steam to a minimum quality of $99.75 \%$. These steam generators derive their name (recirculating) from the fact that the water, which is stripped from the steam in the separators, is recirculated back into the boller. Thus all of the nonvolatile feedwater contaminants are concentrated. For the recirculating $\mathrm{plants}, \mathrm{pH}$ is controlled between 7.0 and 9.2, depending upon whether the plant is all ferrous- or ferrous/copper-design and whether boric acid is used to mitigate tube denting. The levels of boron in the SCS coolant are very small (typically $5 \mathrm{ppm}$ ) compared to the boron which enters the coolant as a result of an SGTR (typically up to $700 \mathrm{ppm}$ [BOL.] or $35 \mathrm{ppm}$ [EOL]). Therefore, the small initial SCS boron concentration was ignored. The $\mathrm{pH}$ is zontrolled between 8.5 and 9.2 for plants with no boric acid addition. Morpholine concentrations are typically 2 - 4 ppm with a nominal concentration of $3 \mathrm{ppm}$. Hydrazine is added, in parts per billion (ppb) concentrations, to the feedwater to react with and eliminate free oxygen. In the steam generator, hydrazine quickly decomposes to ammonia and, in this study, was combined with the much larger concentrations of ammonia which is the principal $\mathrm{pH}$ control agent. Ammonia concentrations typically vary between 1 and $7.5 \mathrm{ppm}$, depending on the desired $\mathrm{pH}$. Thus, for Westinghouse and CE plants (i.e. plants with recirculating steam generators) the calculations were based on initial steam 
generator chemistry concentrations of $1-7.5 \mathrm{ppm}$ for Ammonia and $3 \mathrm{ppm}$ for morpholine.

Babcock and Wilcox (B\&W) plants contain a unique steam generator design, named the once-through steam generator (OTSG). Water is fed into the OTSG where it is boiled and then superheated prior to exiting via the steam 1 ine. There is no recirculation of water within the boiler and, therefore, less concentracing of contaminants in the feed water. However, solid contaminants will deposit upon the tube surfaces and potentially cause corrosion. Because of their different thermal/hydraulic design, OTSGs require somewhat different chemical controls than recirculating steam generators. Morpholine is typically maintained at a higher concentration (5 ppm vs $3 \mathrm{ppm}$ for recirculating steam generators). The $\mathrm{pH}$ range is somewhat smaller $(8.8-9.6)$ resulting in a smaller potential concentration range of ammonia 10.0 $2.0 \mathrm{ppm})$. Even though it is anticipated that some ammonia will be in the SCS coolant under all conditions, the $\mathrm{pH}$ ranges listed in the EPRI guidelines can be met with a concentration of $0.0 \mathrm{ppm}$. Therefore, the concentration used for the "low ammonia" calculation cases was 0 ppm ammonia.

The third system that interacts during an SGTR is the makeup system. The only makeup system chemical considered in this study was boron, used for reactivity control during an accident. Typical makeup system boron concentrations range from $600 \mathrm{ppm}$ to $1200 \mathrm{ppm}$, depending upon plant design. Therefore, the above range was used in this study.

The chemical concentrations used for this study are summarized in Table 1 (recirculating steam generator designs) and Table 2 (OTSG designs). The resultant SCS chemical concentrations are included in Appendix $A$. There are, obviously, wide ranges of chemical concentrations to consider, due to the ranges of $\mathrm{pH}$ (in the RCS and SCS), as well as core age (from BOL to EOL). The princ, al calculations assumed BOL conditions and $\mathrm{pH}$ on both RCS and SCS to initially be at the lower end of their ranges. This provided the most acidic conditions which would be expected to exist in a PWR while still remaining within the technical specifications of the individual plants. Since $P C_{1}$ decreases with $\mathrm{pH}$, this analysis results in the smallest expected value for 
$P C_{1}$, and the highest expected concentration of lodine in the steam generator steam volume.

\section{PLANT THERMAL/HYDRAULICS}

There are 74 different operating PWRs in the U.S.. A detailed analysis of the SCS PH during an SGTR for each of these different plants was not possible within the available budget and schedule, nor was such a detailed analysis considered necessary to the overall objective of this study. Therefore, it was decided to group the plants with common designs and to not include those PWRs which were one-of-a-kind. In this manner, ten detailed analyses were conducted that represented $59(80 \%)$ of the operating PWRs. This section includes a description of the specific thermal and hydraulic parameters used in the analyses and the selection process used to group these PWRs.

Appendix $A$ includes a detailed discussion of the analysis methodology used to calculate the SCS chemical concentrations during an SGTR. In the derivation of this methodology, it was assumed that: 1) the makeup system is, in general, capable of maintaining RCS mass inventory during the 30 min transient; 2) the chemical concentration (of any chemical used in this analysis) in the makeup system is constant during the transient (in effect this means that the boron concentration in the makeup system is constant as there are no other chemical additives in this system); 3 ) the corcentration of any chemical in either the RCS, SCS, or makeup system is independent of the concentration of any other chemical - that is, the concentrations of the various chemicals can be determined individually; 4) mixing of chemicals in the RCS and SCS during an SGTR is both instantaneous and complete; 5) the effect of the initial SCS boron concentration can be ignored; and 6) the affected steam generator is isolated at transient initiation. A discussion of the validity and effects of each of these assumptions is included in Appendix A. In addition, deviations from the design-basis accident recovery procedure and these assumptions are discussed in Appendix $C$. 
Use of the above assumptions greatly simplifies the analysis and results in only three basic plant design parameters plus the initial chemical concentrations (discussed in Operating PWR Chemistry) being required for the analysis. The plant design parameters are the initial SCS mass inventory, initial RCS inventory, and average break mass flow rate. The break mass flow rate was averaged over the 30 minutes transient for each design and this constant value was used in each analysis. Not only do these assumptions simplify each analysis, they also enable the PWRs to be grouped into ten basic designs, thus reducing the number of detailed analyses which are required.

Using this methodology, there is one basic B\&W design, which accounts for seven operating plants. ${ }^{11}$ The parameters for the B\&W design are listed in Table 3. The data for the B\&W design (excepting the break mass flow rate) were obtained from a report issued by the Nuclear Safety Analys is Center. ${ }^{12}$ The break mass flow rate represents an average of the break flow rates taken from FSARs for several B\&W-design PWRs.

There are currently 15 operating PWRs designed by Combustion Engineering. However, of these, four are one-of-a-kind plants (Palisades, Arkansas Nuclear One Unit 2, Fort Calhoun, and Maine Yankee) and were not included in the analysis. The remaining 11 plants can be grouped into three basic designs: 2700 MWt Plants (five plants); System 80 Plants (three plants); and Modified System $80 \mathrm{Plants}$ (three plants). The design data for these three designs were obtained from FSARs and are included in Table 3.

There are current1y 52 operating Westinghouse-design PWRs. Of these, 42 can be reasonably represented by 6 basic designs. The designs are: 4-10op RCS with either Series 51 or Series D steam generators (22 plants); 4-10op with Series 44 steam generators ( 2 plants); 4-10op with Series $E$ steam generators (2 plants); 4-10op with Series F steam generators (5 plants); 3-10op with either Series 51 or Series D steam generators ( 8 plants); and 2-10op with Series 51 steam generators ( 3 plants). The design data for the Westinghousedesign plants were obtained from FSARs and are included in Table 3. 
In summary, there are 74 operating PWRs in the U.S.. Of these, 59 have been grouped into ten basic designs for this study, representing approximately $80 \%$ of the operating PWRs. Most of those which were not specifically included in this analysis were old and/or one-of-a-kind design.

\section{CHEMICAL ANALYSIS}

All of the chemical analyses of the response of the SCS pH to a postulated SGTR were performed using the Facility for Analys is of Chemical Thermodynamics (FACT). ${ }^{13,14}$ FACT is a computer program which enables one to perform commonly encountered thermochemical calculations using a computer terminal. All input is internally checked both for logical and numerical validity. In addition, the system has its own data base consisting of the thermodynamic properties of over 3800 stoichiometric compounds and a number of binary solutions. This computer program has been designed to be of use to many branches of fundamental and applied chemistry. In our case the principal FACT program which was used was EQUILIBRIUM.

EQUILIBRIUM is based on the latest version of SOLGASMIX ${ }^{15}$ and can be used to calculate the thermodynamic equilibrium speciation of a mixture of reactants in gas, liquid, aqueous, and solid phases. EQUILIBRIUM differs from SOLGASMIX in that it has much more flexibility. Up to 12 elements can be input, while SOLGASMIX only allows for the input of 8 elements. A maximum of 500 compounds can be included in the resultant data. Thus the entire chemical make up of a given chemical system (with specified simplifications) in these studies could be examined in a single integrated calculation.

The FACT collection of codes includes a large data base of inorganic compounds, with more than 60010 phases (chemical compounds in various physical conditions, gas, liquid, solid, or aqueous). In addition, a user constructed data base can be developed to include those compounds which are of interest to the specific analysis and are not in the main data base. A review of the literature was performed so that the thermochemical properties of morpholine, examined and checked for consistency over the applicable temperature range, 
would be available for this task. The data, including morpholine in liquid, aqueous, and gas phases as well data for the morpholinium ion in the aqueous phase, were then entered into the data base. A detalled discussion of these data is included in Appendix B.

As stated in the introduction to this report, the main purpose for this analysis was to calculate the SCS pH during an SGTR so that the iodine partition coefficient $\left(P_{1}\right)$ could be determined. Thus, a correlation between SCS $\mathrm{pH}$ and $\mathrm{PC}_{1}$ is required to complete the analysis after the SCS $\mathrm{pH}$ has been calculated. This correlation was experimentally measured at the 0ak Ridge National Laboratory (ORNL). 4,16 The experimental procedure, as discussed in these two references, was as follows:

1. Orthoboric acid was dissolved in demineralized distilled water sufficient to result in a concentration of 0.05 to $0.5 \mathrm{M}$.

2. If necessary, $1.0 \mathrm{M} \mathrm{NaOH}$ was added \pm 0 adjust the $\mathrm{pH}$ to the desired value (either 5, 7, or 9) and the volume was adjusted to a sperified value.

3. Just before each experiment, ${ }^{131}$ I was added to the solution in the form of $\mathrm{NaI}$ in a $0.1 \mathrm{NaOH}$ solution, diluted to give $1 \times 10^{-9}$ to $5 \times 10^{-9} \mathrm{M}$ concentration.

4. The $\mathrm{pH}$-adjusted solution was poured into an autoclave reactor and heated to $558 \mathrm{~K}$ and pressurized to $6.90 \mathrm{MPa}$ to simulate operating steam generator SCS conditions.

5. After the solution had been at temperature and pressure for several hours, liquid and vapor samples were taken and the iodine concentrations in each were measured by counting the iodine radioactivity in the aliquots using a $\mathrm{NaI}$ well detector. The $P C_{1}$ was calculated from the iodine concentration measured in the vapor and liquid samples.

The FACT system, specifically the EQUILIBRIUM thermochemical code, was used for all calculations performed in this task. In each case, except where specifically stated otherwise, the assumed temperature and pressure were $298 \mathrm{~K}$ and $0.1 \mathrm{MPa}$. These conditions were used to match those of the $\mathrm{pH}$ measurements 
in the ORNL experiments. The results from these calculations are divided into two separate sections: a.) Validation Calculations to duplicate those results presented in the Electric Power Research Institute's (EPRI) publications (References 5 and 6 ) as well as pH measurements of commercial PWR RCS coolant reported by Vollleque ${ }^{17}$; and b.) Steam Generator Calculations for the reactor designs discussed in "Plant Thermal/hydraulics" for the postulated SGTRs.

\section{Validation Calculations.}

The EQUILIBRIUM code was tested for its ability to jiplicate the values presented in the EPRI manuals 5,6 by examining test cases taken directly from the manuals under various conditions. The results of these efforts are found in Table 4.

The results of one of the validation experiments for the SCS are shown in Figure 1 below. The calculated results are based on a solution consisting of: $10 \mathrm{ppm}$ morpholine, $1.0 \mathrm{ppm}$ ammonia, dissolved in water at 300 degrees Kelvin and a pressure of one atmosphere. Quantities shown in brackets are the actual molar concentrations which were entered, and the computer output is shown in Figure 1. The complexity of the speciation in these systems should be noted. The calculated $\mathrm{pH}$ for the solution was 8.88. For comparison, the EPRI $\mathrm{pH}$ value for the solution (taken from Reference 6, page $\mathrm{B}-13$ ) is $\mathrm{pH}=$ 8.95. We feel that the difference of $0.07 \mathrm{pH}$ units between our results and those of EPRI is acceptable. Additional FACT validation results compared to EPRI values are summarized in Table 4 . In all but one case, the FACT values are within $0.5 \mathrm{pH}$ unit of the EPRI numbers and in every case, the FACT values are less than those from EPRI. (The difference in the one case is 0.51.) We consider this to be an acceptable level of precision for this study.

In addition to these validation calculations, the EQUILIBRIUM code was used to calculate the $\mathrm{pH}$ of several PWR RCS samples and to compare these calculations with measurements ${ }^{17}$ made by the operators. Seven samples were extracted from two $\mathrm{plants}$ during the time the plants were being taken from power operations to cold shutdown (in fact, there were many more than seven 
samples taken from these two plants during the cooldown transtents - however, sufficient data for the $\mathrm{pH}$ calculation were only available for these sevend ${ }^{\text {d }}$. The results of the comparisons are presented in Table 5 , including the sample time relative to reactor shutdown, RCS temperature and pressure at the time the sample was taken (note: the actual $\mathrm{pH}$ measurements were made at $298 \mathrm{~K}$ and $0.1 \mathrm{MPa}$ ), boron and 1 ithium concentrations in the samples, $\mathrm{pH}$ measurements, and $\mathrm{pH}$ calculations. In each case, the calculated $\mathrm{pH}$ was within $0.5 \mathrm{pH}$ units and, in each case, the calculated $\mathrm{pH}$ was lower than the measured value.

In summary, the EQUILIBRIUM code within FACT has been assessed for its ability to calculate SCS PH during an SGTR. Results from the code have been compared to EPRI SCS chemistry guidelines and with operating PWR RCS sample $\mathrm{pHs}$ and in general the calculations were within $0.5 \mathrm{pH}$ units. The calculated values were consistently lower than either the EPRI or PWR results. Thus, values calculated using the EQUILIBRIUM computer code and the most acidic boundary conditions should yield results (i.e. $\mathrm{pH}$ values and $P C_{1}$ ) which will be worst-case, though realistic, estimates for these parameters. The $P C_{1}$ determined using these values for $\mathrm{pH}$ and tie ORNL experimental data should therefore represent a realistic, conservative basis for calculating the release of iodine during a design basis SGTR.

The reason for the consistently low calculated values of $\mathrm{pH}$ (relative to the reference data) is not known. As discussed in Appendix $B$, however, the thermal-hydraulic data for the morpholinium ion is not known and had to be estimated for this analysis. Table 6 shows that the discrepancy (between calculated and measured $\mathrm{pH}$ ) tends to be larger with larger morphol ine concentrations. Thus, it has been judged that the discrepancy between calculated and measured $\mathrm{pH}$ is probably a result of the uncertainty associated with the thermal-hydraulic data for the morpholinium ion. This shouldn't appreciably affect the calculated $\mathrm{pH}$ at the end of the transient since by this time the morpholine concentration has been significantly diluted by the break flow. 1991. 


\section{Steam Generator Calculations}

The EQUILIBRIUM code was used to generate the $\mathrm{pH}$ values for each of the steam generator designs which we examined. Results were obtained using the chemical concentrations at 30 minutes into the transient (see Appendix A) at $298 \mathrm{~K}$ and $0.1 \mathrm{MPa}$ for all ten designs. The results of these calculations are listed in Table 6. The SCS PH at the end of an SGTR transient approachis a value of 6.5 with only slight variations between different PWR designs.

In addition to these calculations at 30 minutes, two time history calculations were made, using one PWR from Westinghouse and one, from C.E.. The $\mathrm{pH}$ was calculated in $600 \mathrm{~s}$ time increments from SGTR initiation to transient termination at 30 minutes. The results, 1 isted in Table 7 , indicate that the SCS PH quickly (within $600 \mathrm{~s}$ of transient initiation) decreases from the pre-SGTR value to a value close to that of the RCS and then remains nearly constant unti1 transiont termination.

An additional set of calculations was performed to calculate the temperature sensitivity of $\mathrm{pH}$ under SCS conditions. These calculations were performed because while the ORNL pH measurements were taken at room temperature and pressure, the lodine partitions in a steam generator at. elevated temperatures and pressures during an actual SGTR. It is we11 known that temperature affects both the ionization of pure water, but also the ionization of acids and bases in water. For example, at $373 \mathrm{~K}$, the hydrogen ion concentration in pure water, $\left[\mathrm{H}^{+}\right]$, is $7.4 \times 10^{-7}$ Molar, resulting in a $\mathrm{pH}_{\mathrm{eff}}$ of 6.13 (where $\mathrm{pH}_{\mathrm{eff}}$ is the effective $\mathrm{pH}$, a measure of hydrogen ion concentration at temperatures and pressures other than $298 \mathrm{~K}$ and $1 \mathrm{~atm}$ ). ${ }^{\text {iB }}$ Thus, it was considered useful to investigate the temperature behavior of $\mathrm{pH}$ under SCS conditions. The temperature sensitivity calculations were made using the conditions represented by the Westinghouse 4-Loop, 51/D stealn generator design at 30 minutes. The results of this temperature sensitivity study are presented in Table 8 and indicate a slight tendency for the effective $\mathrm{pH}$ (i.e. hydrogen ion concentration) to increase with increasing temperature under saturation conditions. Since the correlation between $\mathrm{pH}$ and 
lodine partitioning is based on $\mathrm{pH}$ measured at $298 \mathrm{~K}$ and 1 atm conditions, no inference can be made regarding $\mathrm{pH}$ at elevated temperature and pressure and its affect on $P C_{1}$. This does, however, 111ustrate the care which should be taken in applying the ORNL results to operating PWR conditions.

The results of one steam generator $\mathrm{pH}$ calculation for the SCS are shown in Figure 2. The calculation was performed for tive Westinghouse 4-10op Sertes $51 / D$ steam generator design at standard conditions (298 $\mathrm{K}$ and $0.1 \mathrm{MPa}$ ) and for the high boron, high 1tthium, low ammonia, nominal morpholine concentrations which were judged to be the worst case or most acidic scenario. Quantities shown in brackets are the molar concentrations which were entered, and the computer output is shown in the figure.

Conditions for the calculations were chosen as the "worst case" conditions, or the conditions under which the steam generators would expertence the most acidic pH. These conditions are the ones in which the maximum amount of boric acid is injected into the SCS and are also the ones under which the maximum amount of lithium is injected (to maintain nominal pH in the RCS). Nominal morpholine and low ammonia concentrations were used resulting in the minimuminitial condition SCS pH. As a chec's on this assumption fi.e. that high-boron, high-lithium, low-ammonia, and nominal morpholine concentrations result in the minimum transient $\mathrm{pH}$ ), an "average" or mid-point calculacion was performed on the Westinghouse 51/D plant in which the average values of the ranges for concentration of the reactants (boron, lithium, morpholine and ammonia) were determined and entered into the EQUILIBRIUM program. The resulting $\mathrm{pH}$ from the "average" calculation is 6.7 , as shown in Table 6 . This value i: higher than the pH calculated using the "worst case" chemical concentrations used in the other calculations shown in the table. 


\section{DIscussion}

There are a number of topics which need clarification in this series of analyses. The principle one is an understanding of "pH" under the conditions in which the steam generators operate. During an SGTR, the lodine partitioning takes place at elevated temperatures and pressures. The ORNL experiments developed a correlation between $\mathrm{pH}$, measured prior to heatup of the samples, and fodine partioning at operating conditions. It is, however, the aqueous pH at operating conditions which dominates the iodine speciation and partitioning, not the $\mathrm{pH}$ at cold temperatures and atmospheric pressure. Since $\mathrm{pH}$ is based on the coricentration of hydrogen ions in water at 298 degrees Kelvin and one atmosphere, the very concept of a "pH" at elevated temperatures and pressures is difficult to understand, let alone measure. In the future, it would be preferable for the industry to adopt a more appropriate convention to express the hydrogen ion concentrations of the solutions involved. The method, already recommended by EPRI, of using the hydroxide ion concentration would be quite acceptable, and provide a much more realistic basis for determining $\mathrm{PC}_{1}$.

One additional aspect of the ORNL experiments should also be noted. The experimenters used $\mathrm{NaOH}$ to balance the boric acid and set the pre-heatup $\mathrm{pH}$. The assumption inherent in this is that $\mathrm{NaOH}$ (used in the experiments) and LiOH (typically used to maintain RCS pH in PWRs) behave similarly when subjected to the high temperatures and pressures at, which ORNL measured $P C_{1}$. (Additionally, the experiments ignored any potential effect of typical SCS volatile $\mathrm{pH}$ additives such as morpholine and ammonia on $\mathrm{PC}_{1}$.) It would be beneficial to analytically investigate the validity of these assumptions.

A number of calculations were performed to demonstrate the validity of using the FACT system to calculate the $\mathrm{pH}$ of the solutions in the steam generators at operational conditions. Our results are shown in Tables 4 and 5. The calculations show that, at the concentrations at which the actual steam generators operate, and under which we have modelled the system, the 
degree of error in our calculations is acceptably smal1. Other simple hand calculations were performed to ascertain the overall validity of the systems in question. Finally, each calculation was repeated to be certain that the results were of optimal quality and were reproducible.

The understanding of hydrogen ion concentration under these conditions is another area which needs clarification. In the event of an SGTR, one is transferring the moderately acidic solution of the RCS into the moderately basic SCS $\left(\mathrm{pH}_{\mathrm{RCS}}=6.9-7.4 ; \mathrm{pH}_{\mathrm{SCS}}=8.5-9.2\right)$. Our results show that at the specified conditions the $\mathrm{pH}$ becomes slightly more acidic (i.e. approximat? $\mathrm{pH}=6.5)$. From a simple logical approach such an occurrence follows the principles of chemical thermodynamics.

The results from the ORNL iodine partition coefficient experiments (see Reference 3) are shown in Table 9, which illustrates the correlation between $\mathrm{pH}$ (measured prior to experiment heatup) and $P C_{1}$. The $P C_{1}$ for a $\mathrm{PH}$ of 5 in air is 350 , and at $\mathrm{pH}=7 . \mathrm{PC}_{1}=888$. The expected $\mathrm{pH}$ during an SGTR, based on this study, is approximately 6.5 which corresponds to a $P C_{1}=750$ (based on a linear interpolation). If the $0.5 \mathrm{pH}$ unit uncertainicy is applied, the final $\mathrm{pH}$ could range between 6.0 and 7.0 , with the resulting $\mathrm{PC}_{1}$ ranging from 620 . 890 .

These values for $F C_{1}$ are based on volume concentrations (i.e. concentrations with units of $g_{I} / m_{H_{2} O}^{3}$ ) in the liquid and vapor spaces. The values based on mass concentrations (i.e. concentrations with units of $\left.g_{I} / g_{\mathrm{H}_{2} \mathrm{O}}\right)$ can be determined by dividing the volume-based $\mathrm{PC}$, by the ratio of liquid to vapor water densities. The vapor and liquid water densities corresponding to saturated conditions and an SCS pressure of $4.14 \mathrm{MPa}$ are 20.8 and $795 \mathrm{~kg} / \mathrm{m}^{3}$, respectively, resulting in a ratio of liquid-to-vapor densities of 38. Thus, for these conditions, the range for the mass-based $P C_{1}$ is 16 23 with the best-estimate value of 20 . 


\section{CONCLUSIONS}

The $\mathrm{pH}$ response of the steam generator secondary to a postulated SGTR has been analyzed. A 30 minute transient was assumed in the analysis. Plant thermal and hydraulic data were obtained for 10 generic PWR designs (one B\&W, three CE, and six Westinghouse). EPRI chemistry guidelines were used to determine the initial condition concentrations of ammonia and morpholine in the SCS, boron and lithium in the RCS, and boron in the makeup system. The data were used to calculate the SCS chemical concentrations during an SGTR, from which the transient $\mathrm{pH}$ in the steam generator secondary coolant was determined. In general, it was determined that the $\mathrm{pH}$ decreases from an initial value of approximately 8 - 9 to a value of approximately 6.5 , independent of PWR desiyin. The analyses simulated mixing of RCS and SCS coolants and the measurement of $\mathrm{pH}$ without volatilization of any of the chemical constituents. The methodology is analogous to the experimental procedure used by ORNL in their iodine partitioning experiments. 
Table 1: Initial condition chemistry for Westinghouse and CE plants

System

RCS

SCS

Makeup
Chemical

boron

lithium hydroxide

ammonia

morphol ine

boron
Concentration

0 - 1400 ppm

$0.2-2.3 \mathrm{ppm}$

$1.0-7.5 \mathrm{ppm}$

$3.0 \mathrm{ppm}$

$600-1200 \mathrm{ppm}$ 
Table 2: Initial condition chemistry for B\&W plants

System

RCS

SCS

Makeup
Chemical

boron

lithium

ammonia

morphol ine

boron
Concentration

0 - 1400 ppm

$0.2-2.3 \mathrm{ppm}$

$0.0-2.0 \mathrm{ppm}$

$5.0 \mathrm{ppm}$

$600-1200$ ppm 
Table 3: Design thermal and hydraulic data used in the analysis of SCS $\mathrm{pH}$

Design

$B \& W$

CE $2700 \mathrm{MWt}$

CE Sys 80

CE Mod Sys 80

W $4-L 51 / D^{a}$

W $4-L 44$

W $4-L E$

W 4-L F

W $3-L 51 / D$

W 2-L 51
RCS Mass $(\mathrm{kg})$

$2.33 \times 10^{5}$

$2.30 \times 10^{5}$

$2.95 \times 10^{5}$

$2.38 \times 10^{5}$

$2.53 \times 10^{5}$

$2.53 \times 10^{5}$

$2.88 \times 10^{5}$

$2.30 \times 10^{5}$

$1.90 \times 10^{5}$

$1.32 \times 10^{5}$
SCS Mass (kg)

$3.62 \times 10^{4}$

$6.57 \times 10^{4}$

$7.94 \times 10^{4}$

$7.48 \times 10^{4}$

$4.85 \times 10^{4}$

$4.10 \times 10^{4}$

$6.20 \times 10^{4}$

$4.80 \times 10^{4}$

$4.85 \times 10^{4}$

$4.85 \times 10^{4}$
Break flow $(\mathrm{kg} / \mathrm{s})$

22.3

14.8

18.9

15.3

31.5

17.6

31.5

25.5

31.5

31.5

a. Westinghouse (W) plants are listed according to the number of RCS loops (i.e. $4-L$ means four loops) and steam generator type (i.e. 51/D means Series 51 or Series $D$ steam generator design). 
Table 4: Validation calculations using EPRI data.

$\begin{array}{lcc}\text { Constituent } & \text { FACT } & \text { EPRI } \\ \text { Concentrations } & \mathrm{pH} & \mathrm{pH}\end{array}$

$5 \mathrm{ppm}$ Morpholine

1 ppm Ammonia

$\begin{array}{llll}1 & \mathrm{ppm} \mathrm{B} & 8.5 & 9.1 \\ 2 & \mathrm{ppm} \mathrm{B} & 8.6 & 8.9 \\ 3 & \mathrm{ppm} \mathrm{B} & 8.5 & 8.7 \\ 5 & \mathrm{ppm} \mathrm{B} & 8.5 & 8.5 \\ 10 \mathrm{ppm} \mathrm{B} & 8.2 & 8.3\end{array}$

2 ppm Morpholine

$4 \mathrm{ppm}$ Ammonia

2 ppm B

9.1

9.4

3 ppm Morphol ine

$0.2 \mathrm{ppm}$ Ammonia
$1 \mathrm{ppm}$ B
8.3
8.7
$10 \mathrm{ppm} \mathrm{B}$
7.6
7.9

$1300 \mathrm{ppm} \mathrm{B}$

$2.60 \mathrm{ppm} \mathrm{Li}$

6.4

6.4 


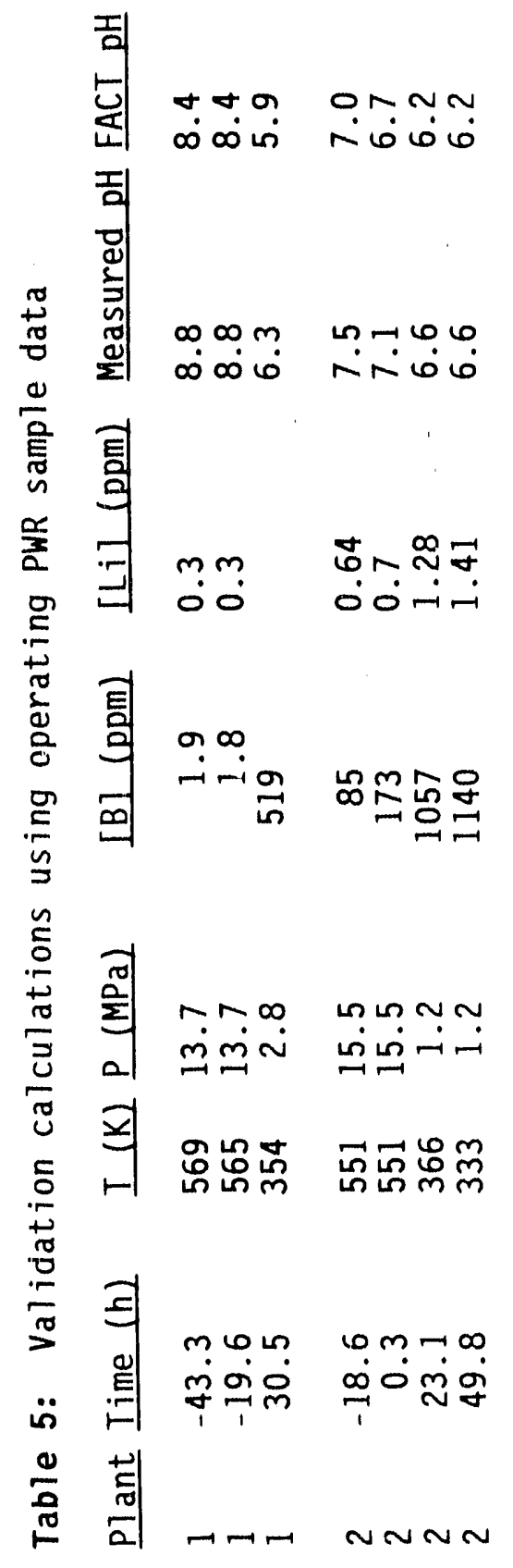


Table 6: Steam generator pH calculations performed using the utility supplied data 1800 seconds after tube rupture.

PWR

Design

FACT

$\mathrm{pH}$

Westinghouse-design PWRs

W4-L $51 / D^{b}$

6.4

"Average" $4-\mathrm{L} 51 / \mathrm{D}^{\mathrm{C}}$

6.7

W4-L 44

6.5

W4-LE

6.4

W4-L F

6.4

W3-L 51/D

6.4

W2-L 51

6.4

Combustion Engineering-design PWRs

2700MWt

6.5

Sys 80

6.5

Mod Sys 80

6.6

B\&W-design PWRS

6.5

\footnotetext{
a. All calculations (except where specifically noted) were made assuming "worst case" initial chemical concentrations (high-boron, high-lithium, low-ammonia, and nominal-morpholine).

b. This nomenclature denotes the Westinghouse 4-10op Series 51/D steam generator design PWR.

c. "Average" conditions denote SCS concentrations at the midpoint of the calculated ranges at 30 minutes.
} 
Table 7: SCS pH time proftles for selected plant designs at $298 \mathrm{~K}$ and $0.1 \mathrm{MPa}$ temperature and pressure, $\mathrm{pH}^{\prime} \mathrm{s}$ are FACT calculated.

\begin{tabular}{lccccc} 
Plant Design & \multicolumn{6}{c}{$\begin{array}{c}\text { Time (in seconds) } \\
900\end{array}$} & 600 & 900 & 1800 \\
\hline $\begin{array}{l}W-L 51 / D^{a} \\
2700 M W t^{b}\end{array}$ & 8.8 & 6.6 & 6.5 & 6.3 & 6.4 \\
& 8.8 & 6.8 & 6.7 & 6.6 & 6.5
\end{tabular}

a. This is the Westinghouse 4-70op 51/0 steam generator design PWR.

b. This is the Combustion Engineering $2700 \mathrm{MWt}$ design PWR. 
Table 8: Sensitivity of $\mathrm{pH}$ to temperature under saturated condittons" Temperature

(K)

Pressure
(MPa)

\begin{tabular}{lll}
\hline 298 & 0.003 & 6.36 \\
350 & 0.042 & 6.13 \\
400 & 0.246 & 6.28 \\
450 & 0.932 & 6.45 \\
500 & 2.64 & 6.67 \\
525 & 4.14 & 6.79 \\
545 & 5.67 & 6.88
\end{tabular}

a. These calculations utilized the chemical concentrations for the Westinghouse 4-10op 51/D plants (W4-L 51/D) at 30 minutes.

b. This is the "effective" $\mathrm{pH}$ and is a measure of $\left[\mathrm{H}^{+}\right]$at the indicated temperature and pressure. 
Table 9: $\quad P C_{1}$ measured during ORNL expertments ${ }^{a}$

\begin{tabular}{llr} 
Atm & $\mathrm{pH}$ & $\mathrm{PC}_{1}$ \\
\hline Argon & 5 & 6870 \\
& 7 & 5180 \\
& 9 & 47500 \\
Air & 5 & 350 \\
& 7 & 888 \\
& 9 & 7160
\end{tabular}

a. Taken from Reference 3 . 
Figure 1: FACT system output for EPRI validation calculations.

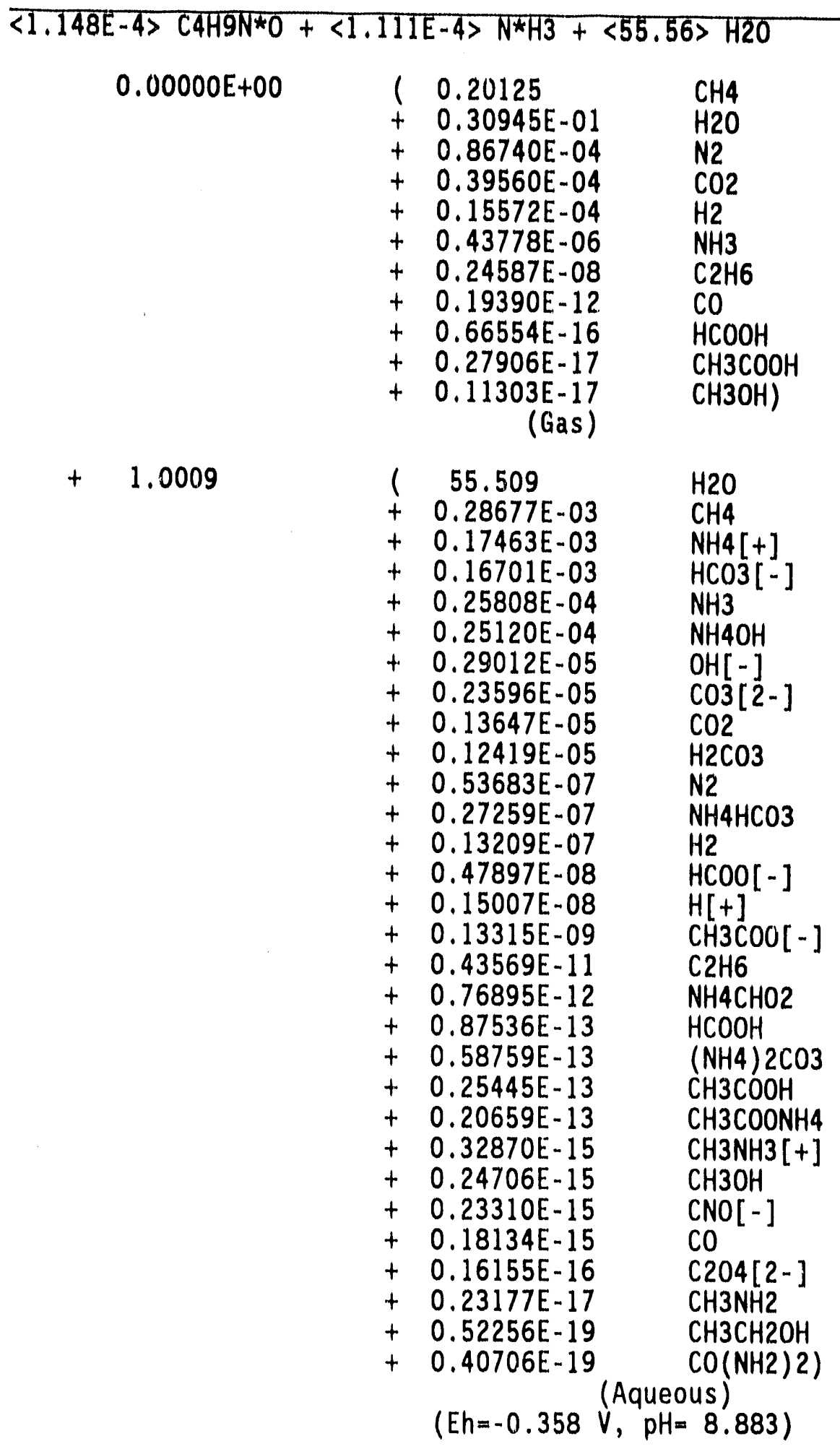


Figure 2: FACT system output for the W4-L 51/D system at full power, and 1800 seconds after tube rupture.

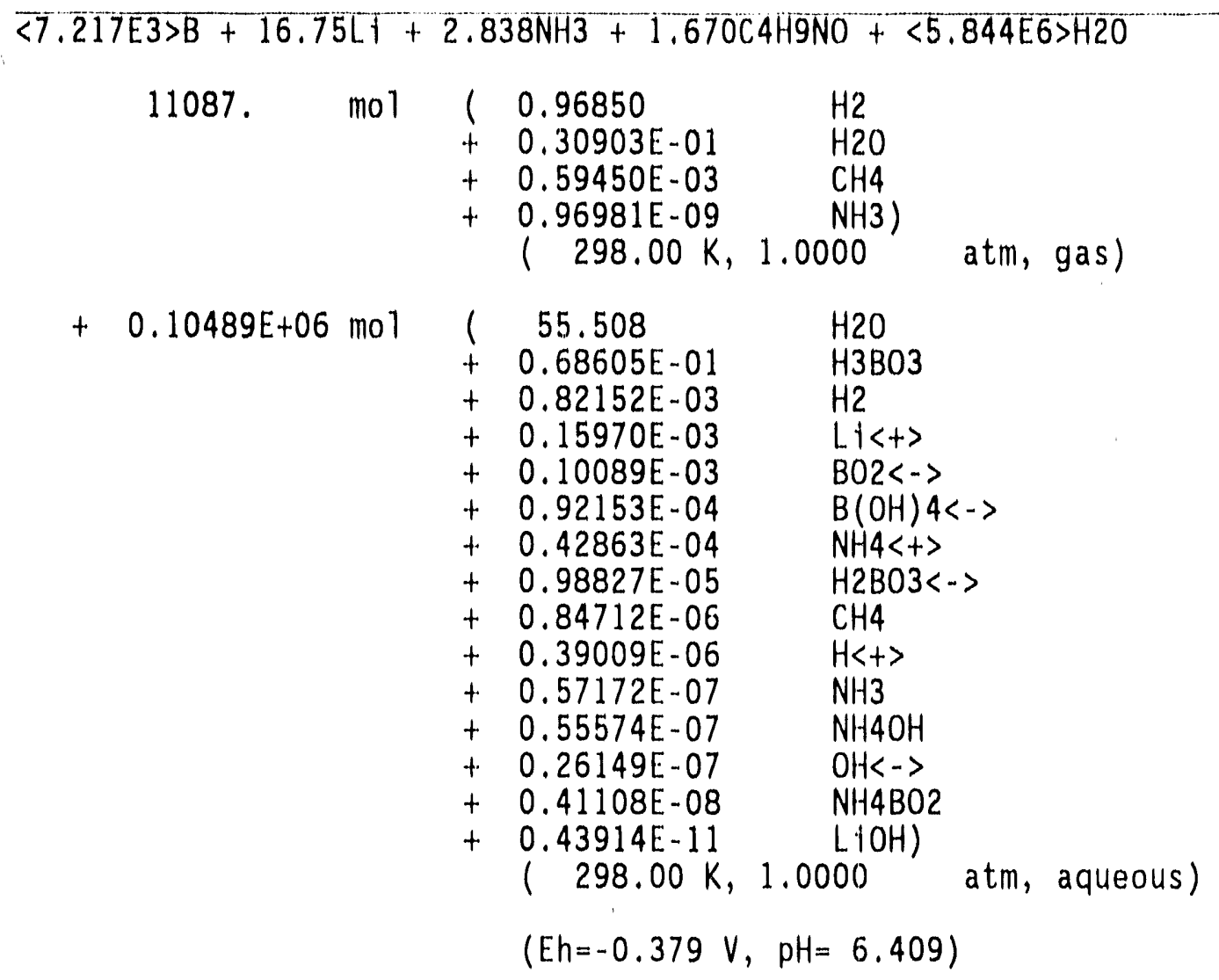




\section{REFERENCES}

1. J. P. Adams, Iodtne Spiking Data from Commerctal PWR Operattons, EGGNERD-8395, 1989.

2. J. P. Adams and C. L. Atwood, Probabil tty of the lodine Spike Release Rate During an SGTR, EGG-NERD-8648, 1989.

3. J. T. Bell, M. H. Lietzke, and D. A. Palmer, Predicted Rates of Formation of lodine Hydrolysis Species at $\mathrm{pH}$ Levels, Concentrations, and Temperatures Anticipated in LWR Accidents, NUREG/CR-2900, ORNL-5876, 1982 .

4. E. C. Beahm, et a1., Iodine Spectation and Partitioning in PWR Steam Generator Accidents: Final Report, NUREG/CR-5365, ORNL/TM-11168, 1989.

5. PWR Primary Water Chemistry Guidelines: Reviston 2, EPRI NP-7077, 1990.

6. PWR Secondary Water Chemistry Guidelines, Revision 2, EPRI NP-6239, 1988 .

7. 0. Menet, A. Lenormand, and B. Arizzo11, "Flow Assisted Corrosion in EdF," Proceeding of the EPRI Workshop on Erosion-Corrosion, Washington D.C., Apr11 14-15, 1987.

8. On-Line Monitoring of Secondary-Cycle Chemistry with Morpholine at the Beaver Valley Power Station, Research Project 2647-1, Final Report, EPRI NP-E266, 1987.

9. Neutralization of Steam Generator Denting, Volumes 1 and 2, Research Project S112-01 Fina1 Report, EPRI NP-3023, 1983.

10. Boric Acid Application Guidel ines for Intergranular Corrosion Inhibition, Research Project S302-13 Topical Report, EPRI NP-5558, 1984.

11. "World List of Nuclear Power Plants, " Nuclear News, Vol. 34, No. ?, pp. 53, February 1991. 
12. J. R. White, G. E. Santee, and R. T. Jensen, Response of a B\&W Plant to Steam Generator Tube Ruptures, NSAC-101, 1986.

13. W. T. Thompson, A. D. Pelton, and C. W. Bale, Eacllity for the Analysts of Chemical Thermodynamics - Guide to Operations, McGil1 University, Montrea1, Canada, May 1985.

14. C. W. Bale and G. Eriksson, "Metallurgical Thermochemical Databases - A Review, " Canadian Metallurgical Citarterly, Vol, 29, No. 2, pp. 1-5-132, 1990.

15. T. M. Besmann, SOLGASMIX-PV A Computer Program to Calculate Equilitbrium Relationships in Complex Chemical Systems, ORNL/TM-5775, Apr 111977.

16. E. C. Beahm, et al., "Iodine Partitioning in Pressurized Water Reactor Steam Generator Accidents," Nuclear Technology, Vol, 90, p16, Apr11 1990.

17. P. G. Volitleque, "Measurements of Radiotodine Species in Samples of Pressurized Water Reactor Coolant," Nuclear Yechnology, Vol 90, 1990.

18. G. D. Christian, Analytical Chemistry, 3rd edition, J. Wiley and Sons, New York, 1980. 
APPENDIX A

CHEMCAL 


\section{APPENDIX A: CHEMCAL}

CHEMCAL is a computer program which calculates the secondary coolant system (SCS) mass inventory and chemical concentration as a function of the initial SCS mass and concentration, reactor coolant system (RCS) mass and concentration, and makeup flow rate and concentration. The SCS concentration of chemical "C", $[\mathrm{C}]_{\mathrm{scs}}$ is:

$$
[C]_{s C S}(i)=\frac{[C]_{S C S}(i-1) * M_{S C S}(i-1)+[C]_{r C S}(i-1) * m_{b r k} * \Delta t}{M_{S C S}(i)}
$$

where:

$$
\begin{aligned}
{[C]_{s C s}(i) } & =S C S \text { concentration at time } i(\mathrm{ppm}) \\
M_{s C S}(i) & =S C S \text { mass inventory at time } i(\mathrm{~kg}) \\
& =M_{s C s}(i-1)+\dot{m}_{b r k} * \Delta t \\
{[C]_{r C s}(i) } & =\text { RCS concentration at time } i(\mathrm{ppm}) \\
\dot{m}_{b r k} & =\text { break flow }(\mathrm{kg} / \mathrm{s}) \\
\Delta t & =\text { preset time increment }(\mathrm{s})
\end{aligned}
$$

and:

$$
[C]_{r C S}(i)=\frac{[C]_{r C S}(i-1) * M_{r C S}+[C]_{m k u p} * \dot{m}_{b r k} * \Delta t-[C]_{r C S}(i-1) * \dot{m}_{b r k} * \Delta t}{M_{r C S}}
$$

where:

$$
\begin{aligned}
{[C]_{\text {mkup }} } & =\text { Makeup system concentration }(p p m) \\
M_{\text {rCs }} & =\text { RCS mass inventory }(\mathrm{kg})
\end{aligned}
$$


There were six assumptions used in the derivation of this algorithm. First, it was assumed that the makeup system is adequate to maintain RCS mass inventory during the transient and, therefore, that $M_{\text {rcs }}$ could be considered constant. In the majority of historical steam generator tube leaks and ruptures, the makeup system was adequate to maintain RCS mass inventory. Additionally, for those few cases where the makeup system may not be capable of maintaining RCS inventory (that is, where the break flow rate exceeds the makeup flow rate), the pressurizer will provide an additional source of water to the RCS and this, for most cases, is sufficient to maintain RCS inventory.

Second, it was assumed that the chemical concentration in the makeup system remained constant. This was based on the large inventory of water in the makeup system tank relative to the water mass which was assumed to be lost from the RCS to the SCS during a typical (30-minute) SGTR.

Third, it was assumed that the concentration $[C]_{\text {scs }}$ for any given chemical " $C$ " was independent of the concentration for any other chemical. Therefore, the concentration could be calculated for each individual chemical specie (i.e. boron, ammonia, lithium hydroxide, and morpholine) and the chemical interactions were analyzed only after the final concentrations of all species in the SCS was determined. While it is known that chemical interactions may occur (for example if makeup water with high concentrations of boron is mixed with normal RCS water), these interactions are reversible and do not appreciably alter the final chemical states after the RCS water is mixed with that in the SCS.

Fourth, it was assumed that mixing of chemicals was instantanecus and complete, in both the RCS and SCS. This assumption is, of course, not strictly correct. However, it is judged that this assumption is reasonable and that deviations from complete and instantaneous mixing are generally conservative and do not affect the final conclusions. For example, incomplete or delayed mixing in the RCS results in a lower than expected boron concentration in the SCS (because the makeup system consistently has a higher boron concentration than the RCS). Therefore, the calculated SCS boron concentration is an upper bound to the actual concentration. Since it is 
primarily boron which reduces the SCS pH and since a lower pH results in a higher iodine concentration in the vapor state (hence, a larger iodine release to the environment), the calculated condition is conservative with respect to iodine release. Incomplete mixing in the SCS could result in localized regions of high boron concentration (or low alkaline concentration) which could cause higher iodine concentrations in the vapor spaces. However, there would be other localized regions with smaller iodine concentrations which would tend to counteract the higher concentrations resulting in an average vapor concentration near that calculated using this assumption.

Fifth, the affected steam generator is isolated at transient initiation. The effect of steaming during the initial phase of an SGTR is discussed in Appendix $C$.

Sixth, the effect of the initial boron in the SCS is ignored. As discussed in the main report, the initial concentration of boron in the SCS is very small relative to the boron mass injected into the SCS with the break flow.

A computer program was written using the above equations and was compiled on an IBM PS/2 Model 70 computer using the Ryan McFarlaine FORTRAN Compiler Version 2.4. The source listing for this computer program, CHEMCAL, is shown in Table A-1. The computer code was checked against independent calculations for three test cases to ensure that the encoding was correct. The first test case included the following initial conditions: $[\mathrm{C}]_{\mathrm{rcs}}=100$ $\mathrm{ppm} ;[\mathrm{C}]_{\text {mkup }}=100 \mathrm{ppm} ;[\mathrm{C}]_{\mathrm{scs}}=0 \mathrm{ppm} ; M_{\text {rcs }}=10^{4} \mathrm{~kg} ; M_{\mathrm{scs}}=10^{4} \mathrm{~kg} ;$ and break $f 10 \mathrm{w}=1 \mathrm{~kg} / \mathrm{s}$. The second test case included the following initial conditions: $[C]_{r c s}=10 \mathrm{ppm} ;[C]_{s c s}=100 \mathrm{ppm} ;[C]_{\text {mkup }}=0 \mathrm{ppm} ; M_{\text {rcs }}=10^{4} \mathrm{~kg}$; $M_{\text {scs }}=10^{4} \mathrm{~kg}$; and break flow $=1 \mathrm{~kg} / \mathrm{s}$. The third test case included the following initial conditions: $[\mathrm{C}]_{\mathrm{rcs}}=10 \mathrm{ppm} ;[\mathrm{C}]_{\mathrm{scs}}=100 \mathrm{ppm} ;[\mathrm{C}]_{\text {mkup }}=0$ $\mathrm{ppm} ; M_{\mathrm{rcs}}=10^{3} \mathrm{~kg} ; M_{\mathrm{scs}}=10^{3} \mathrm{~kg} ;$ and break flow $=1 \mathrm{~kg} / \mathrm{s}$. In each case, the results from CHEMCAL agreed exactly with the independent calculations.

The time-dependent chemical concentrations are shown in Figures A-1 - A10. Figures $A-1$ - A-6 show the results for Westinghouse designs 4-100p 51/D 
(where 51/D refers to the design of the steam generators, Model 51 or Mode1 D), 4-10op 44, 4-10op E, 4-10op F, 3-10op 51, and 2-10op 51 plants, respectively. Figures A-7 - A-9 show the results for Combustion Engineering designs 2700 MWt, System 80, and Modified System 80 plants, respectively. Figure A-10 shows the results for all Babcock and Wilcox design plants. Each figure includes the independently calculated SCS concentration of boron (high case with initial RCS and makeup system concentrations equal to 1400 and $1200 \mathrm{ppm}$ and low case equal to 0 and $600 \mathrm{ppm}$, respectively), 1ithium hydroxide (high case with initial RCS concentration equal to 2.3 and low case with initial RCS concentration equal to $0.2 \mathrm{ppm}$ ), ammonia (high case with initial SCS concentration equal to 7.5 [2.0 for OTSG] ppm and low case with initial SCS concentration equal to $1.0 \mathrm{ppm}$ [0.0 for OTSG]), and morpholine (initial $S C S$ concentration equal to $3.0 \mathrm{ppm}$ [5.0 for $0 T S G]$ ). Thus, for example, Figure $A-1 a, A-1 b, A-1 c, A-1 d, A-1 e, A-1 f$, and A-1g refer to the high and low boron, high and low lithium hydroxide, high and low ammonia, and morpholine concentrations for the Westinghouse 4-10op 51/D plants. Note: Figure A-10-d is not included. This figure, which corresponds to the SCS low ammonia concentration for a B\&W plant, is trivial because the initial SCS pH requirements for an all-ferrous B\&W plant with $5 \mathrm{ppm}$ morpholine can be met with no addition of ammonia during nominal power operations. Therefore, the low-ammonia case is represented by zero concentration at all times during the transient. 
Table A-1: Source Code Listing for the Computer Program CHEMCAL

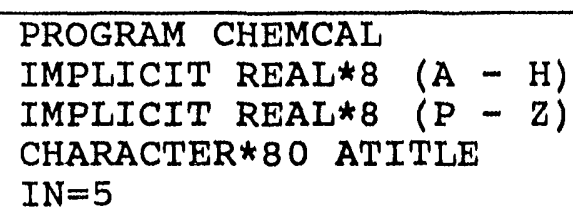

C THIS IS A BATCH PROGRAM USED TO CALCULATE CHEMICAL CONCENTRATIONS IN THE PRIMARY AND SECONDARY COOLANT SYSTEMS OF A PWR BASED ON THE INITIAL CHEMICAL CONCENTRATIONS IN THE RCS, SCS, AND MAKEUP SYSTEMS AND AN ASSUMED STEAM GENERATOR TUBE RUPTURE LEAK MASS FLOW RATE. IT IS ALSO ASSUMED THAT THE MAKEUP FLOW RATE EQUALS THE LEAK MASS FLOW RATE AND THAT MIXING IS COMPLETE AND INSTANTANEOUS IN BOTH RCS AND SCS.

PROGRAMMED BY JAMES P. ADAMS JANUARY 14, 1991

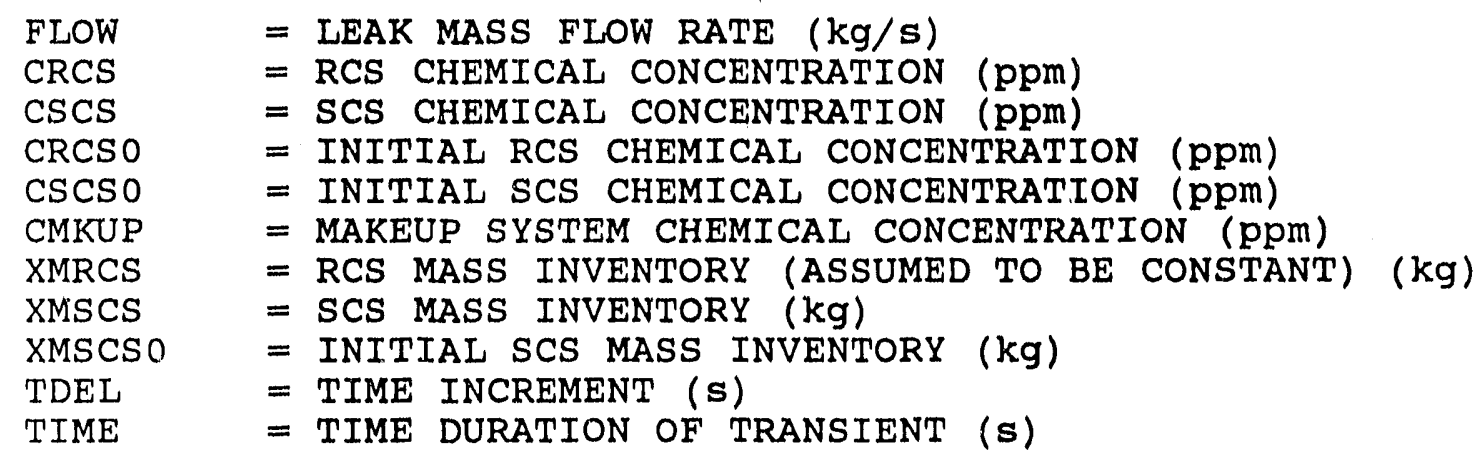




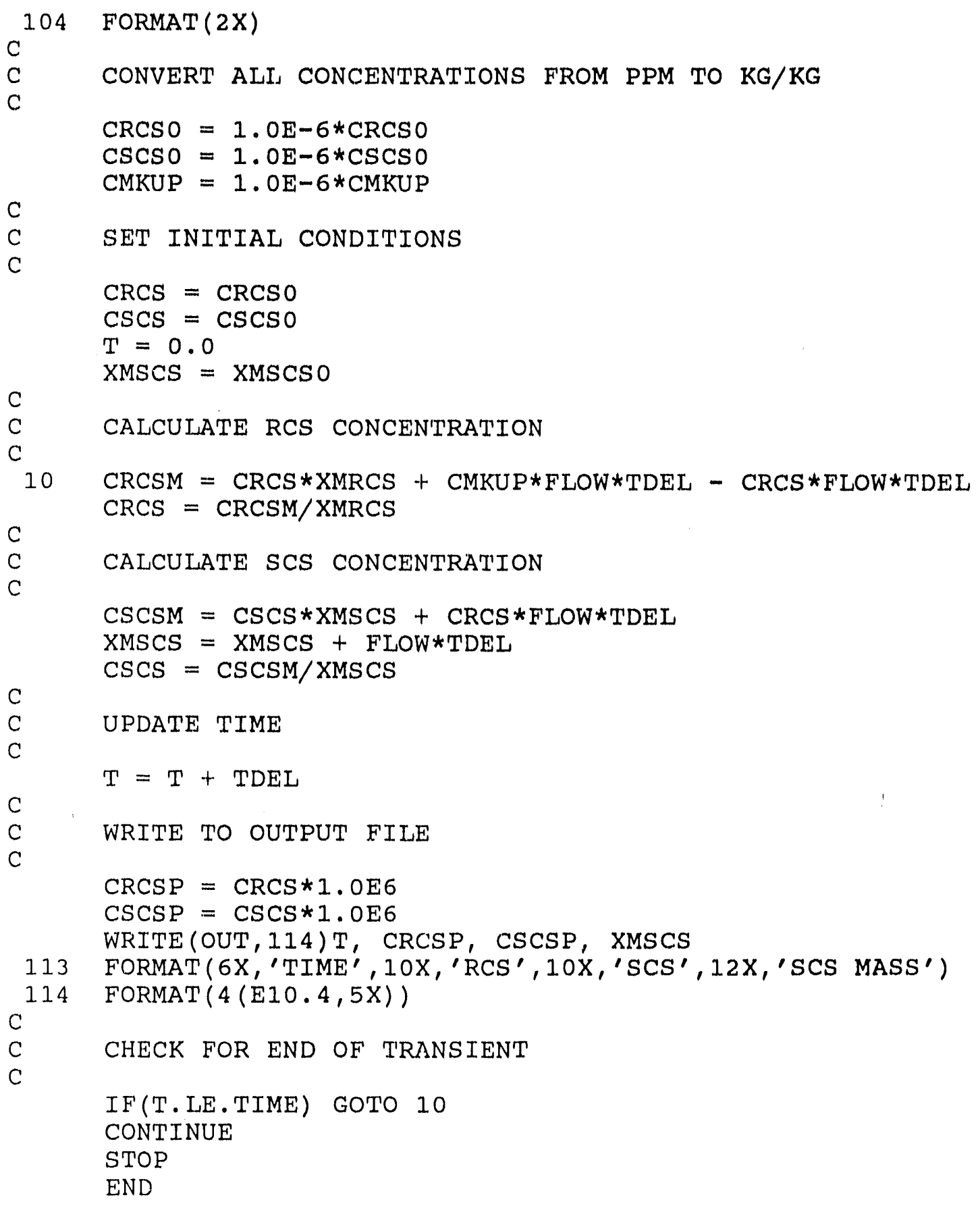




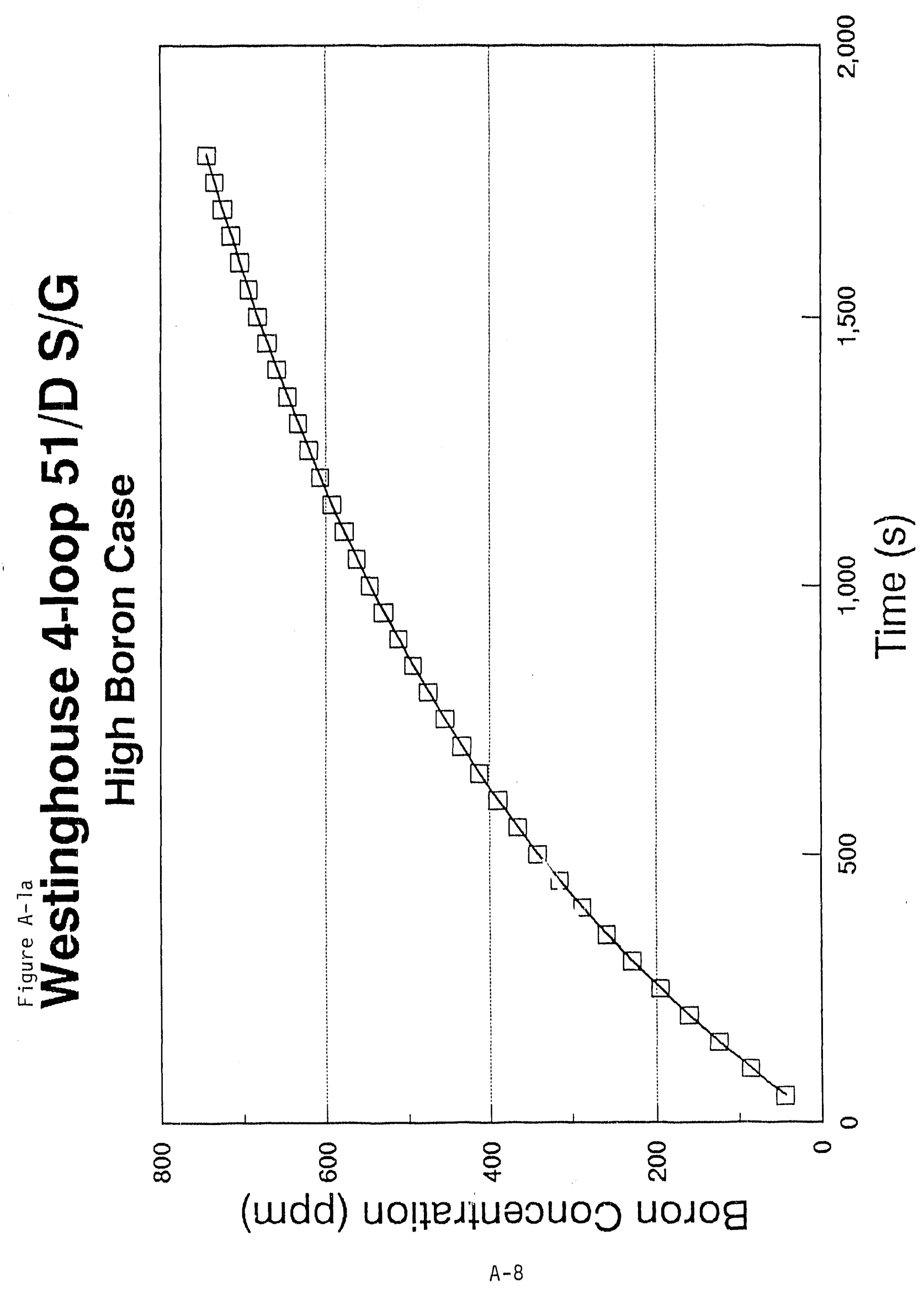




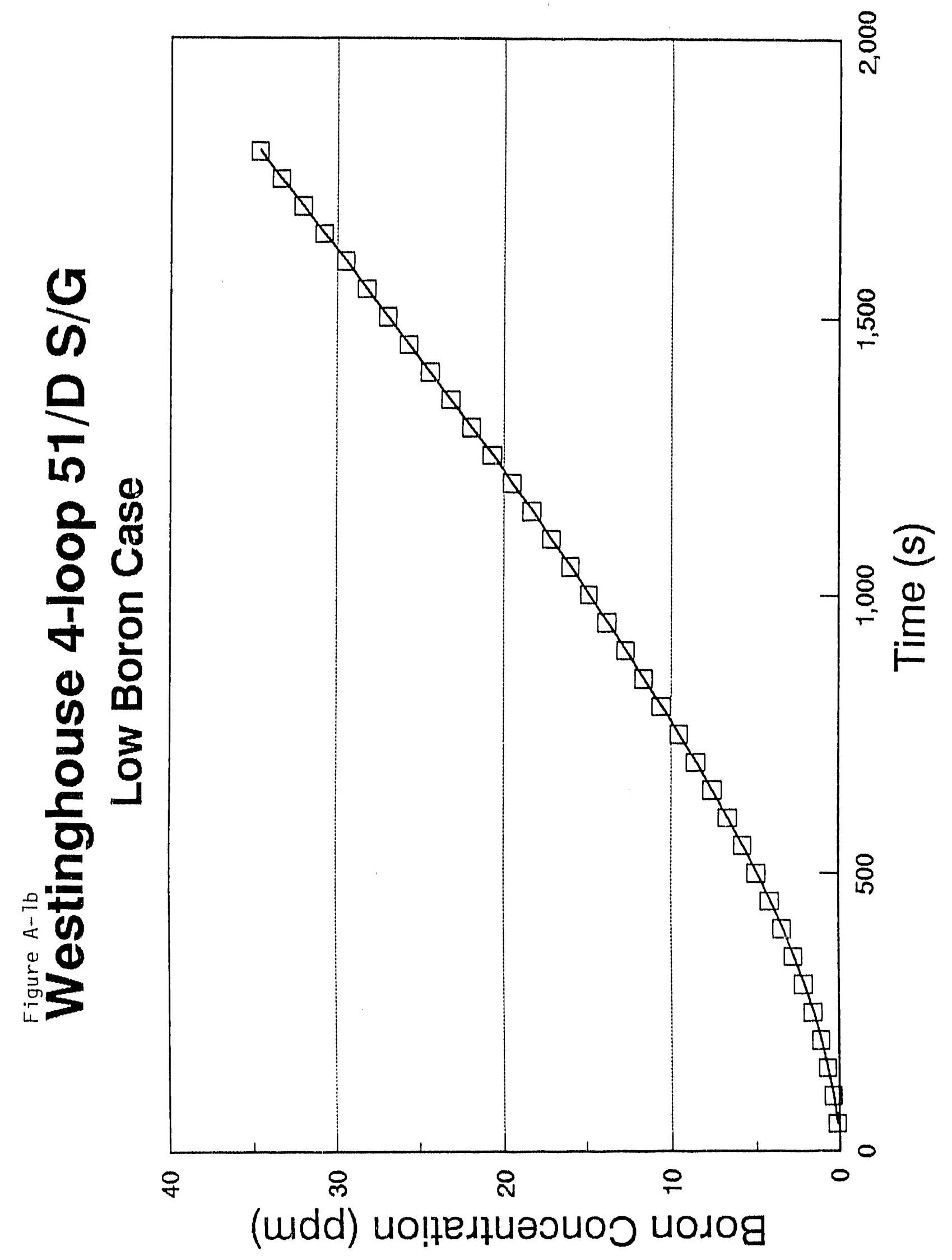




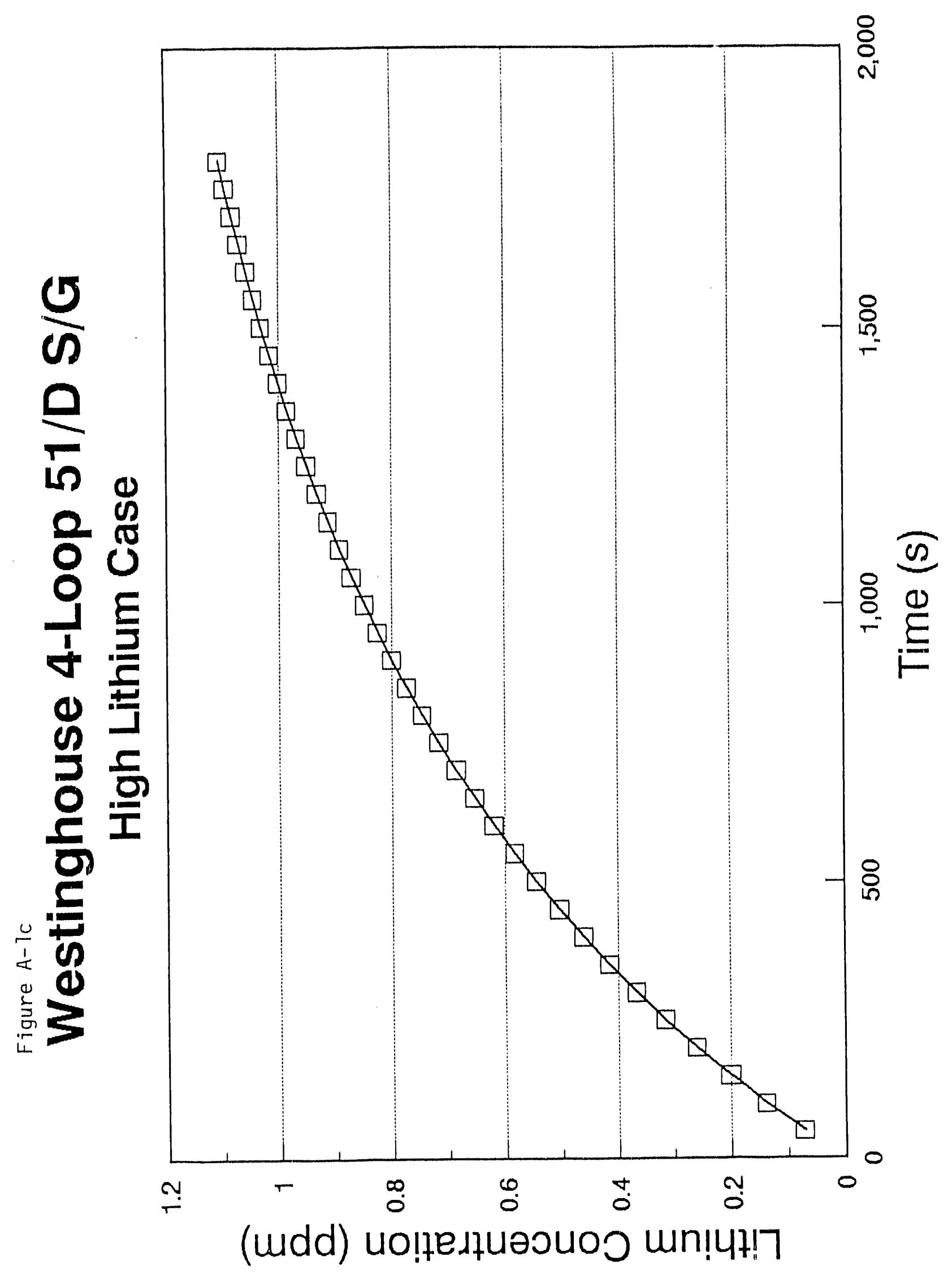

A- 10 


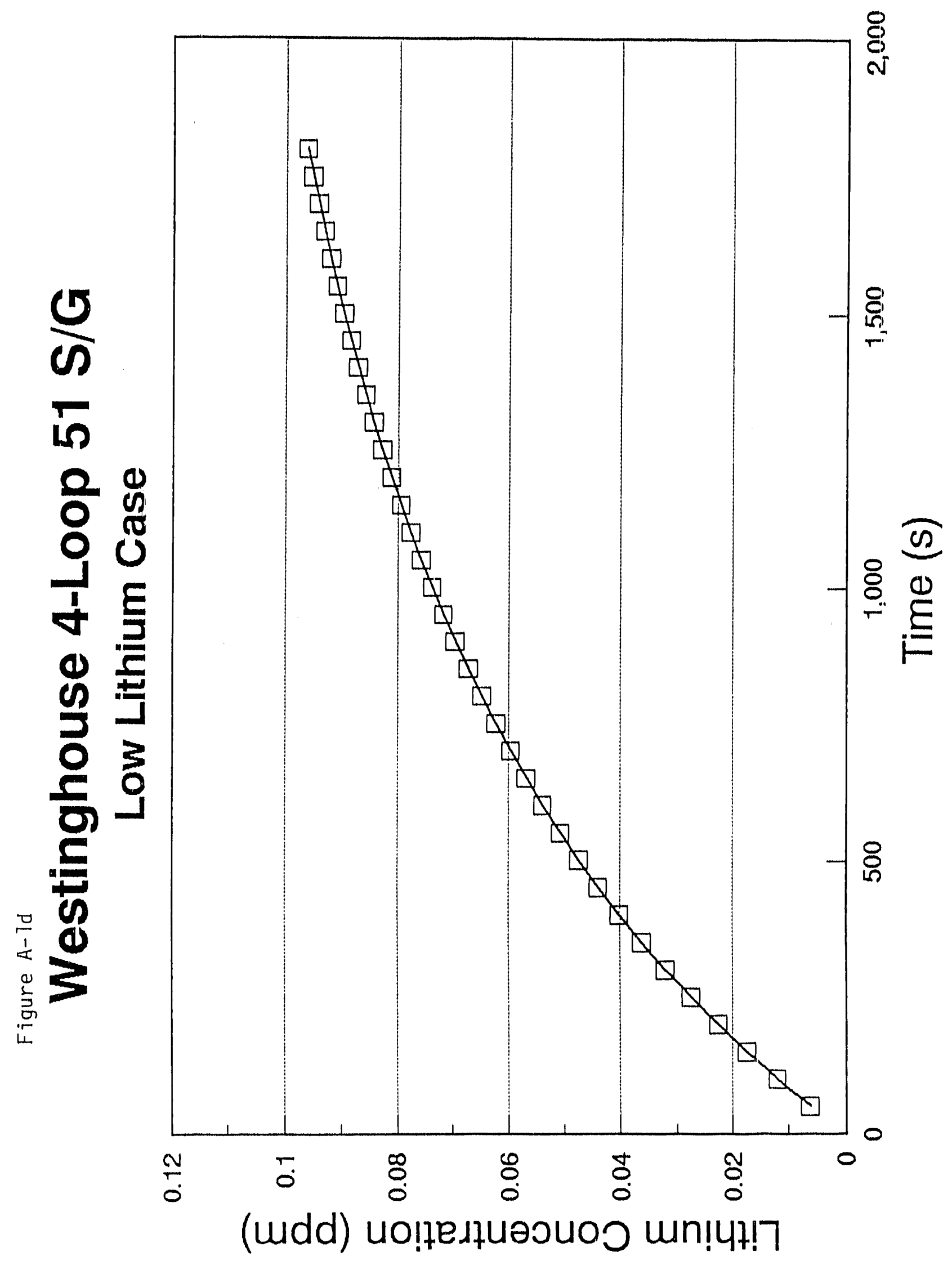




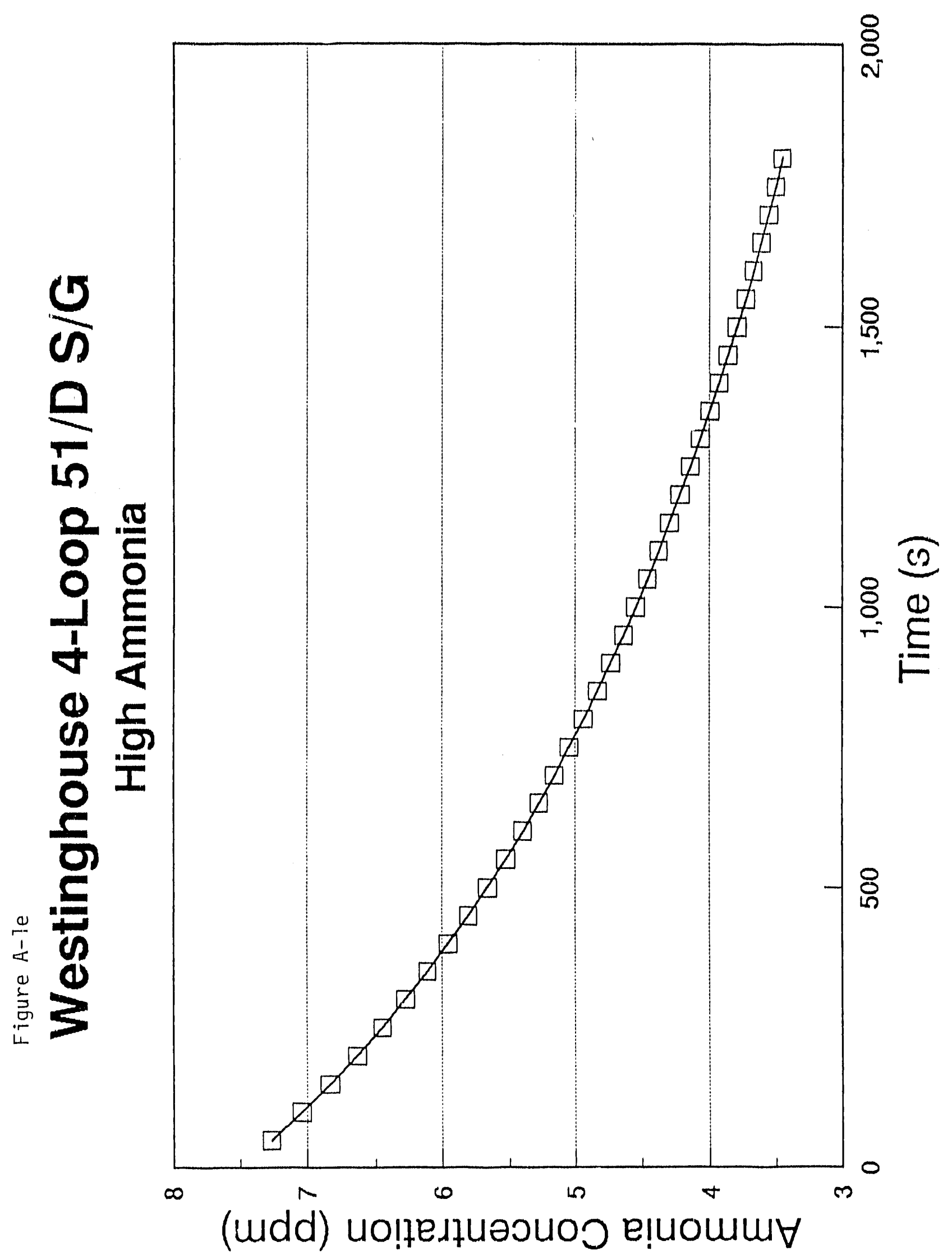

$A-12$ 


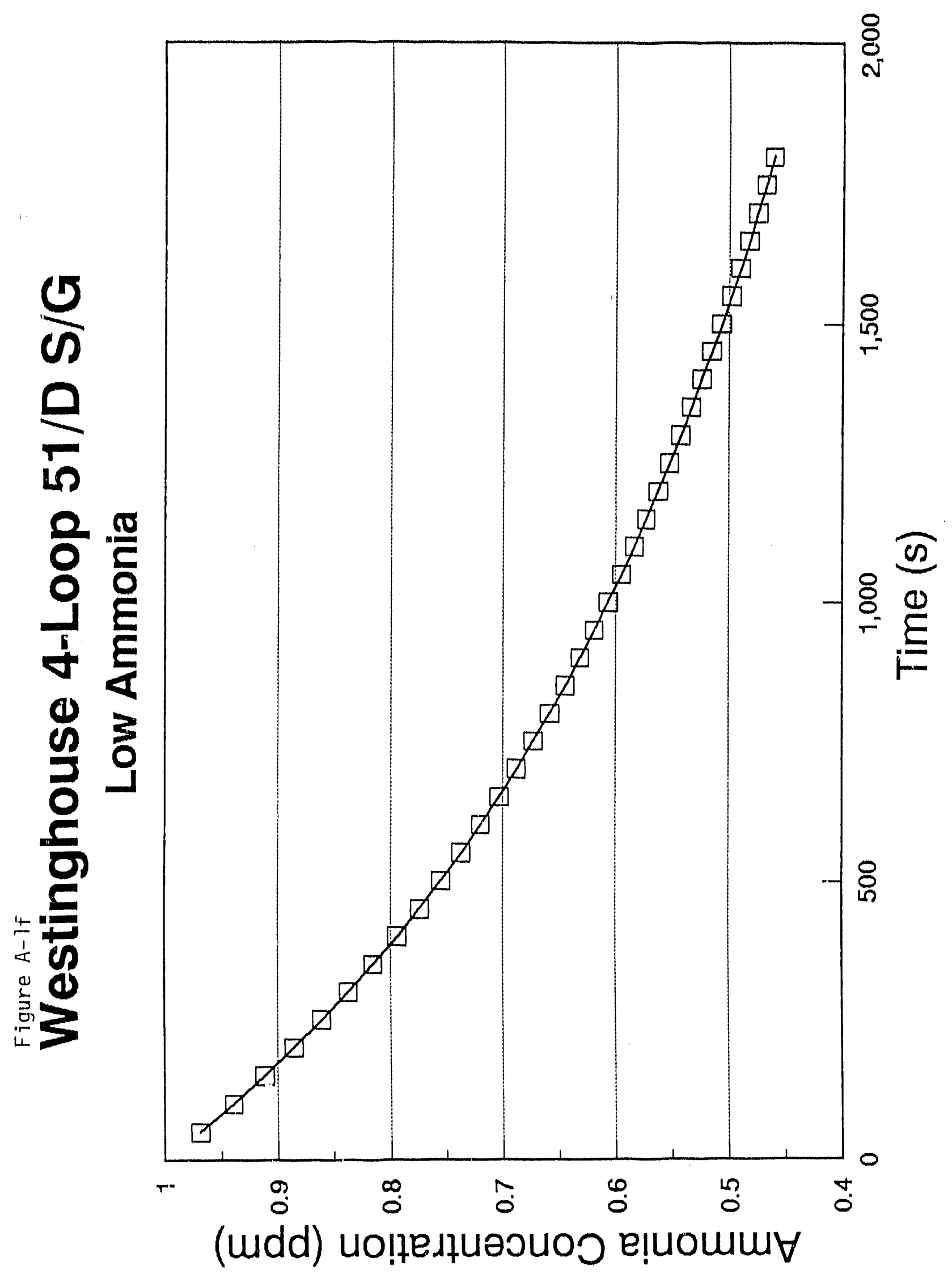

A- 13 


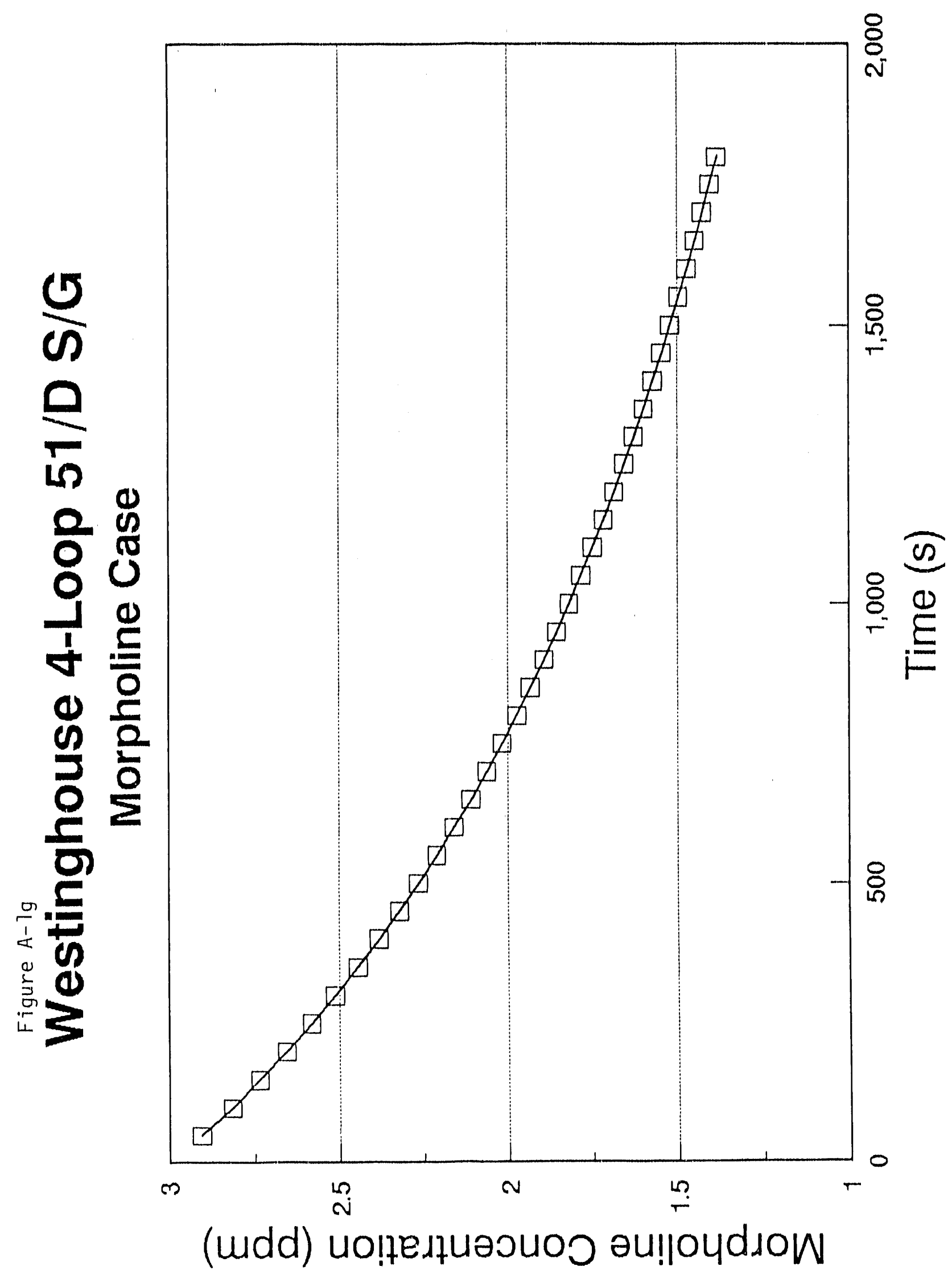

A- 14 


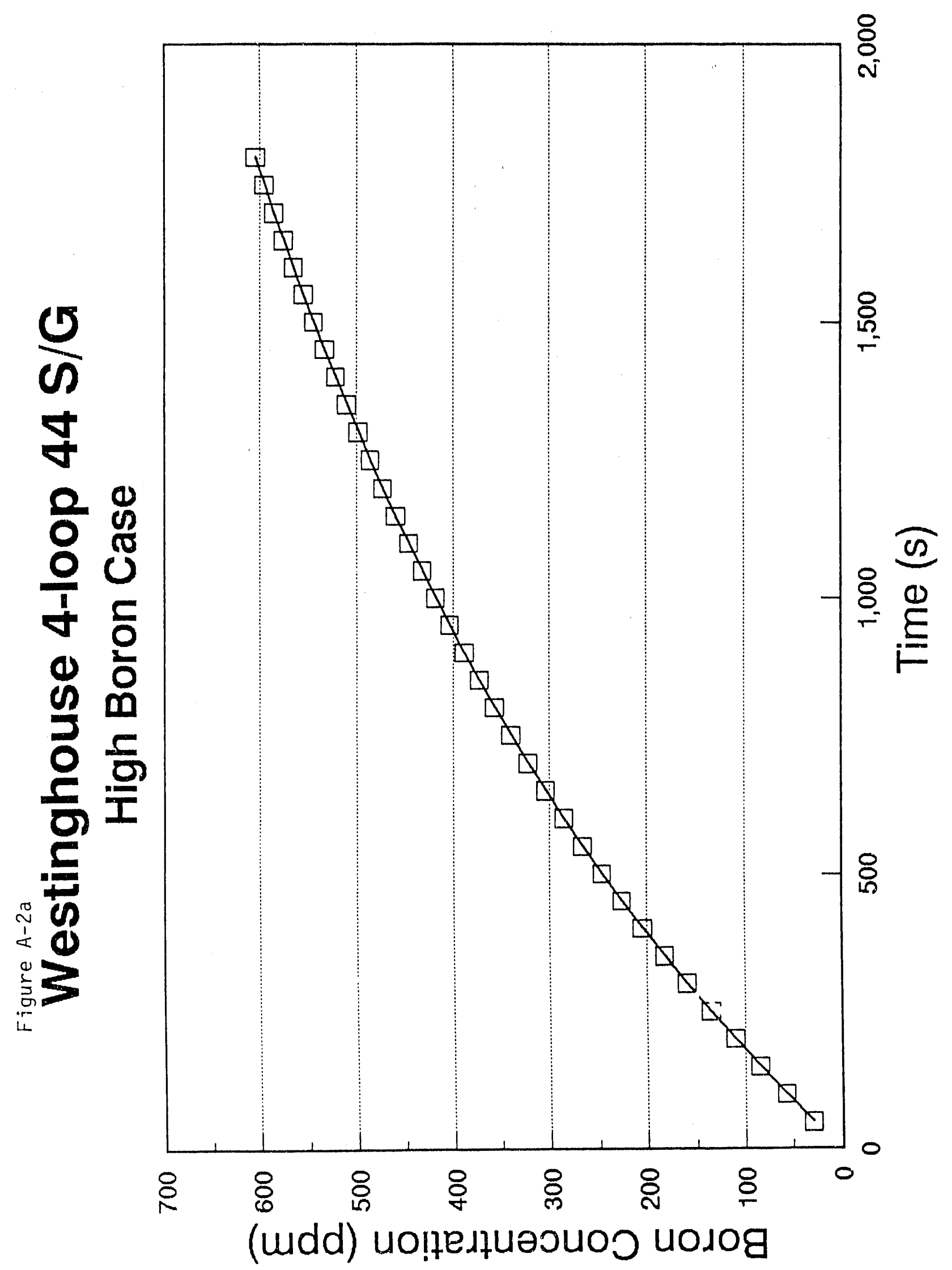

$A-15$ 


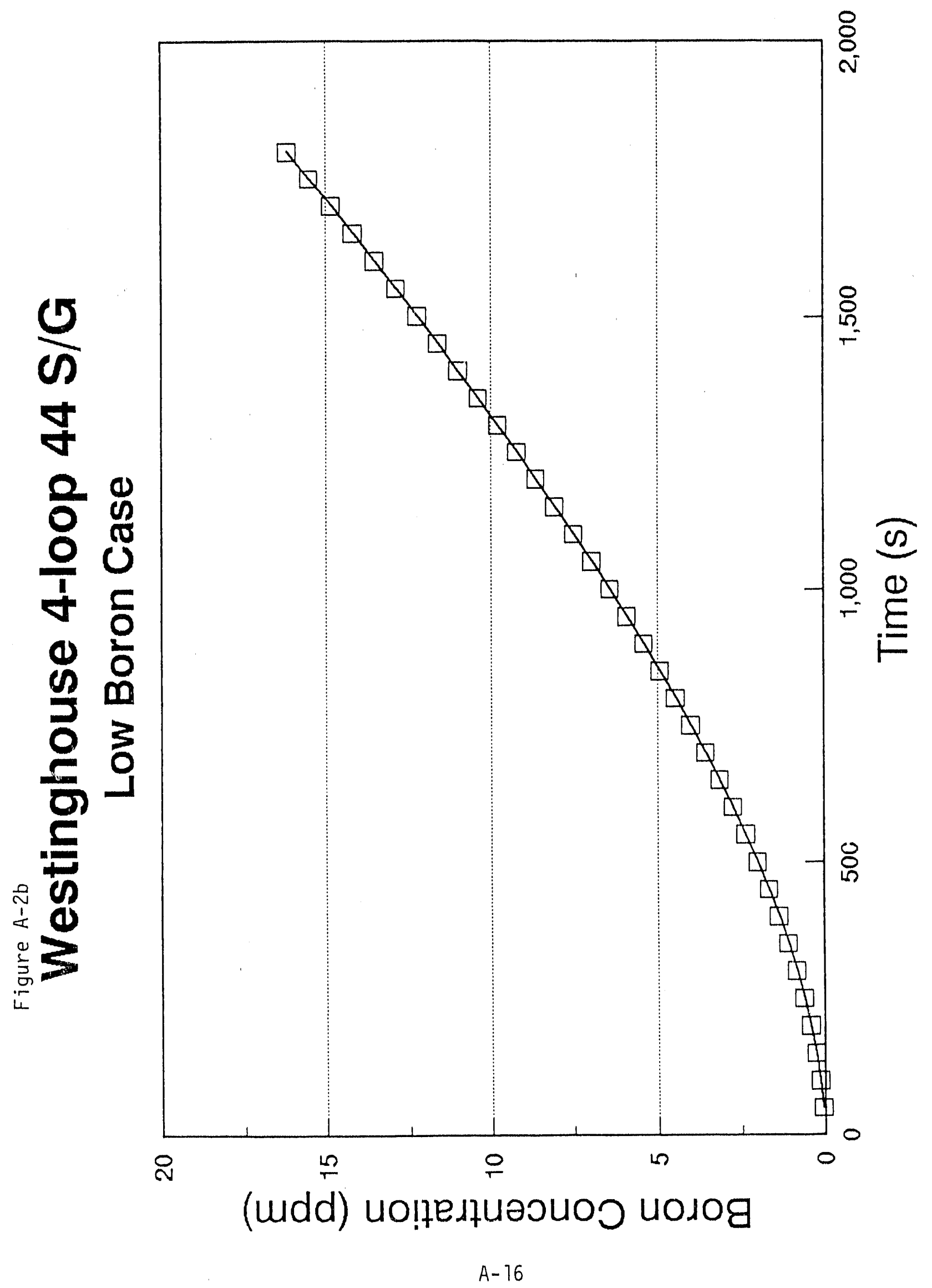




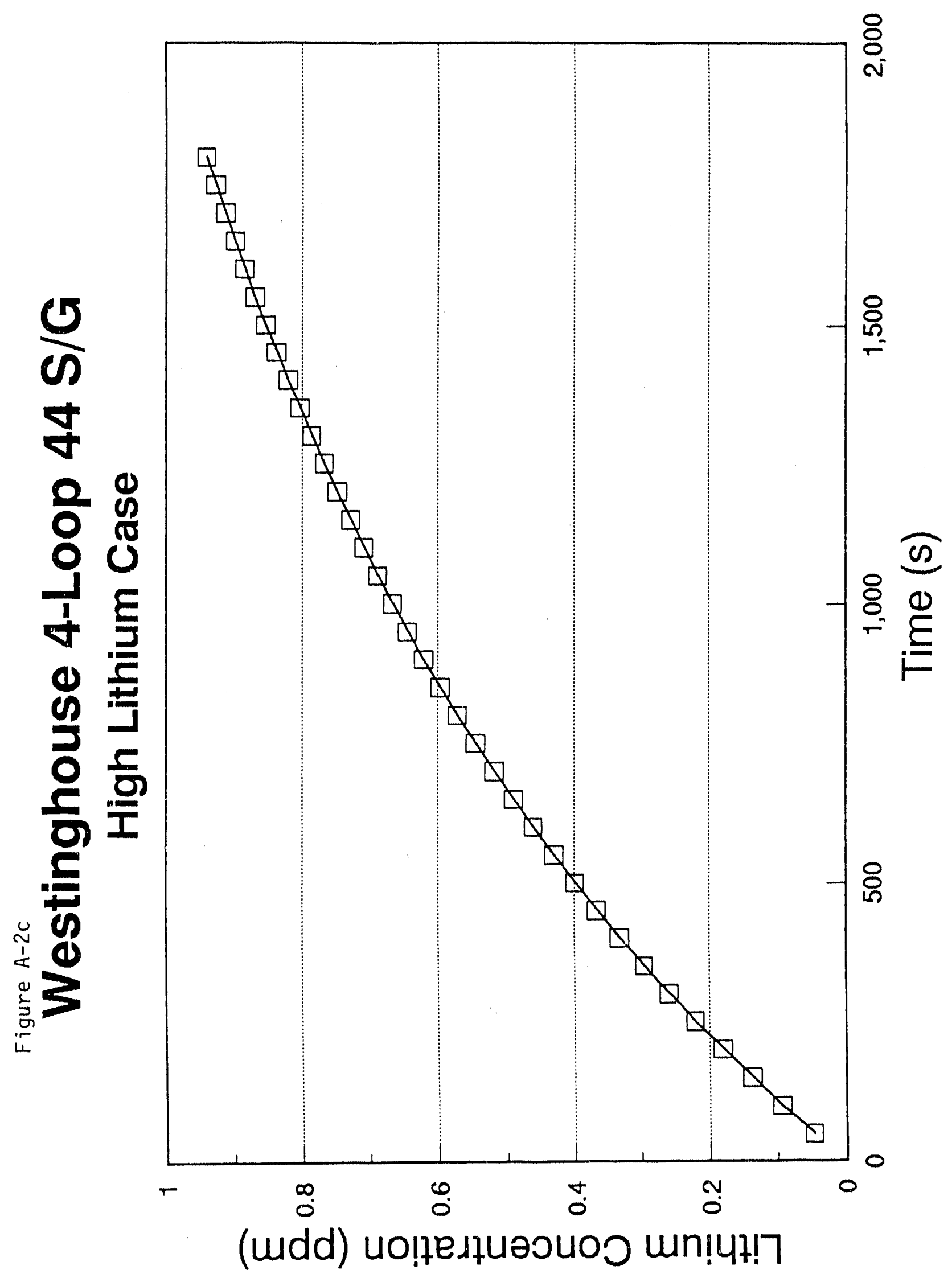

A- 17 


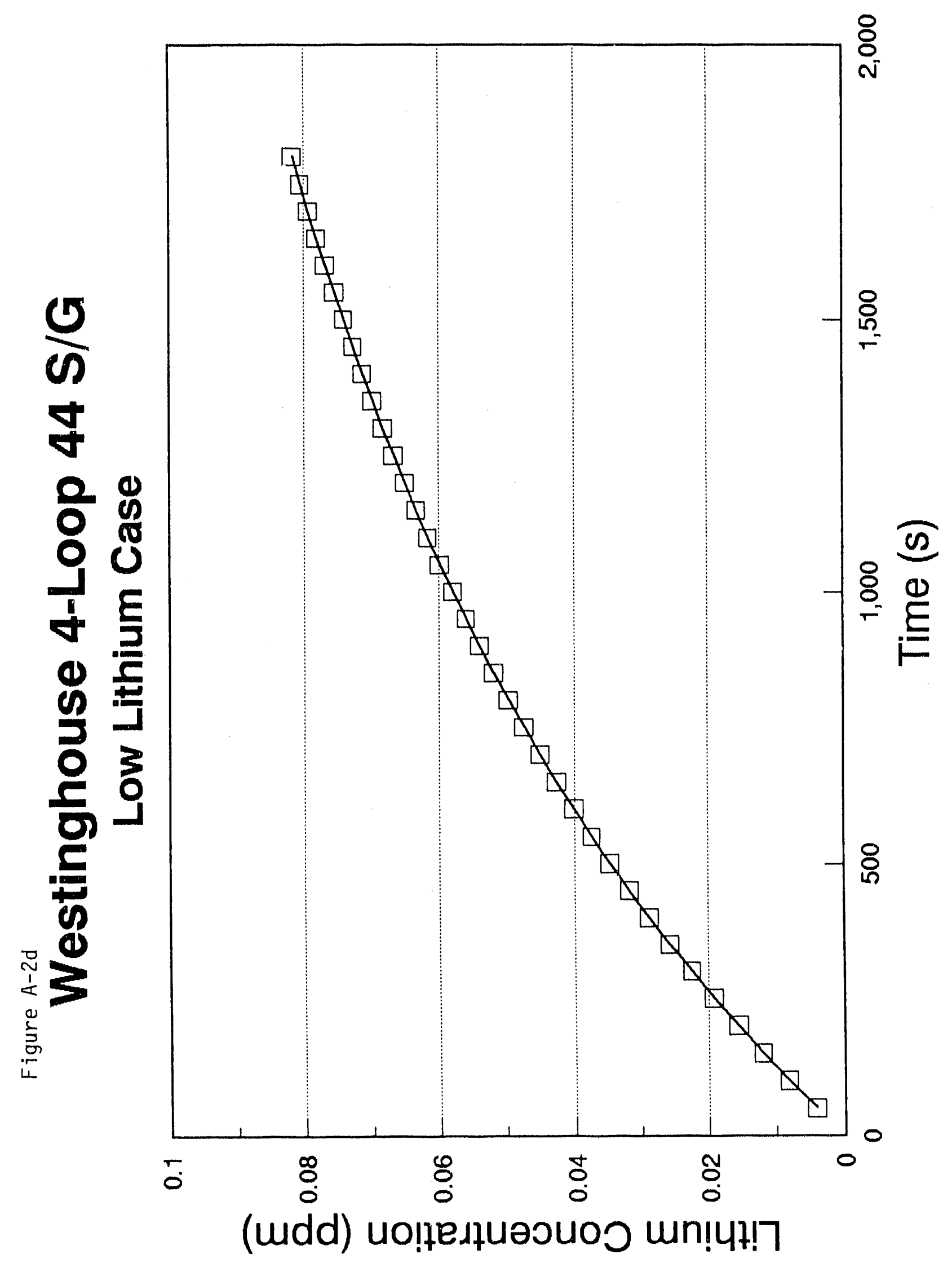

A- 18 


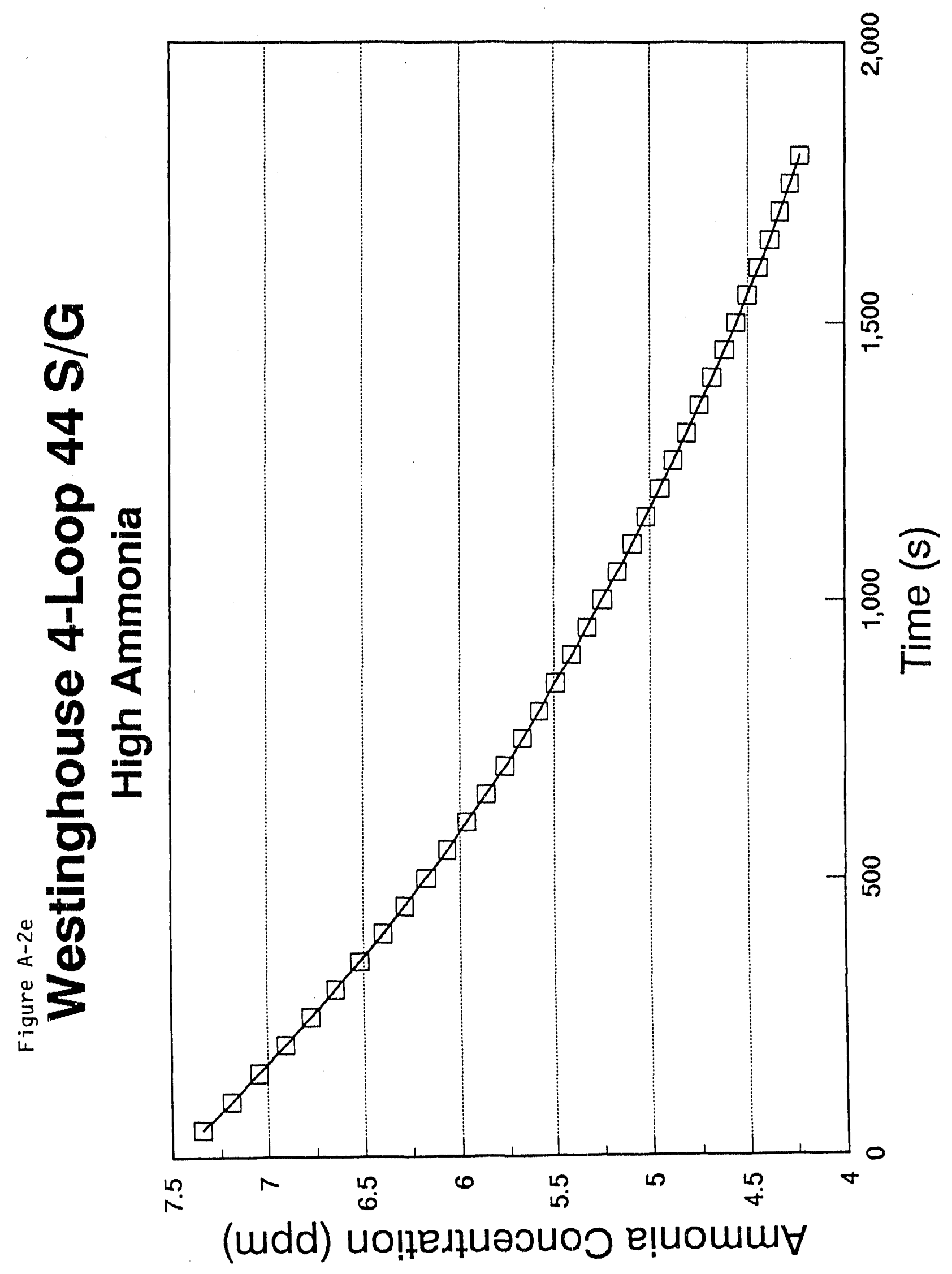




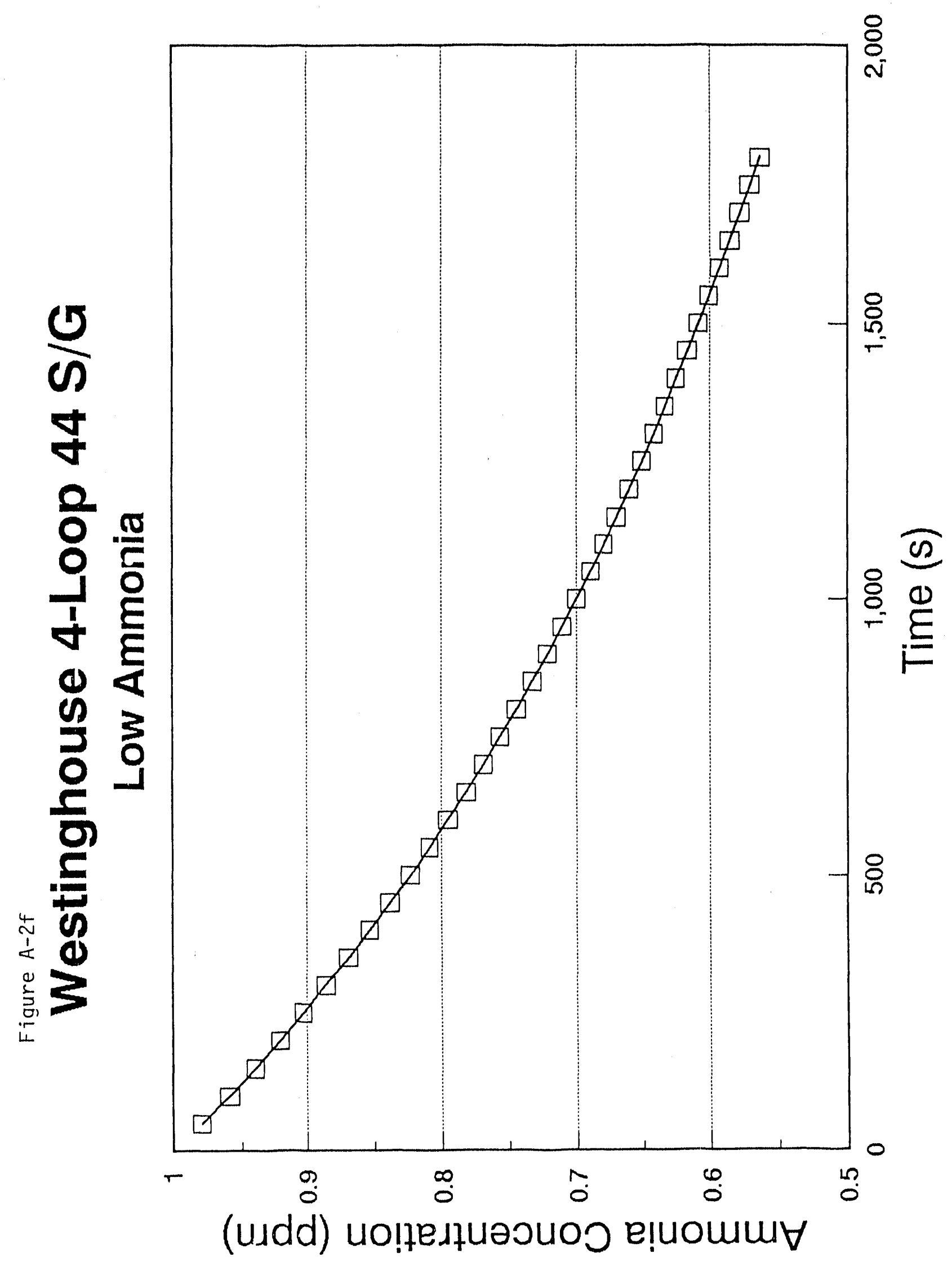




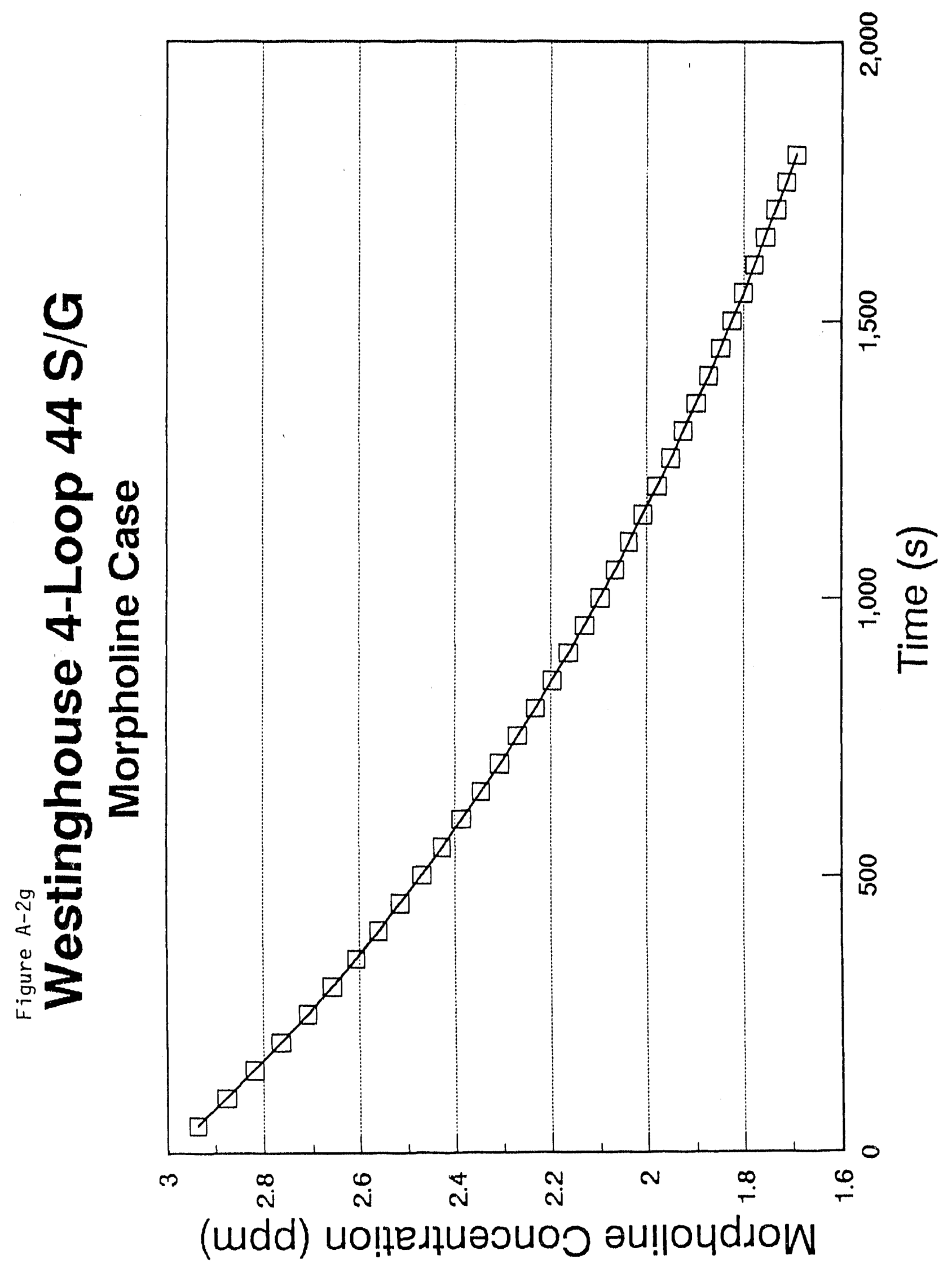




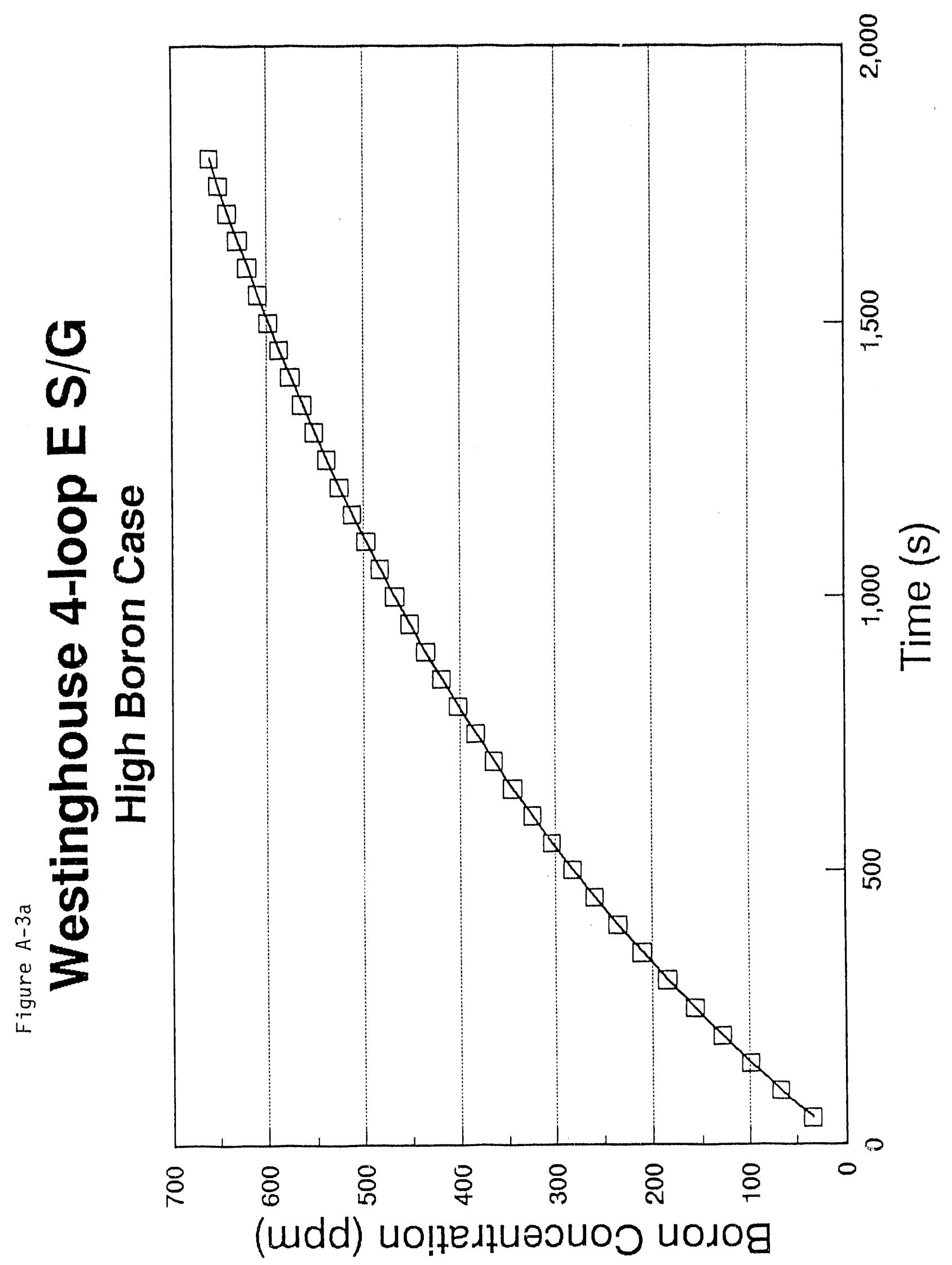




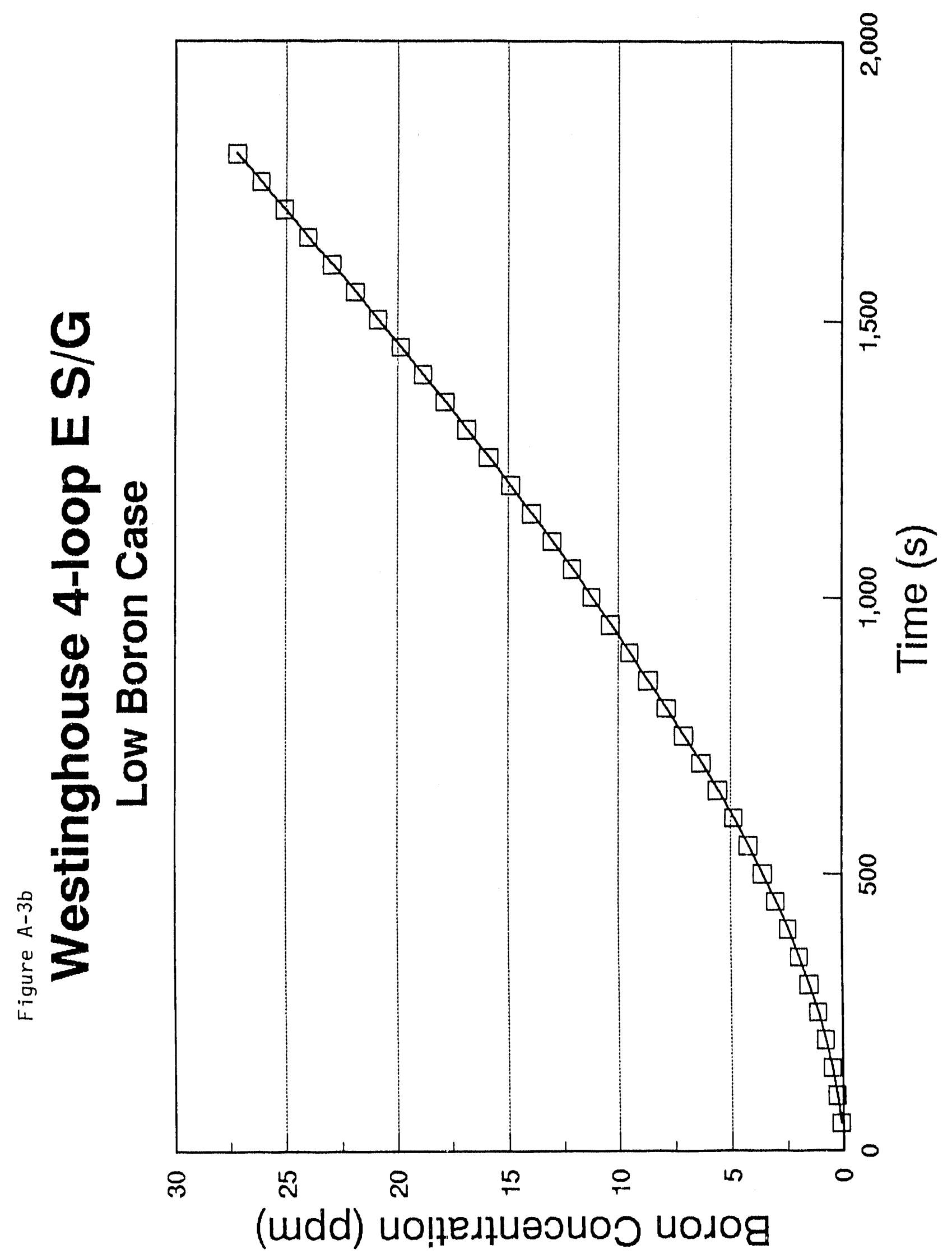




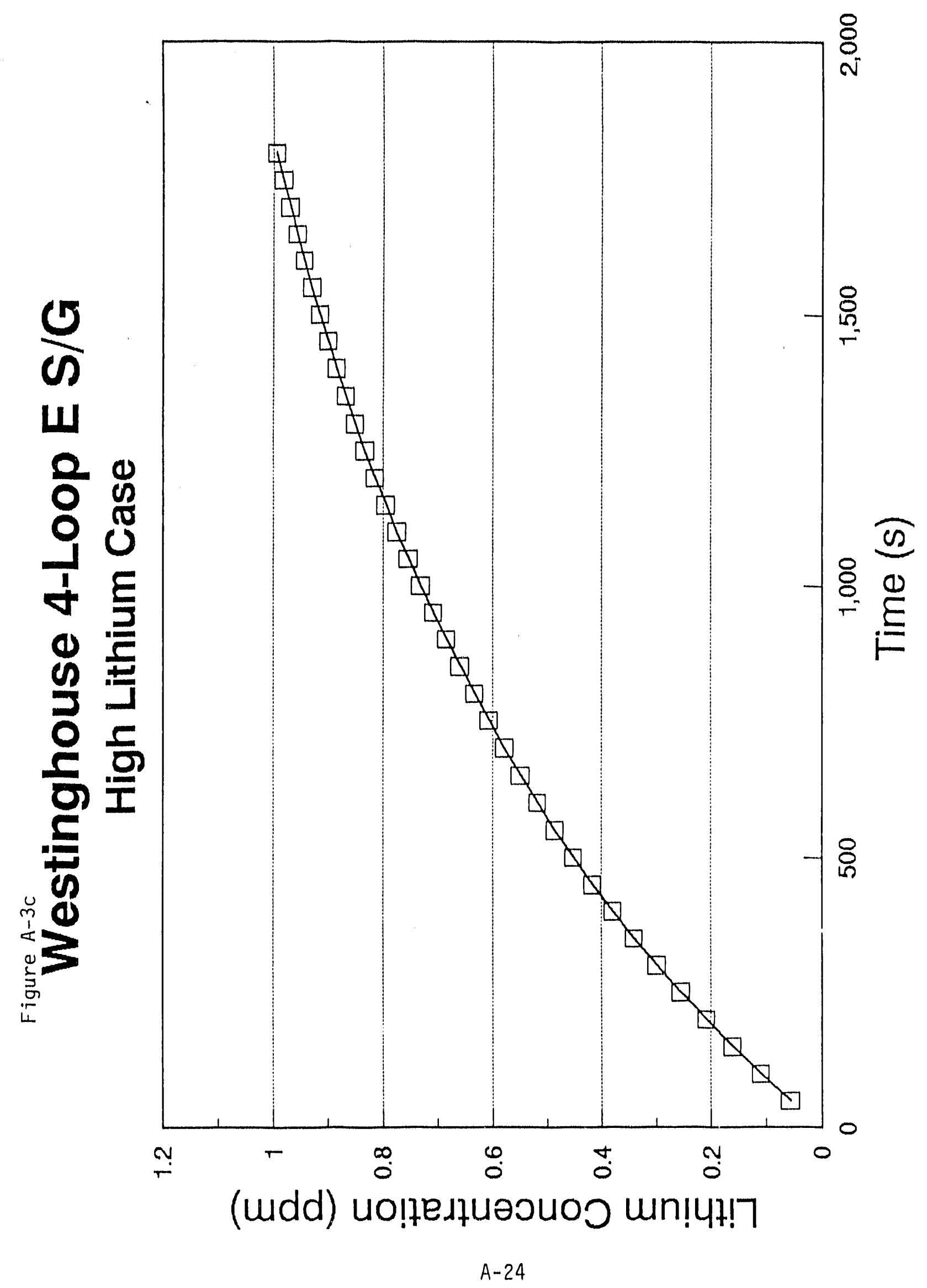




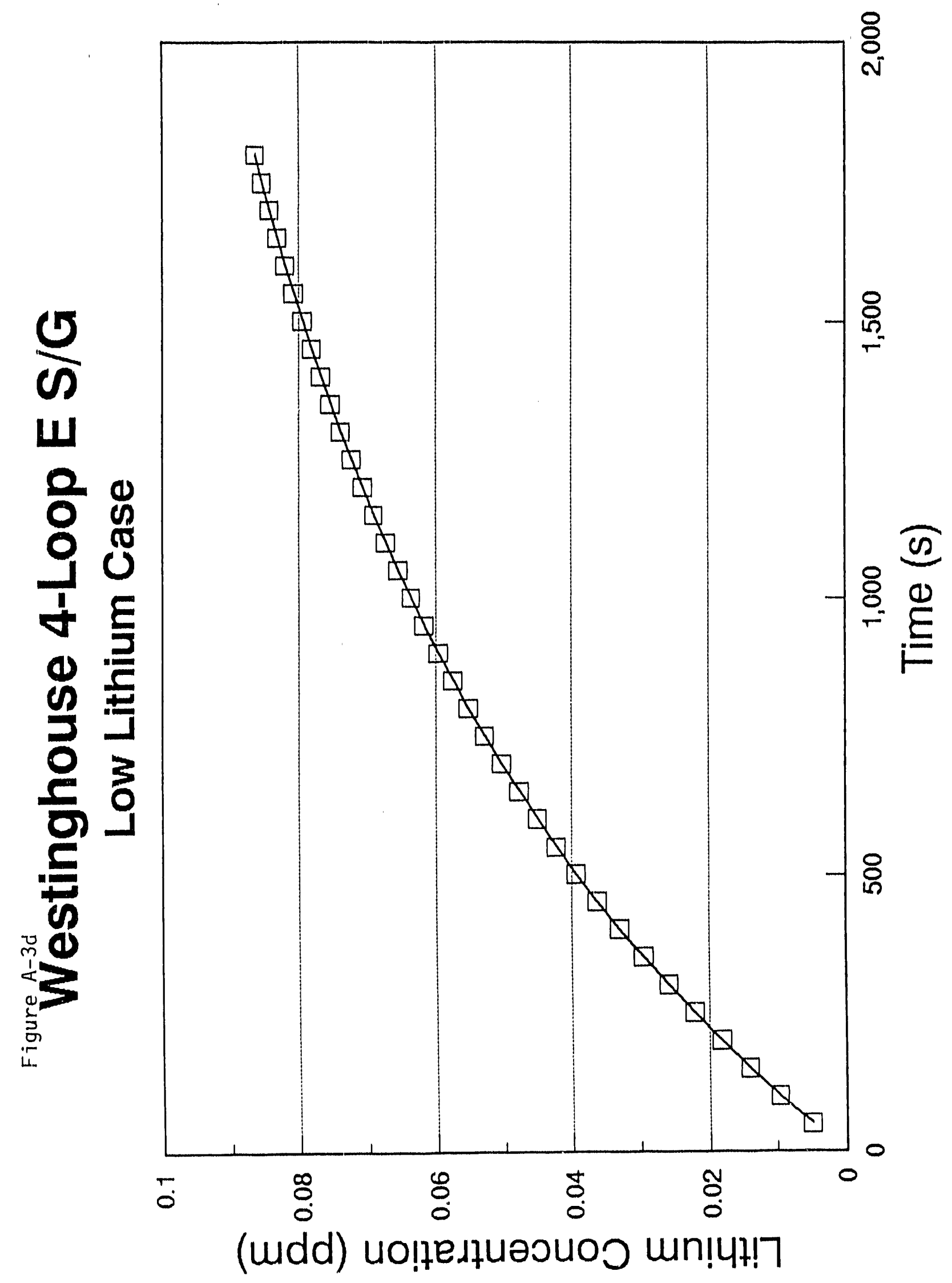




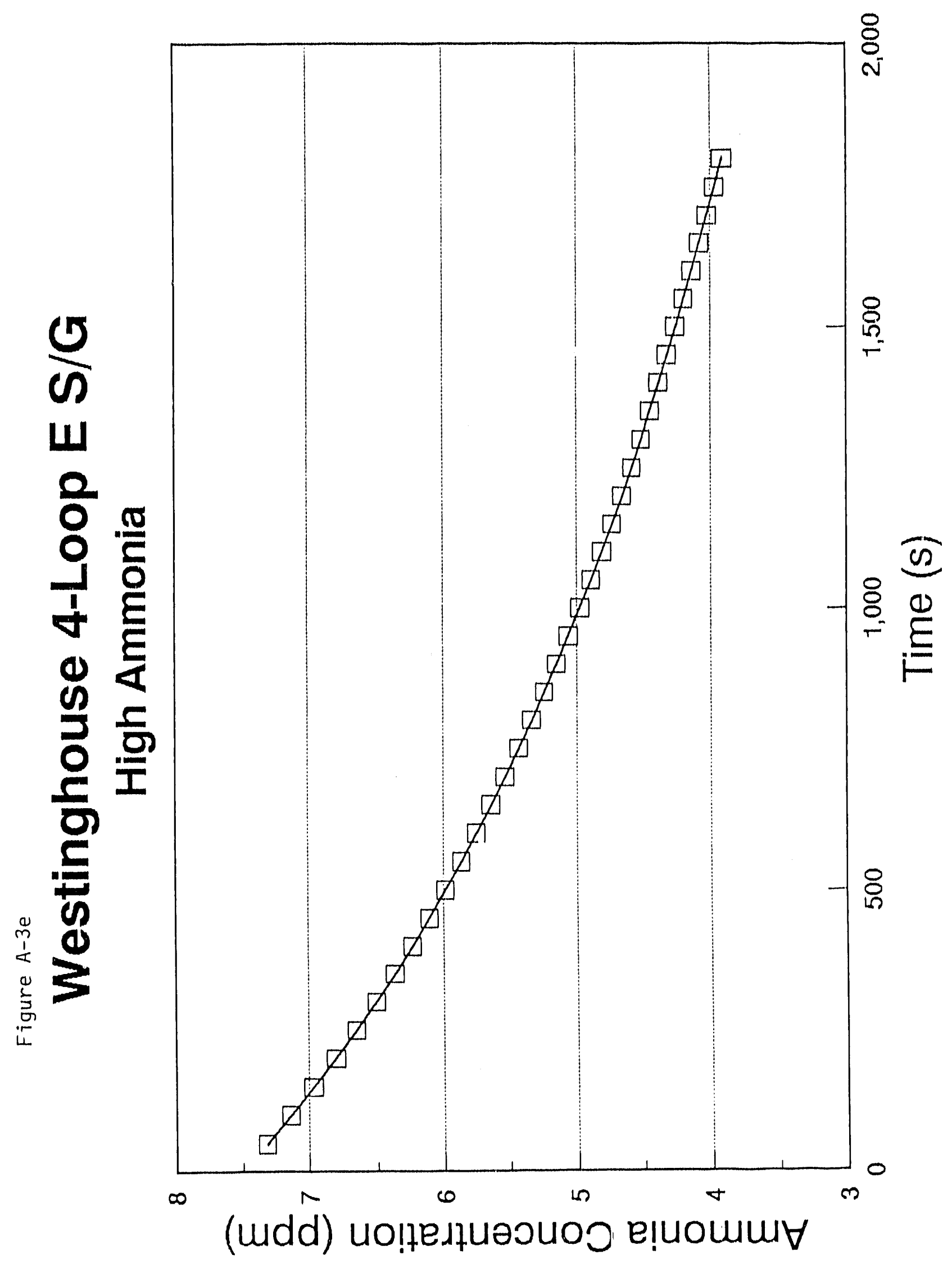

A-26 


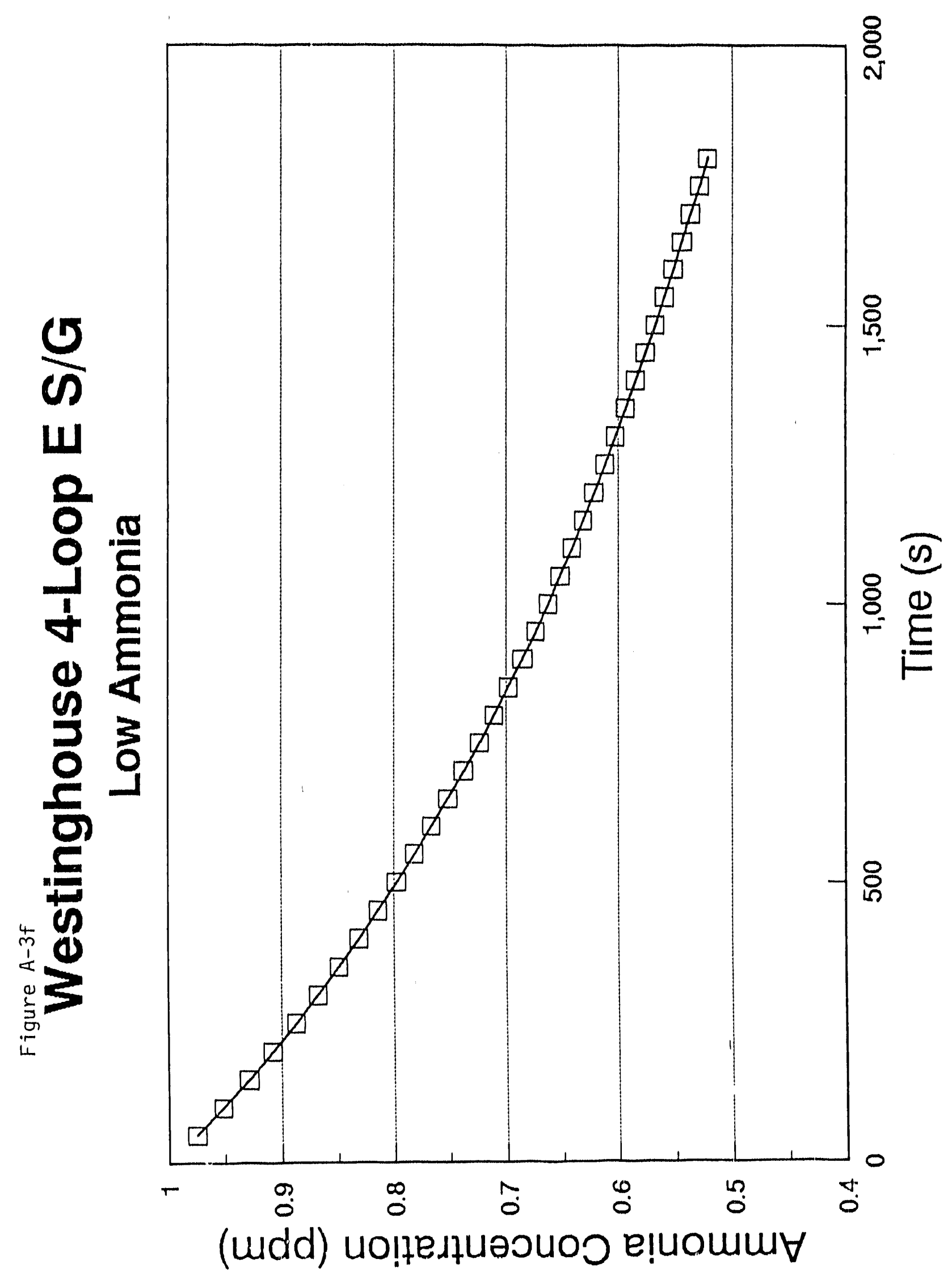




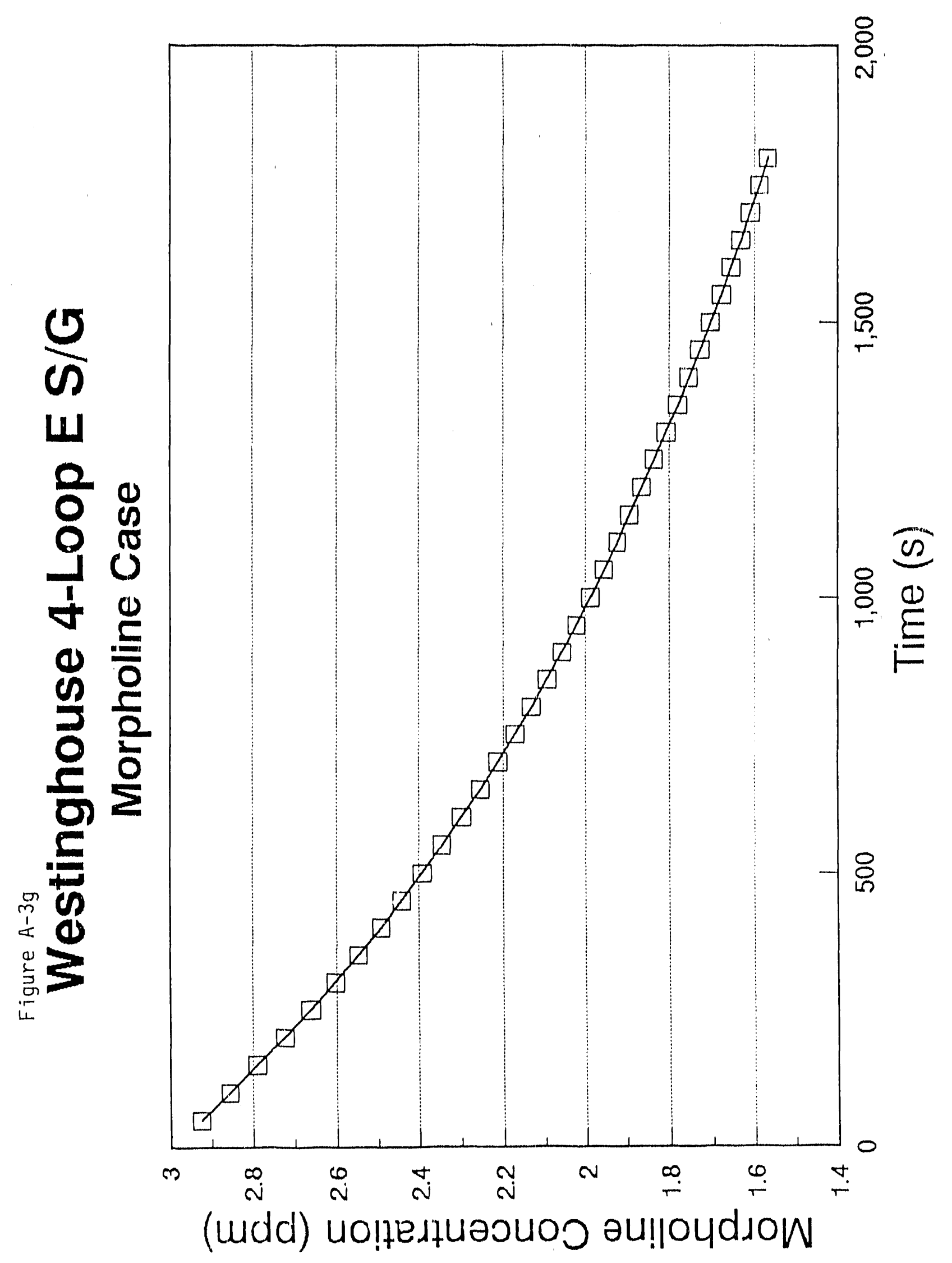




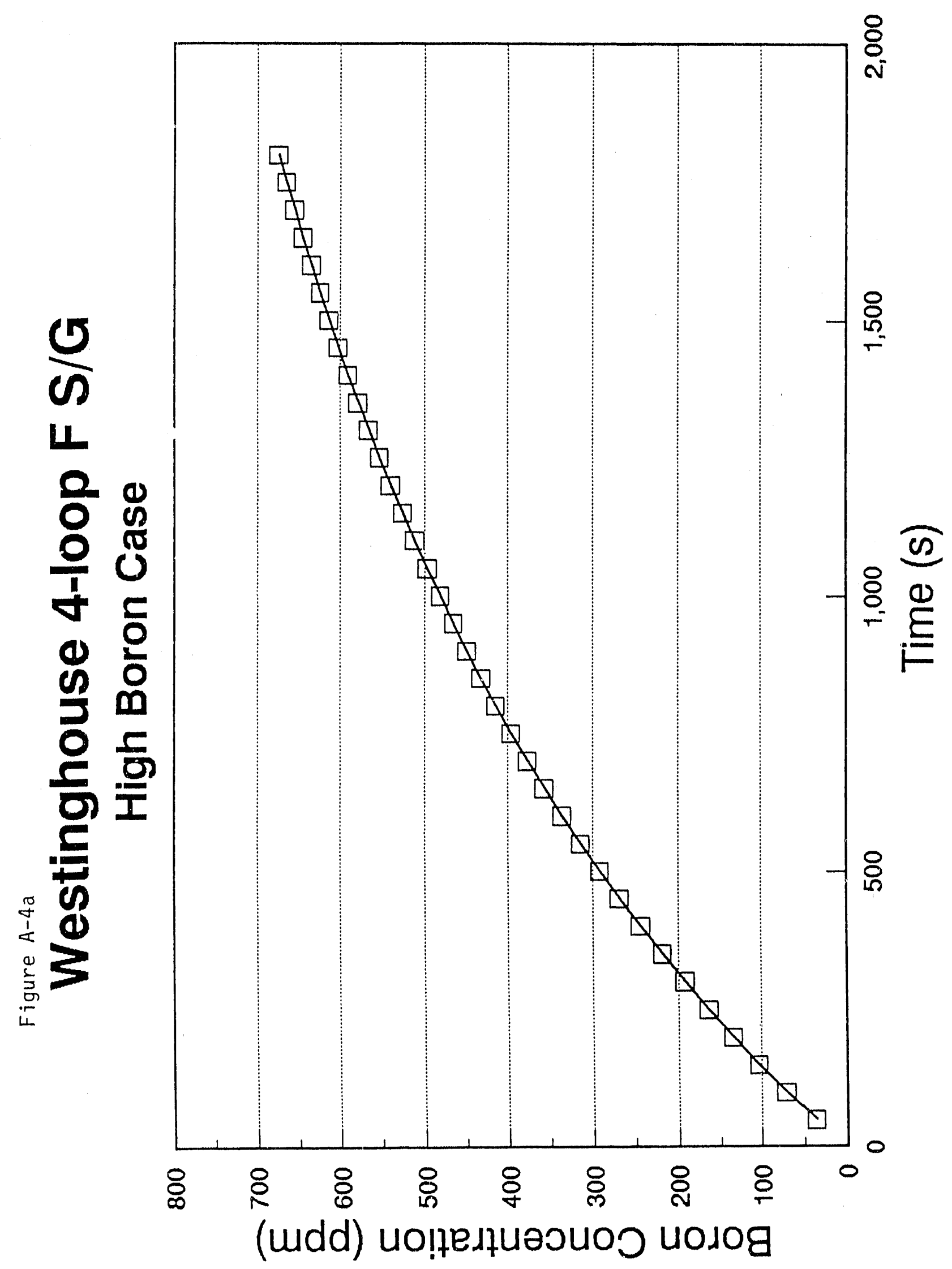




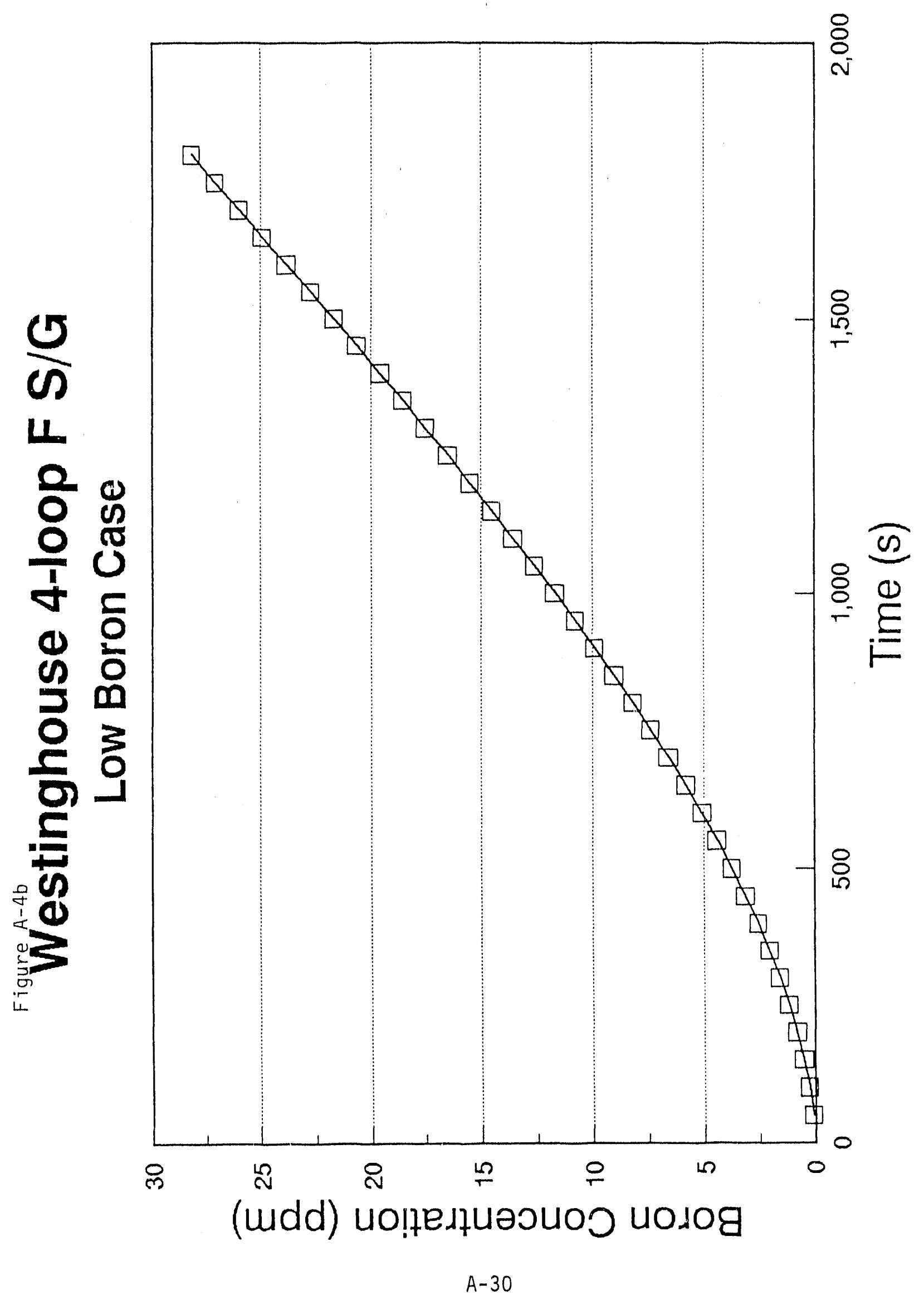




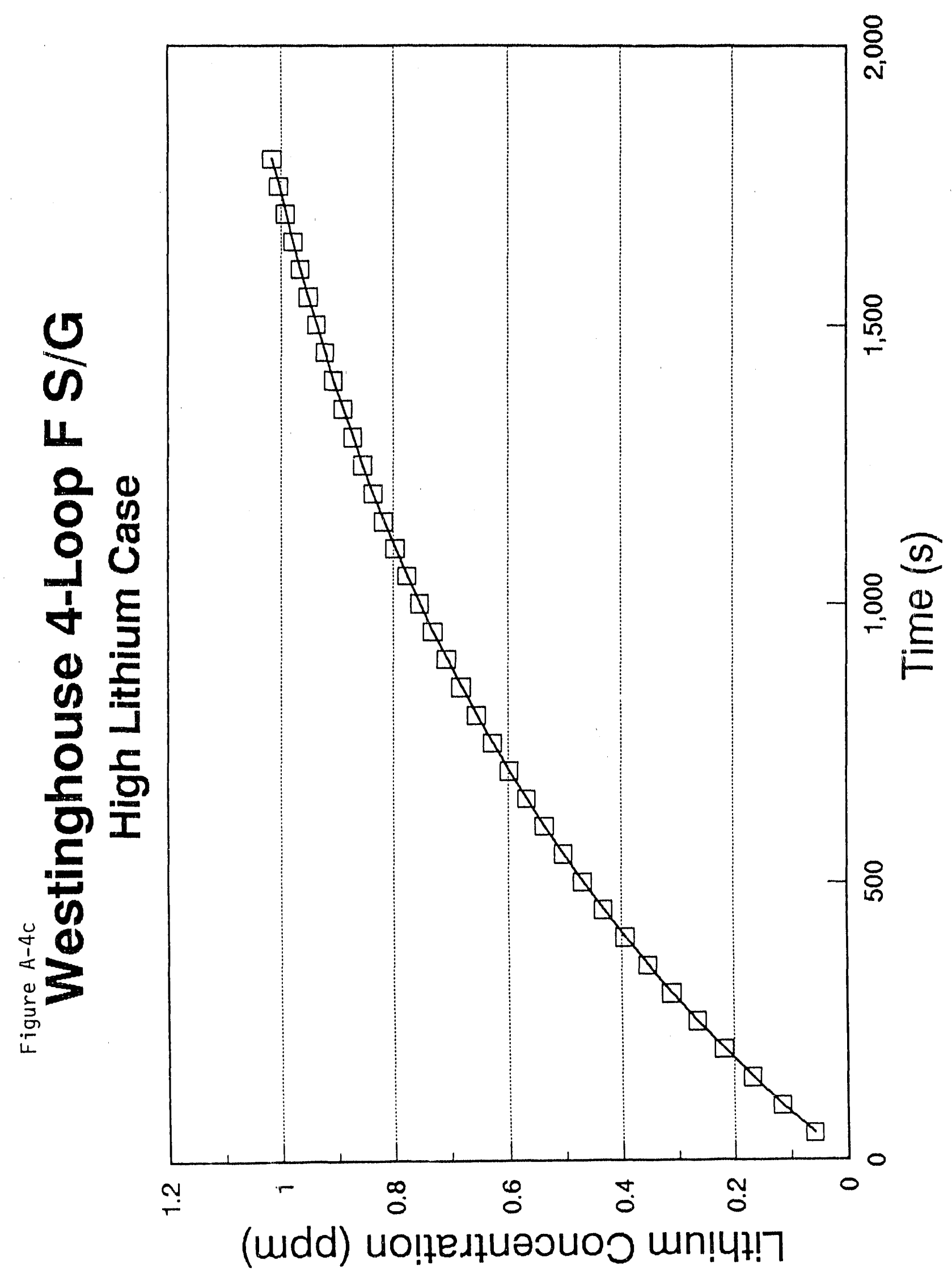




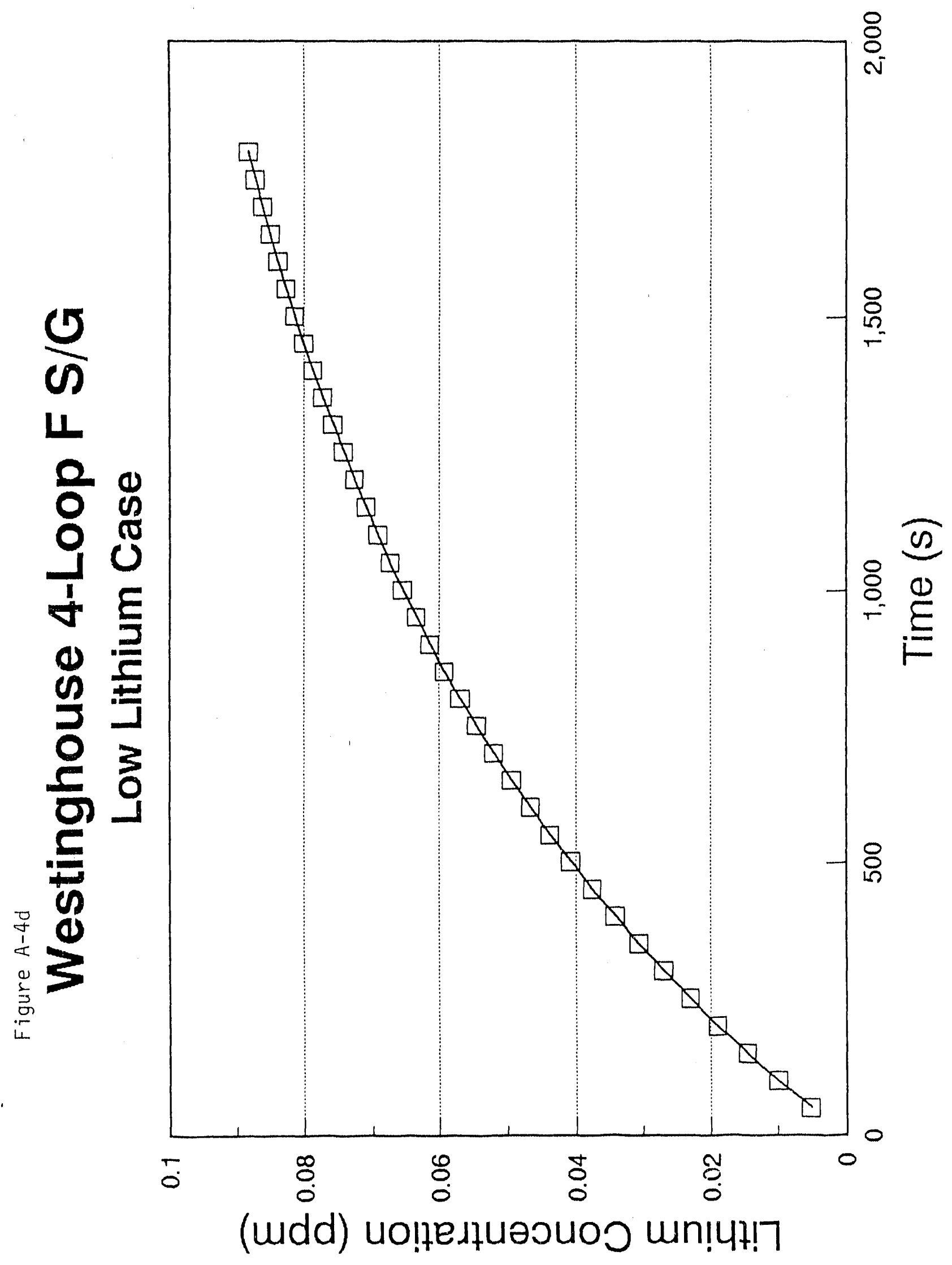

A-32 


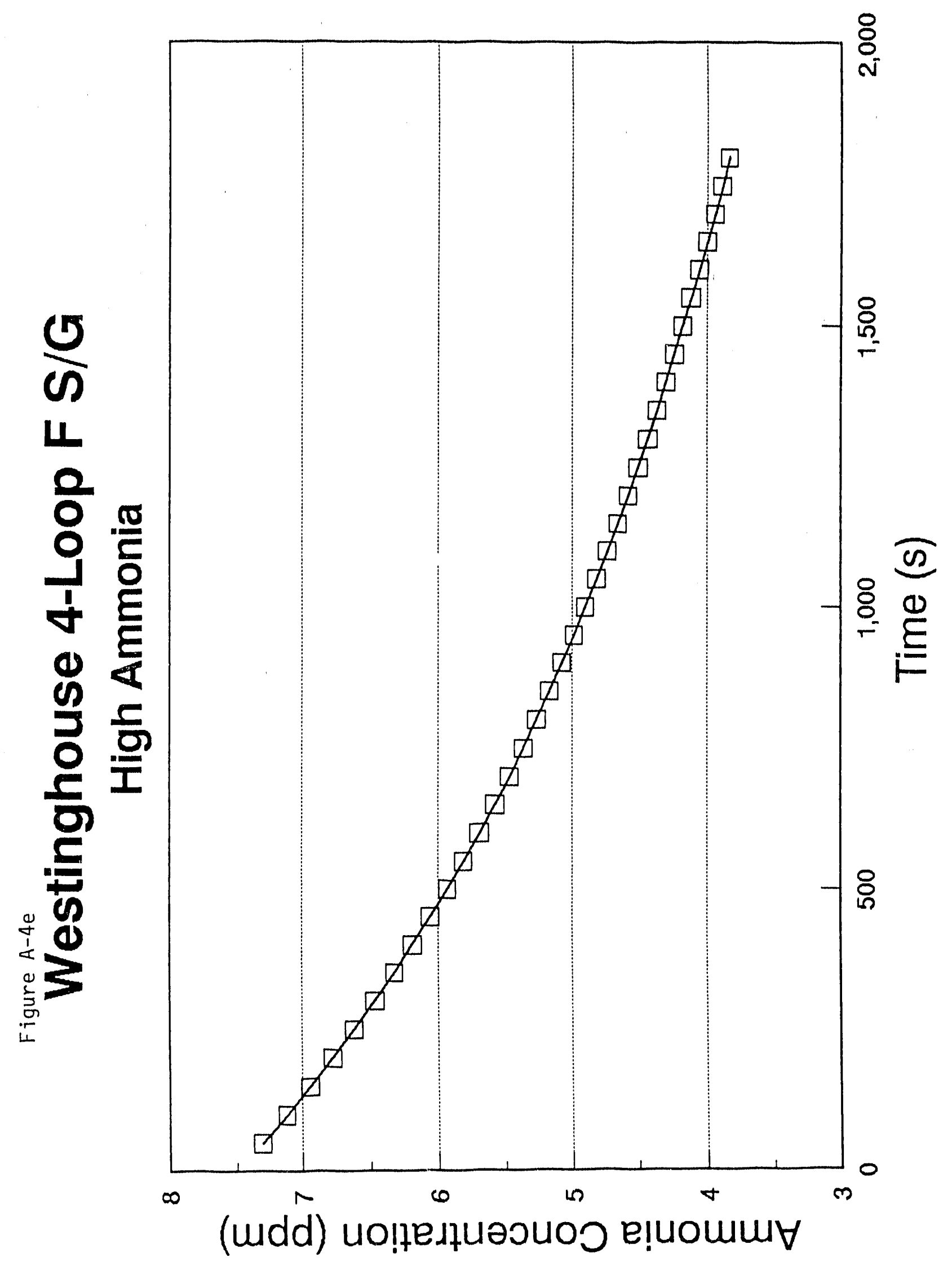




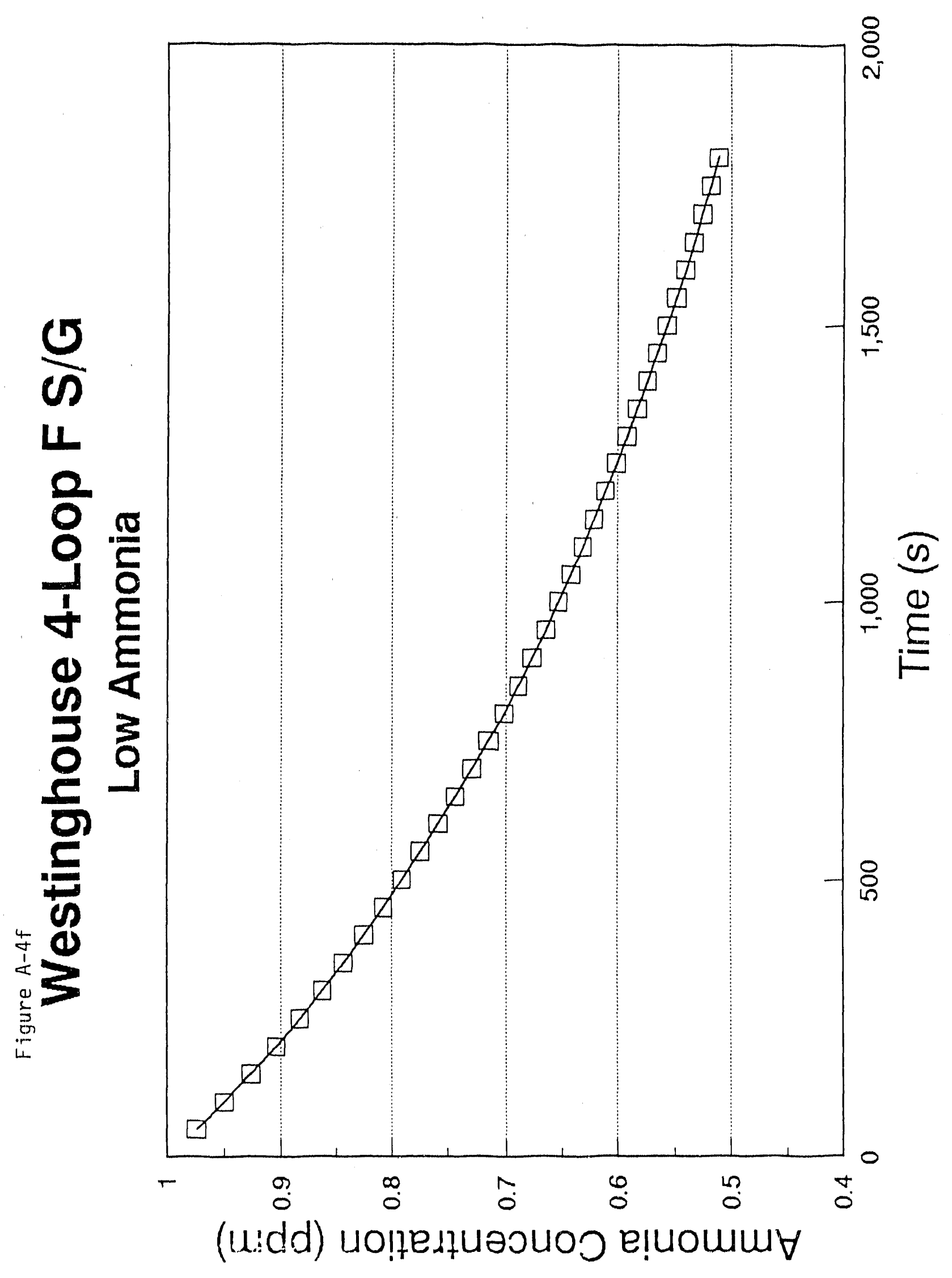

A- 34 


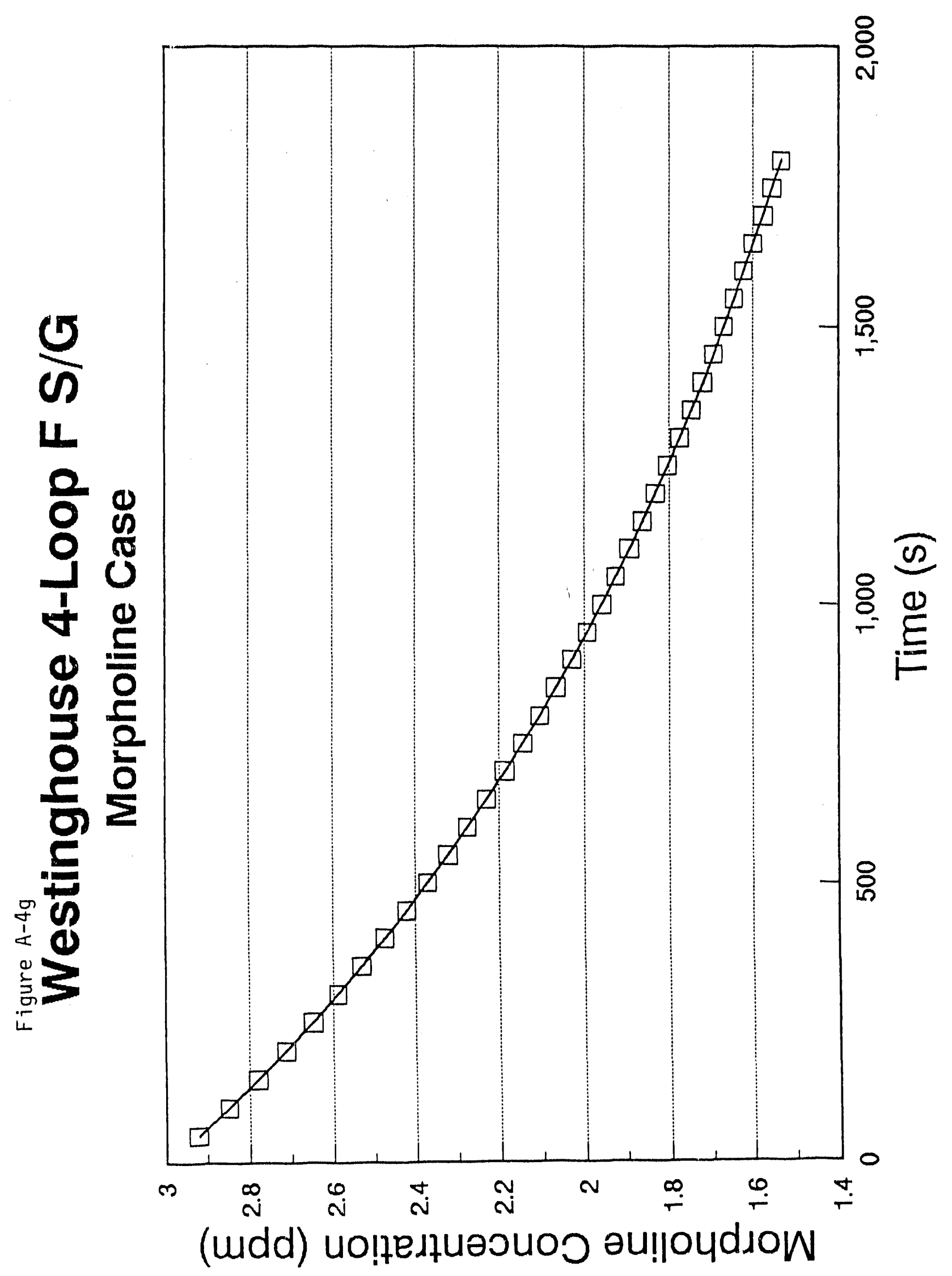

$A-35$ 


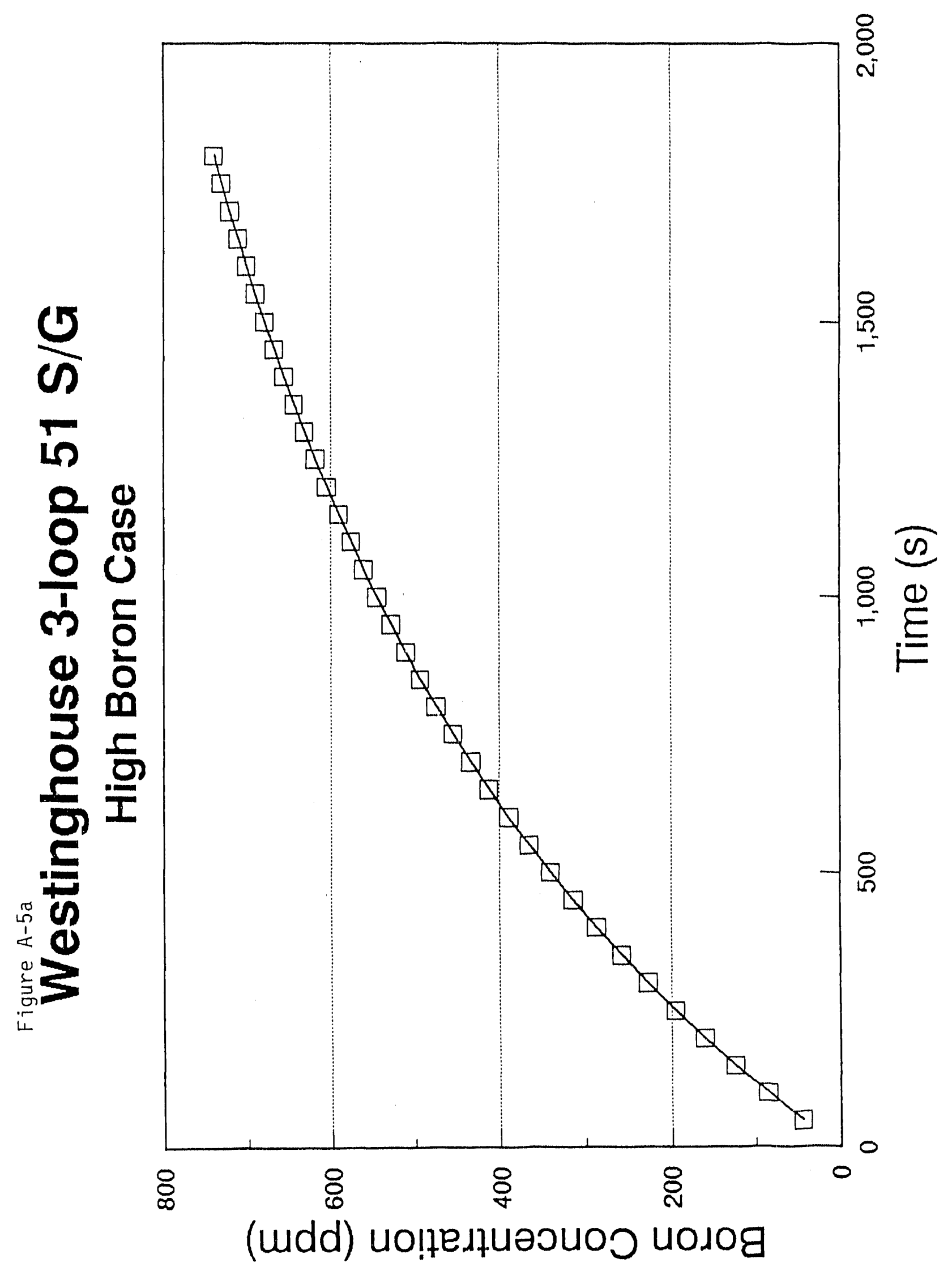




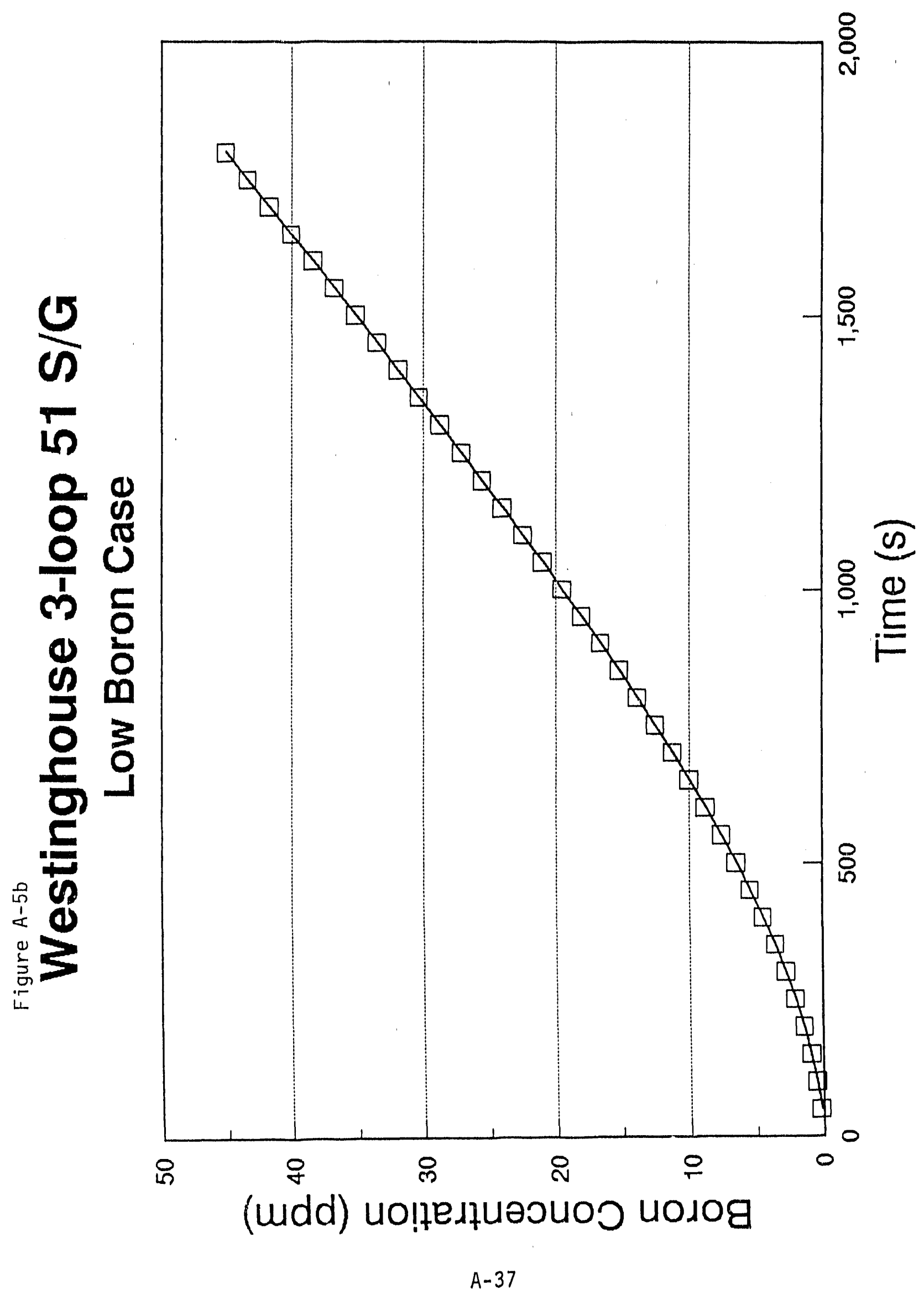




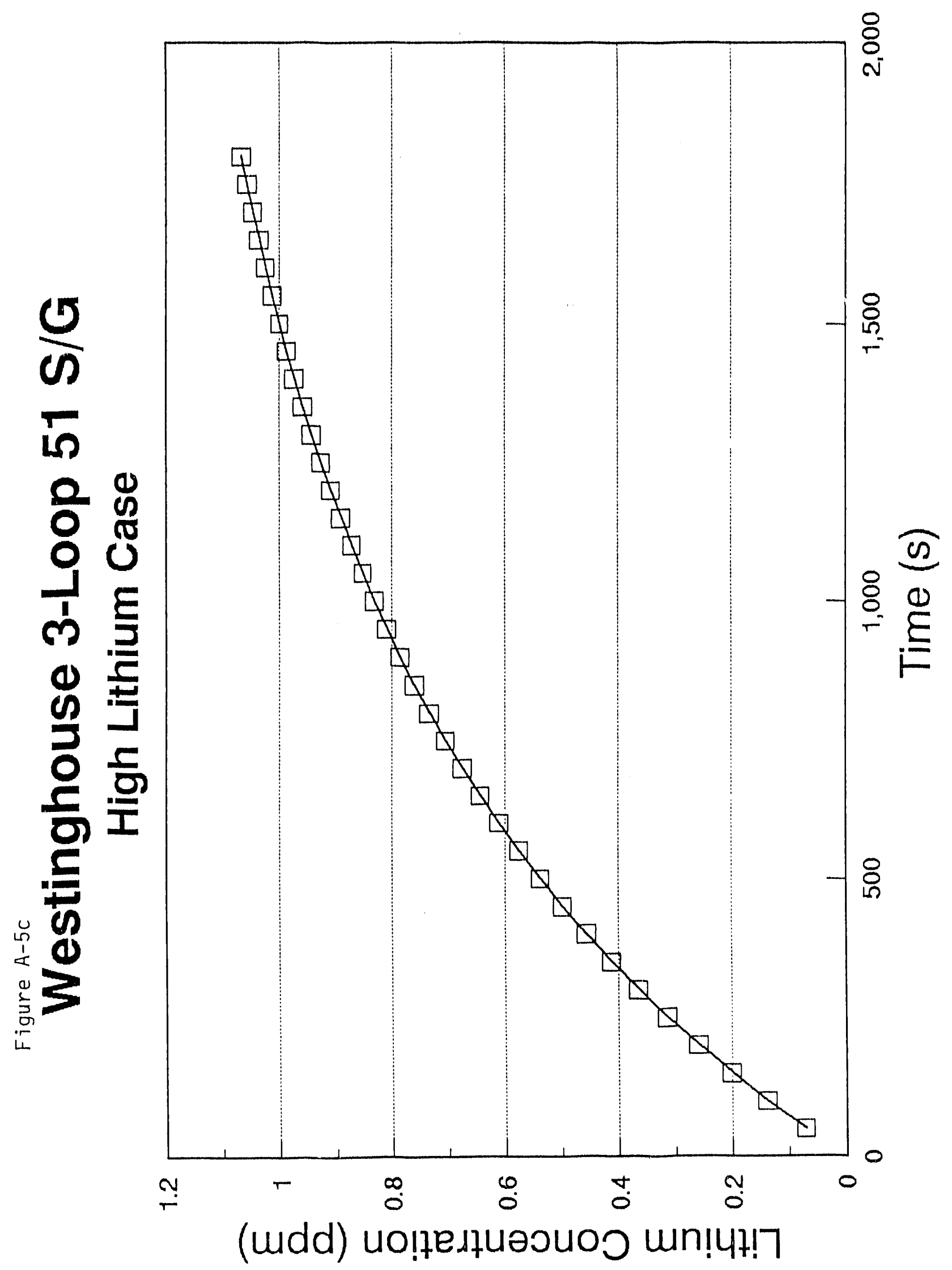

A-38 


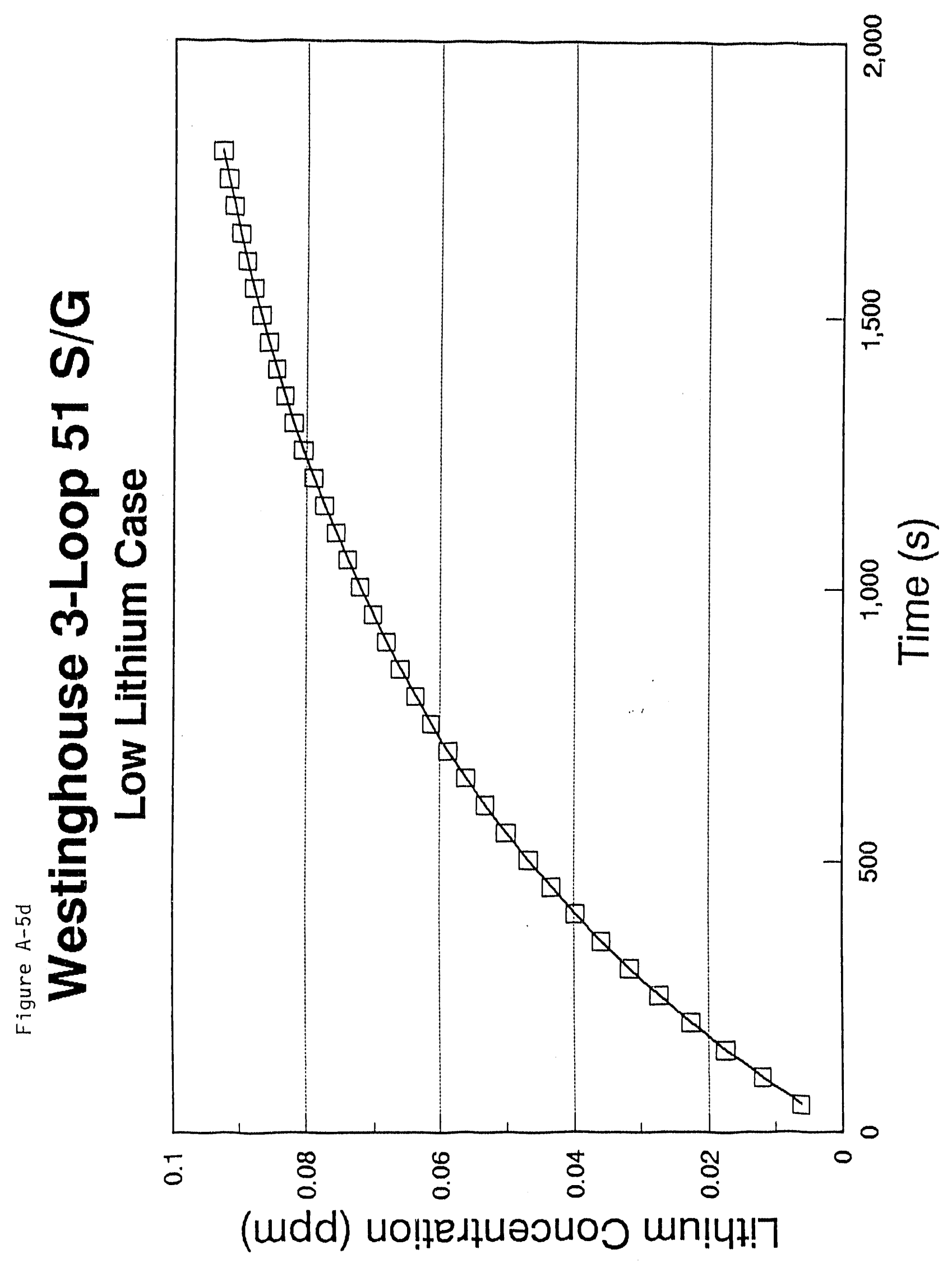

A-39 


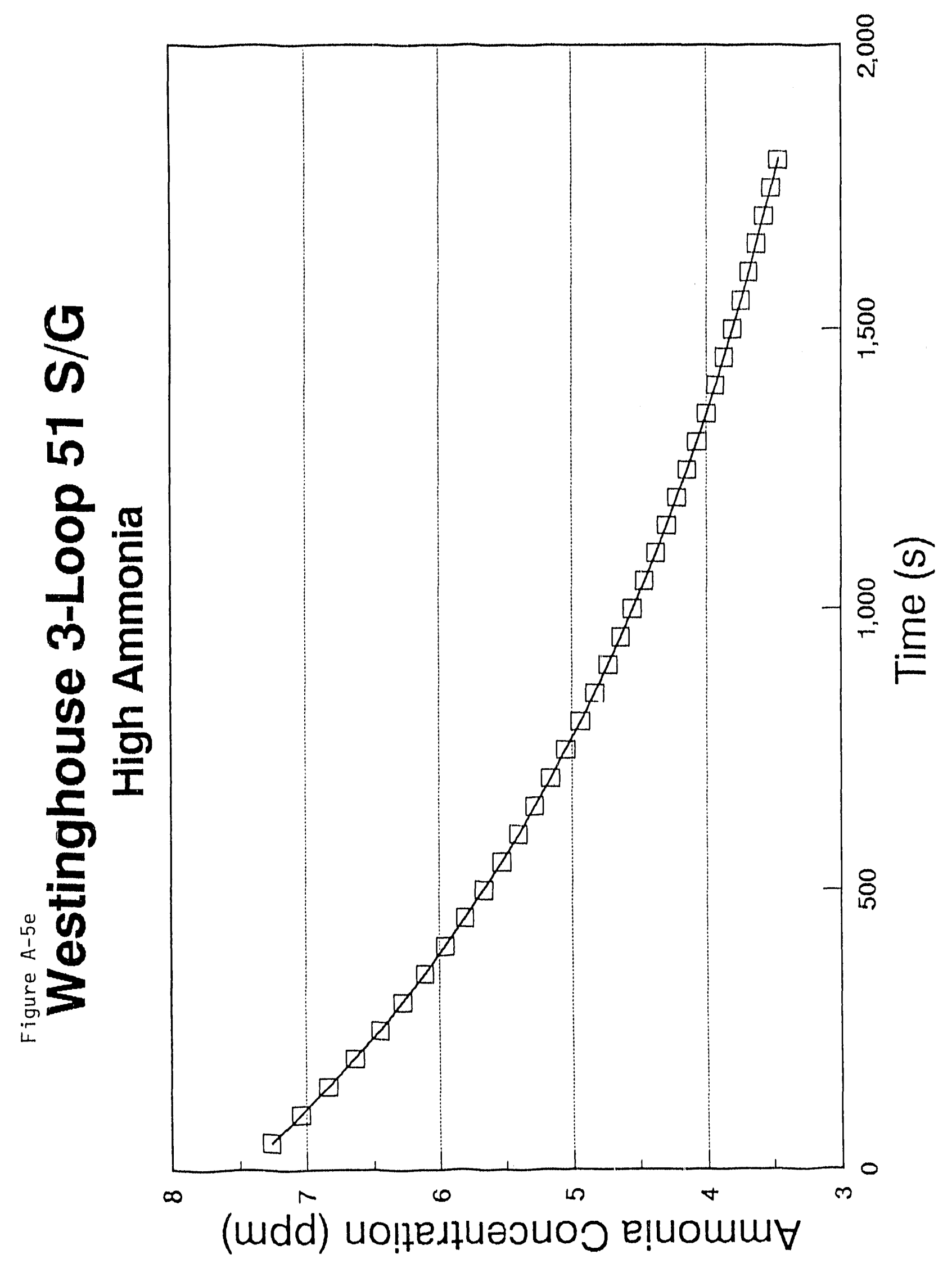

A- 40 


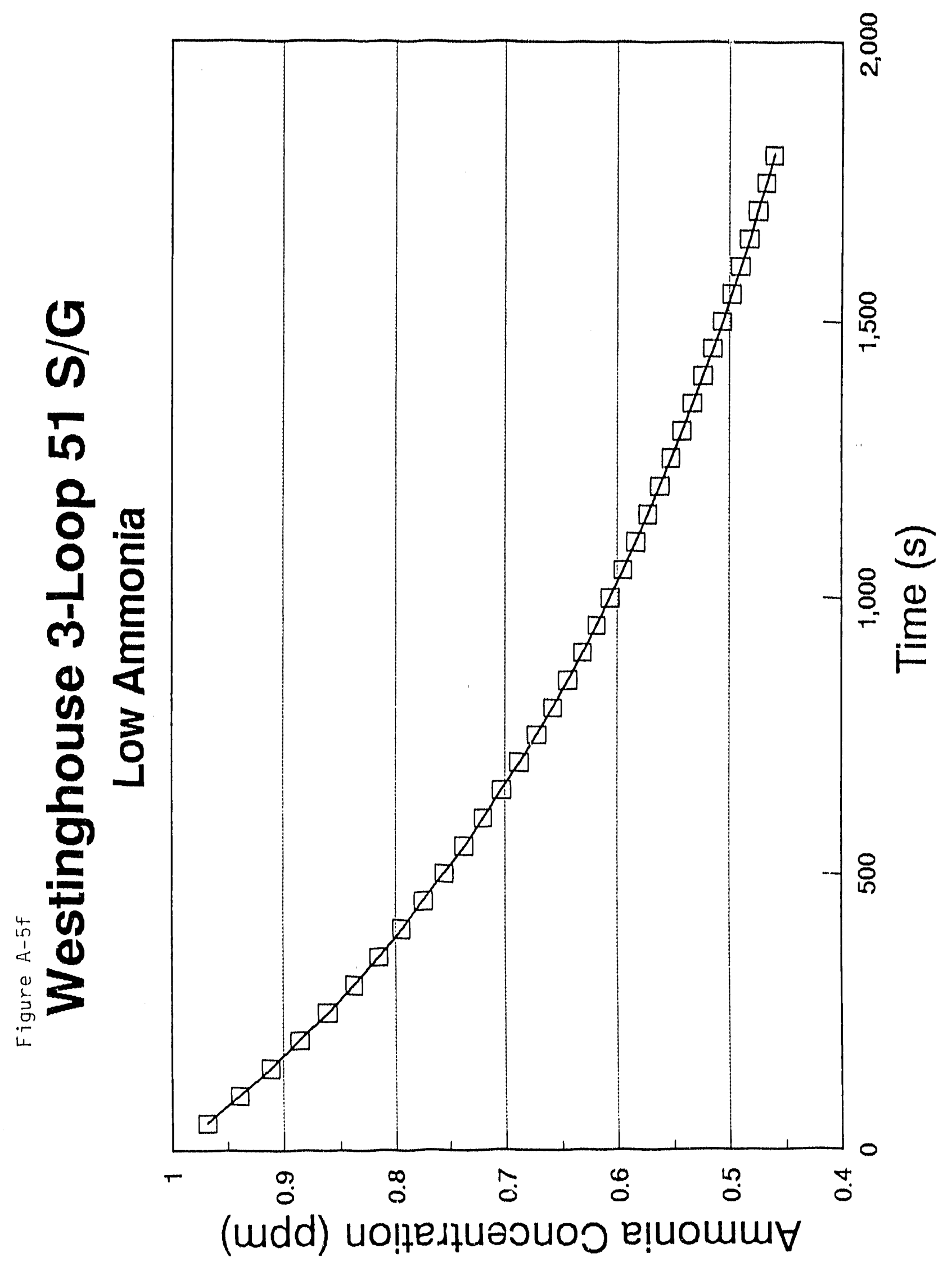

$A-41$ 


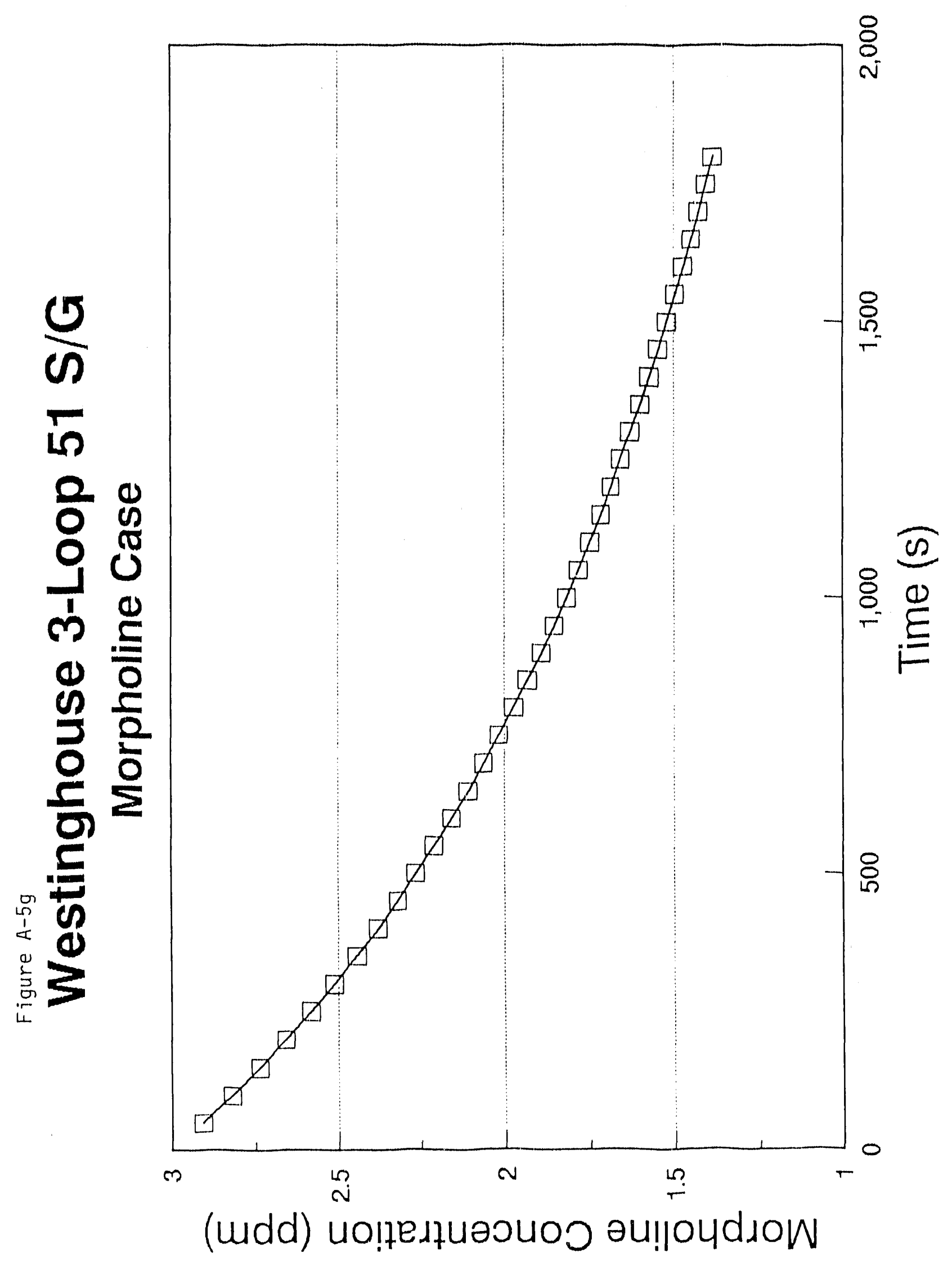




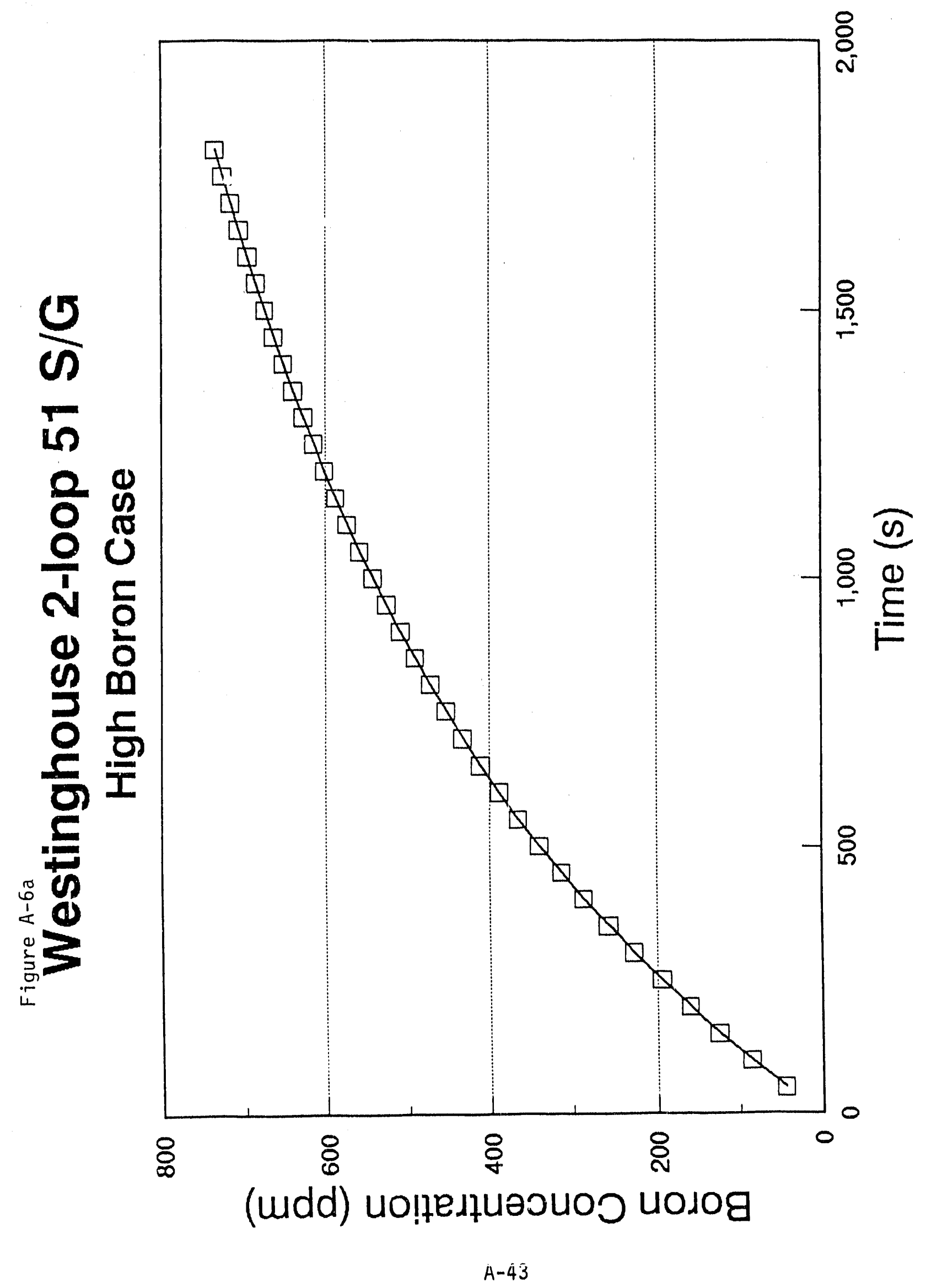




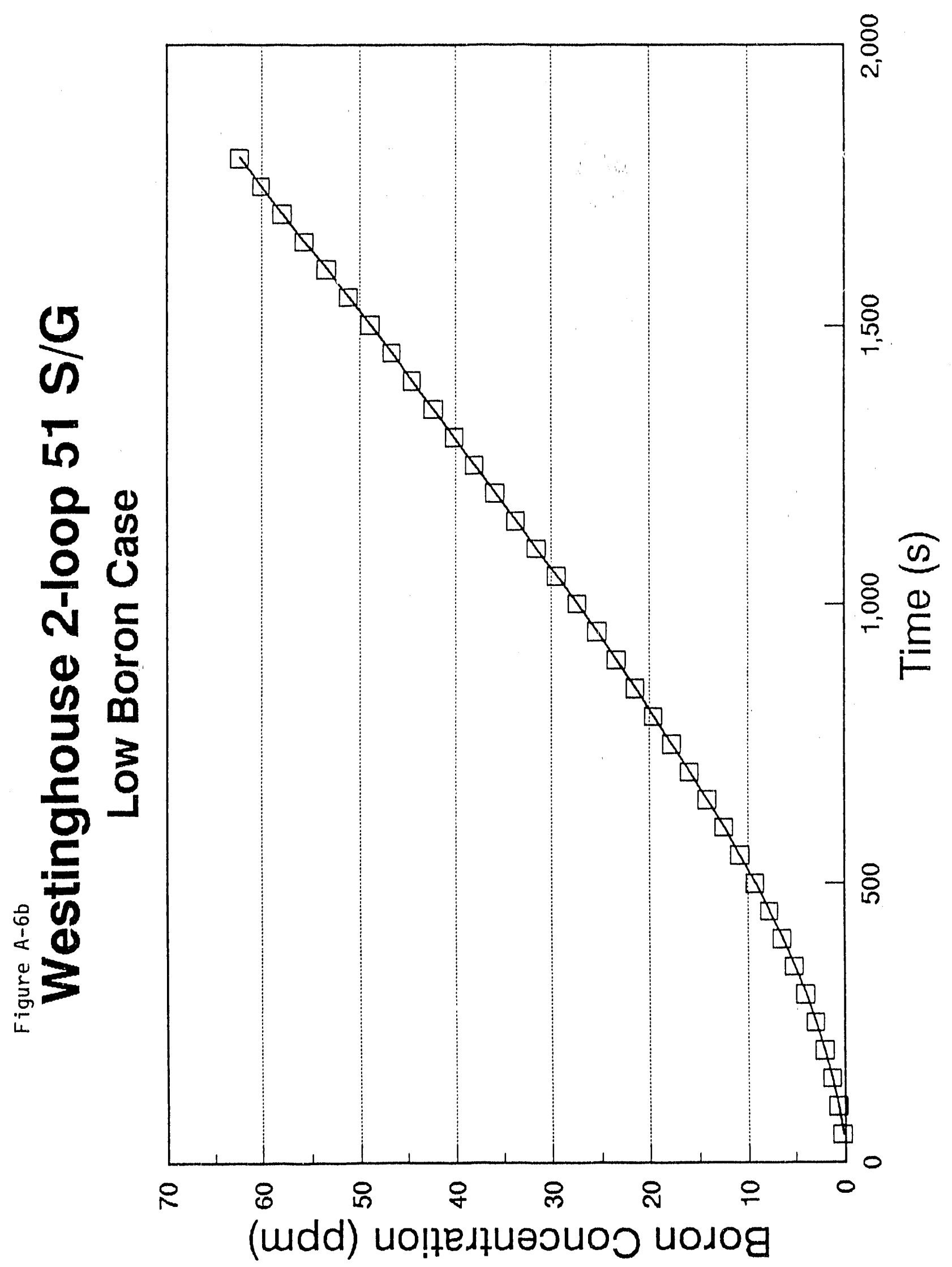




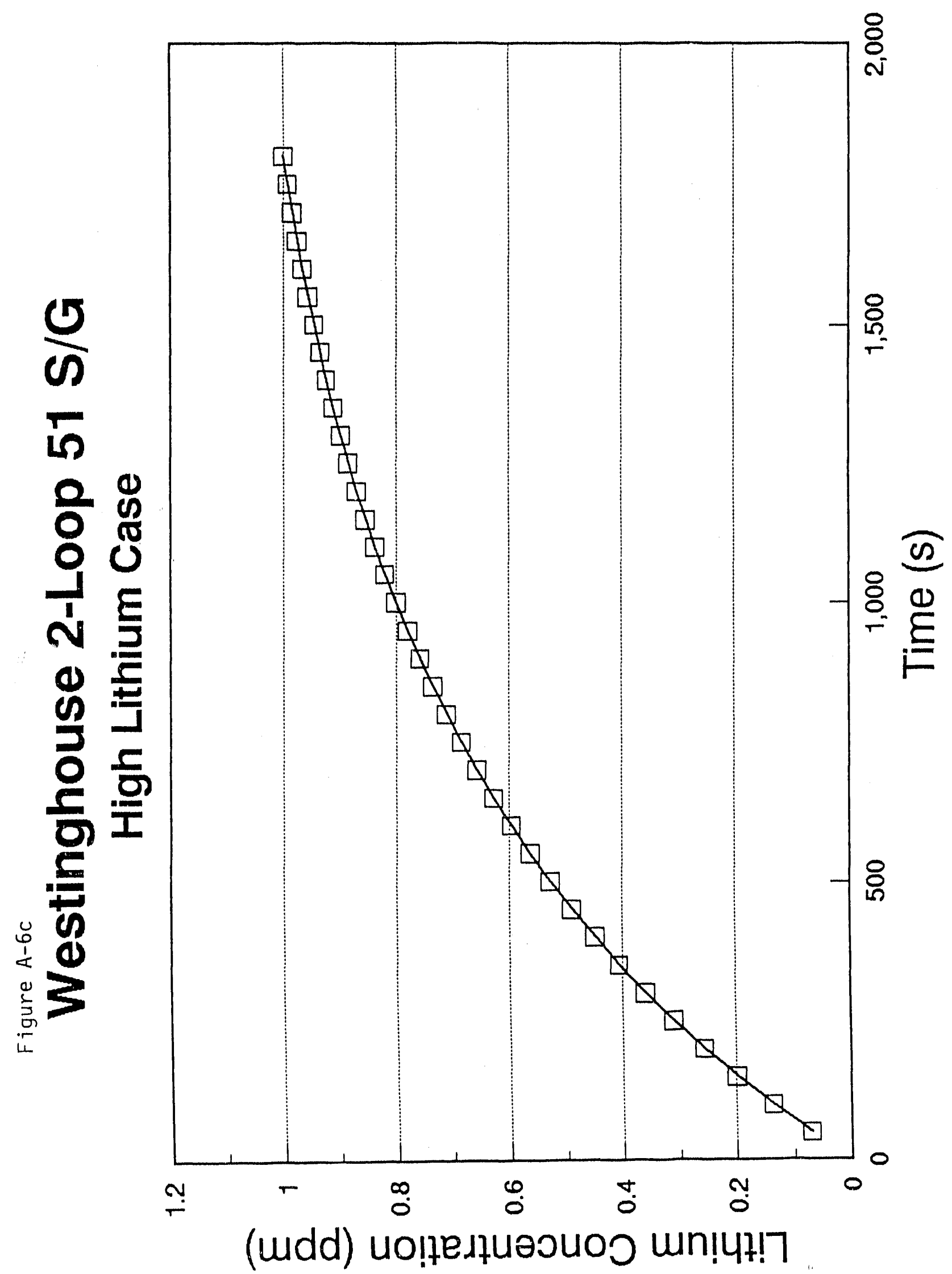




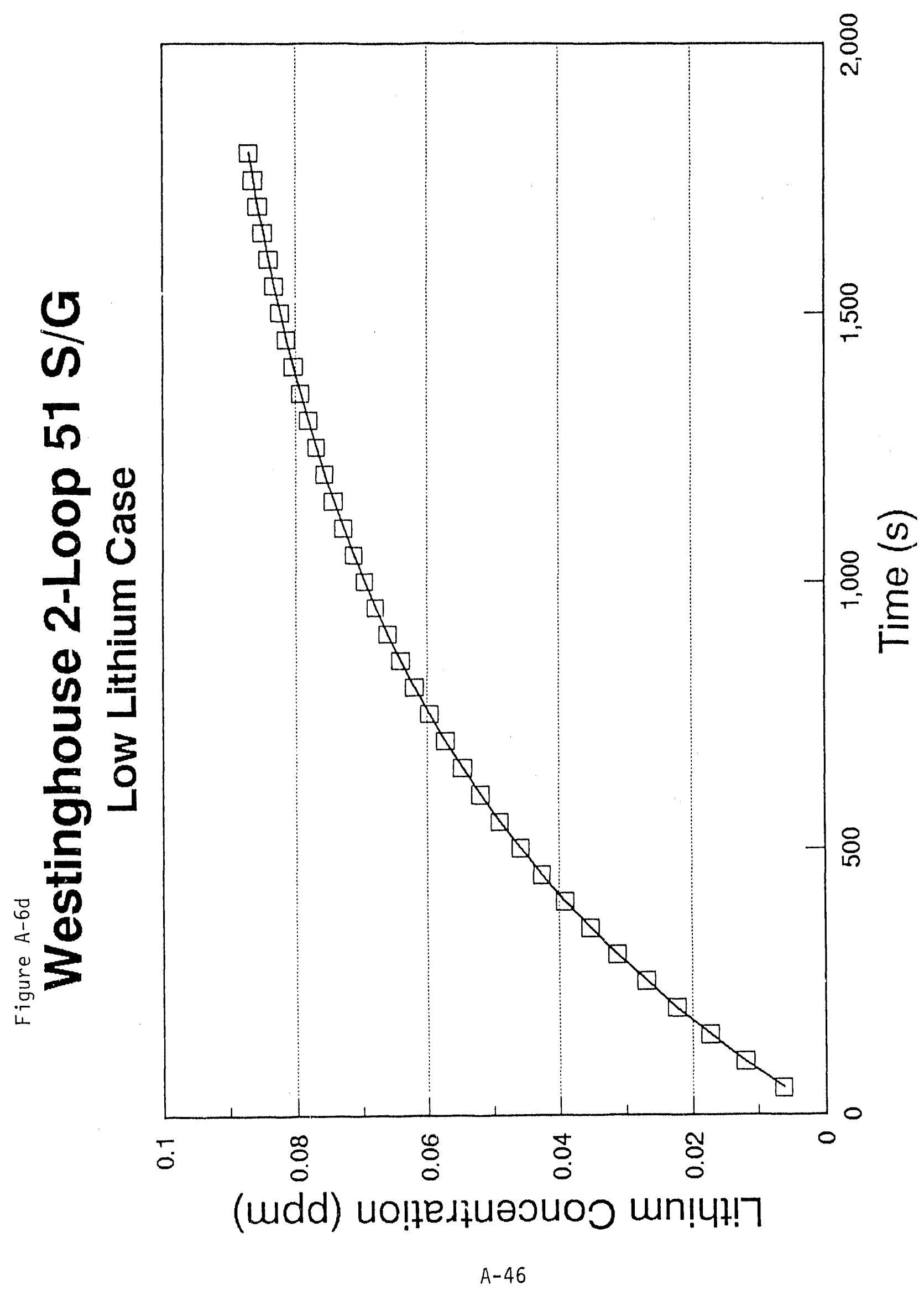




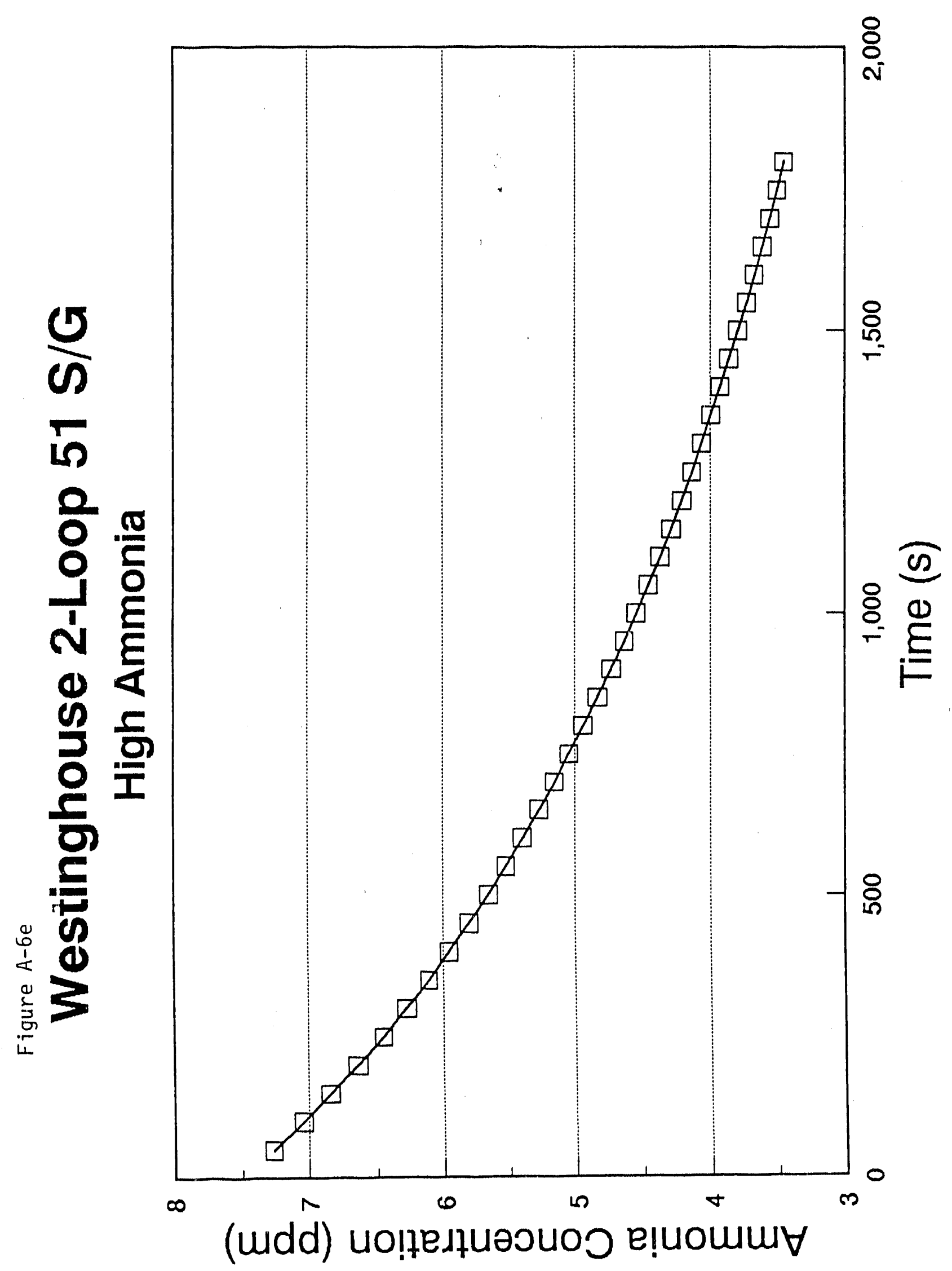




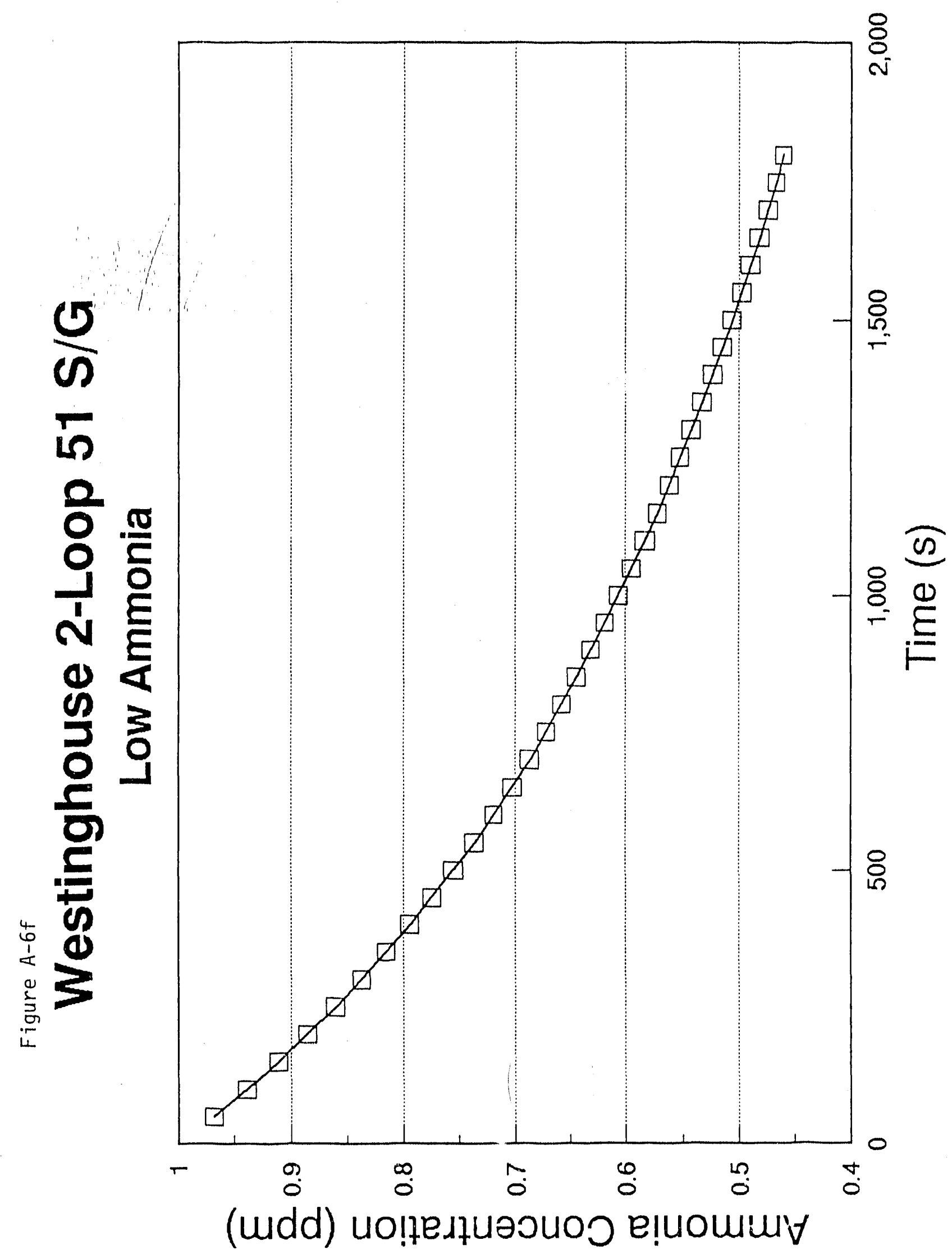




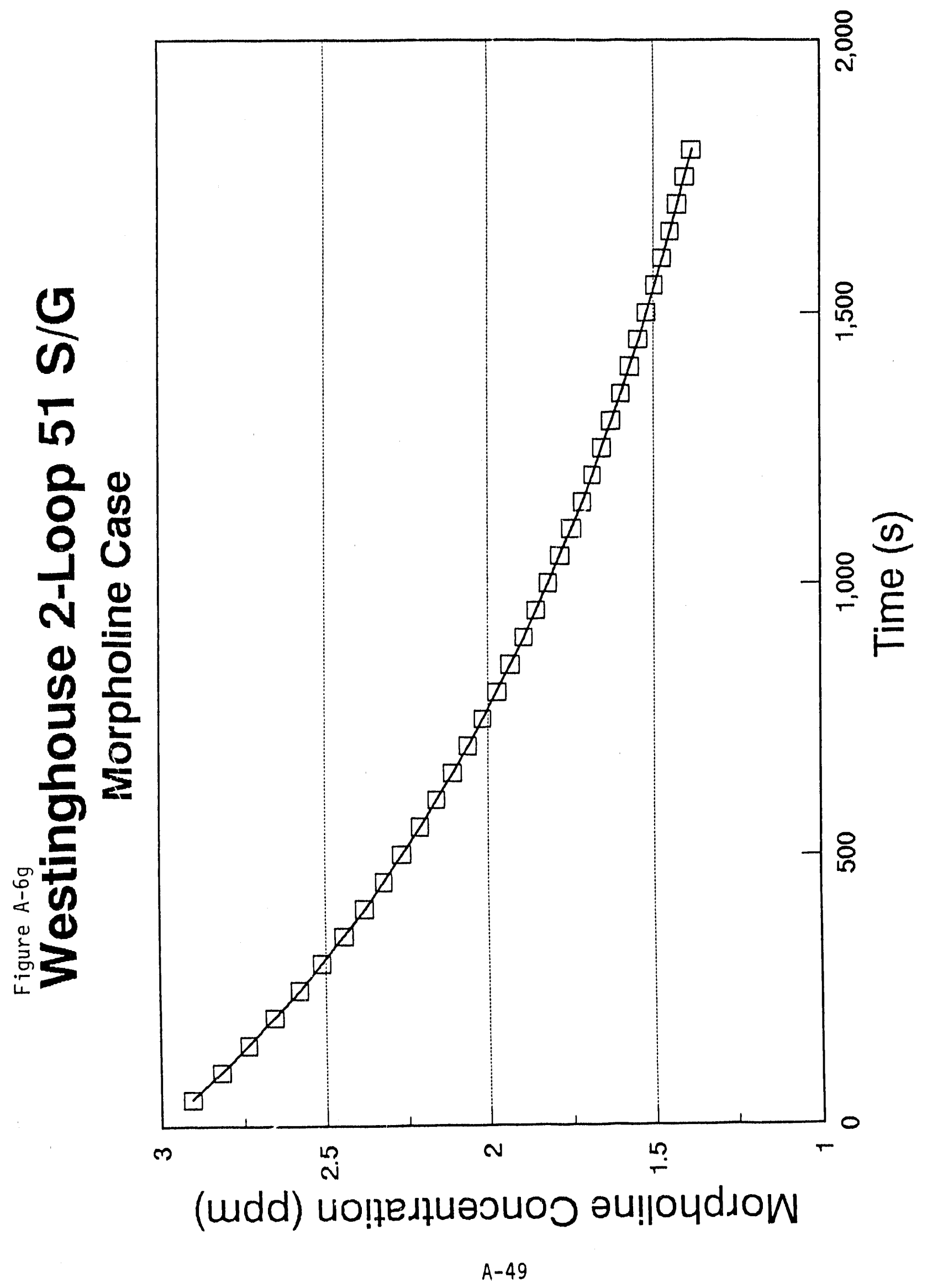




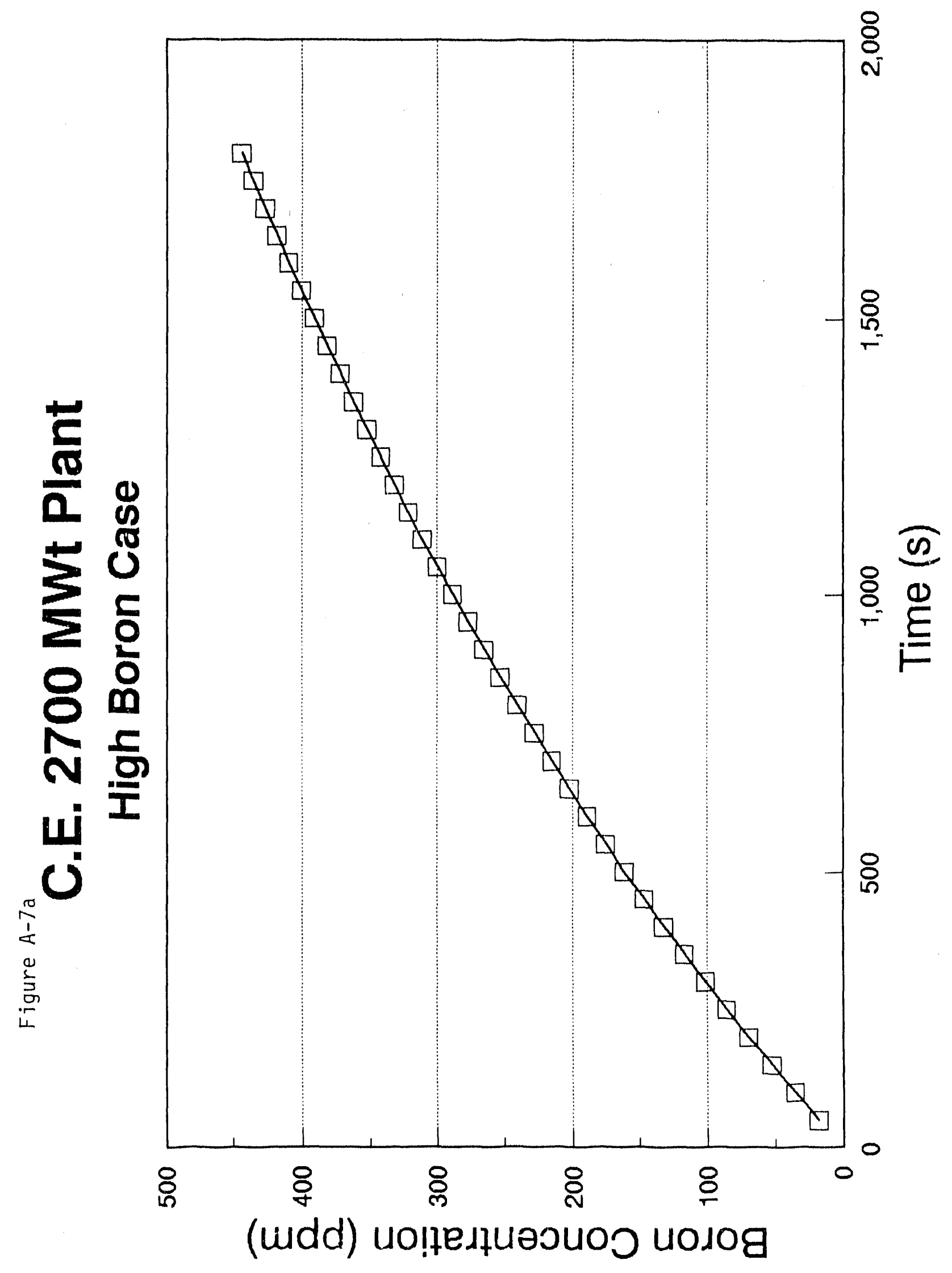




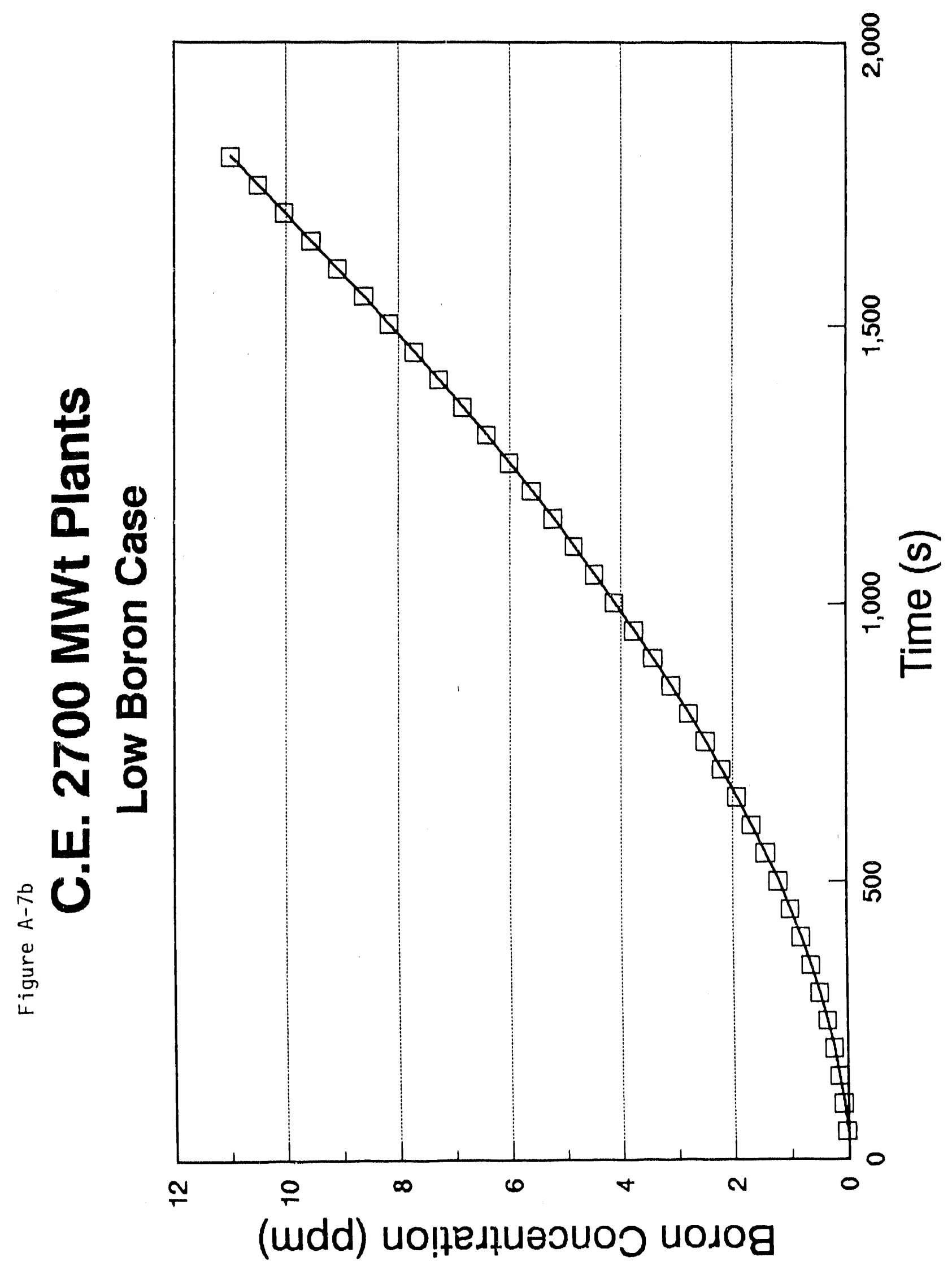




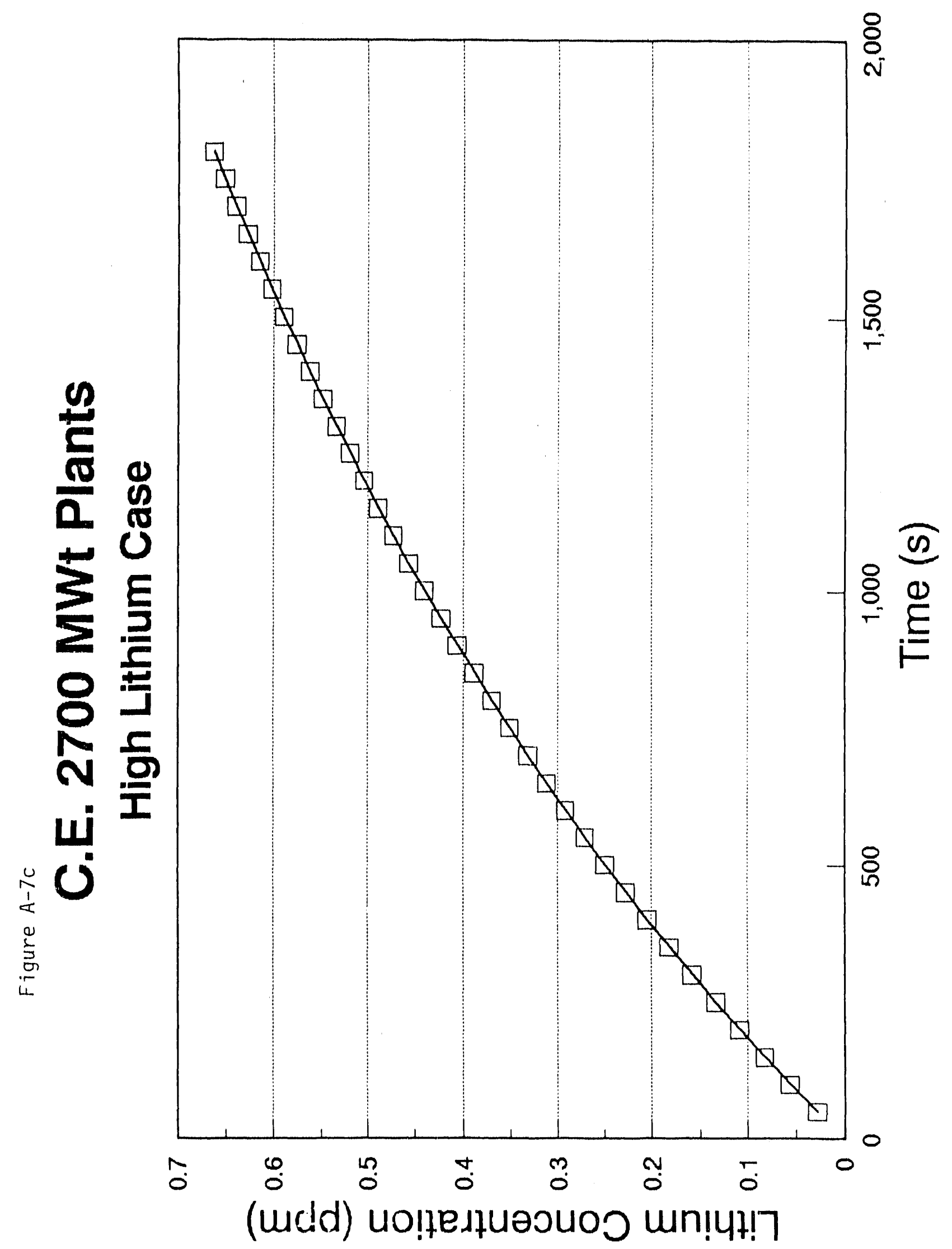

A-52 


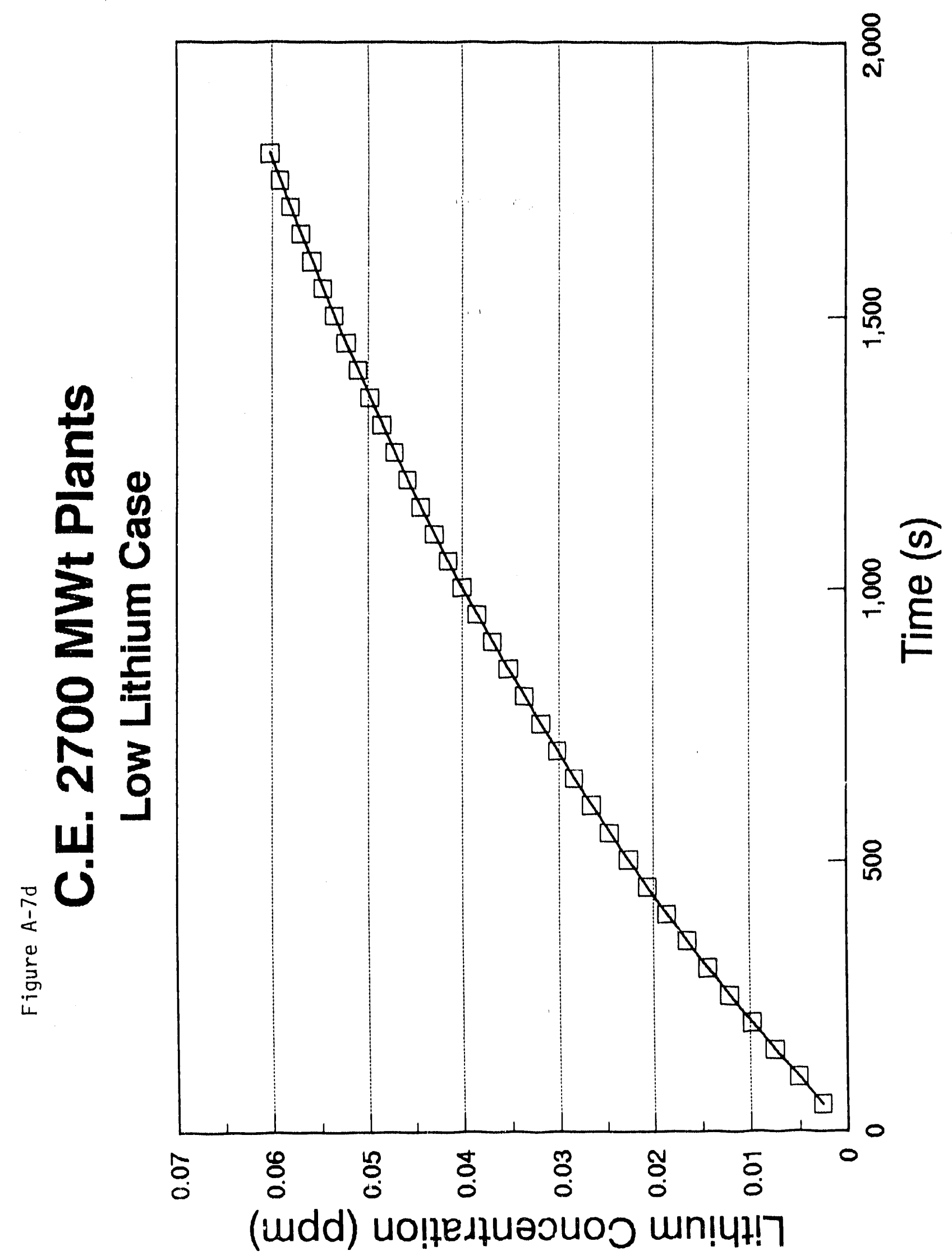




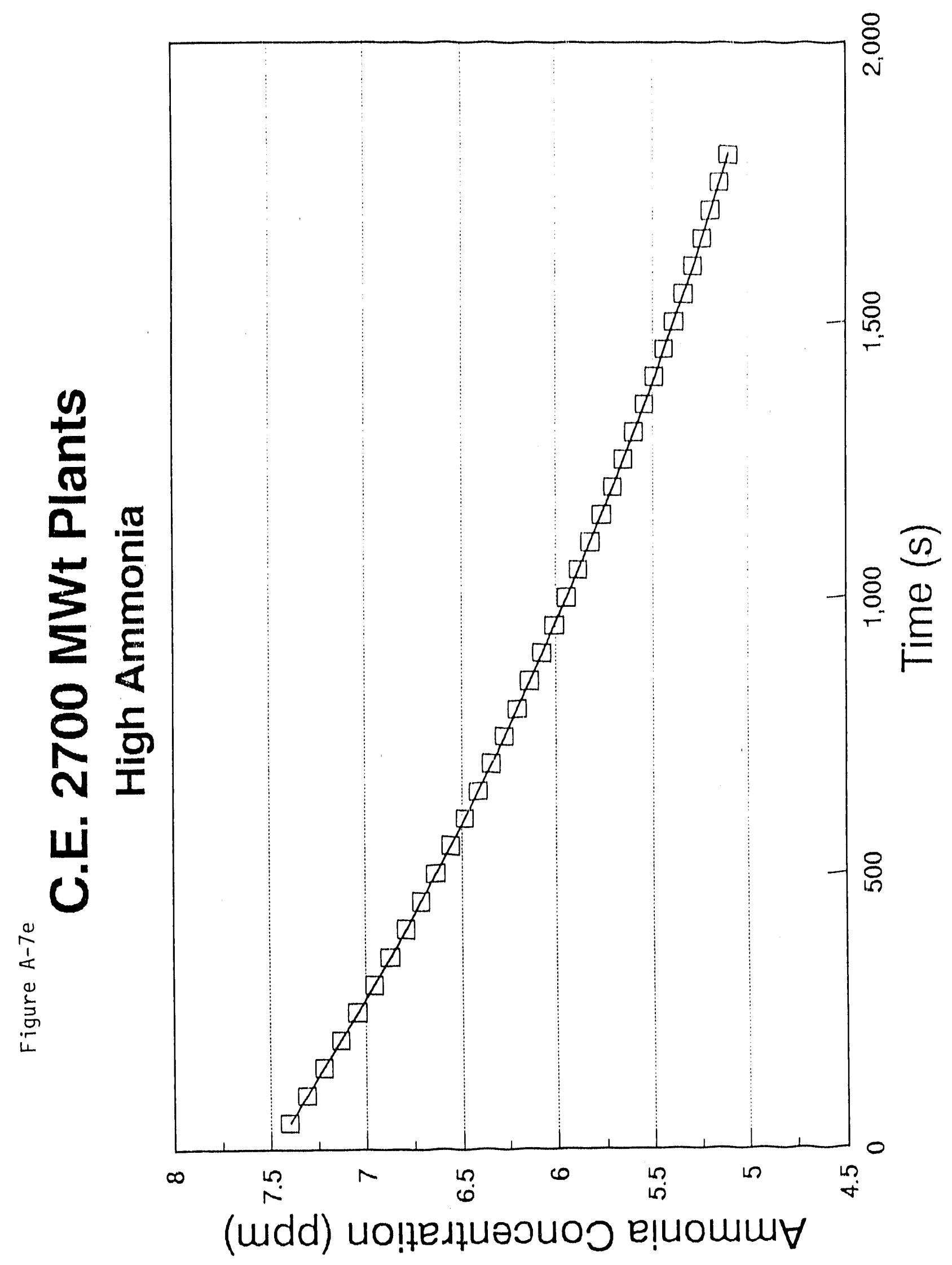

A-54 


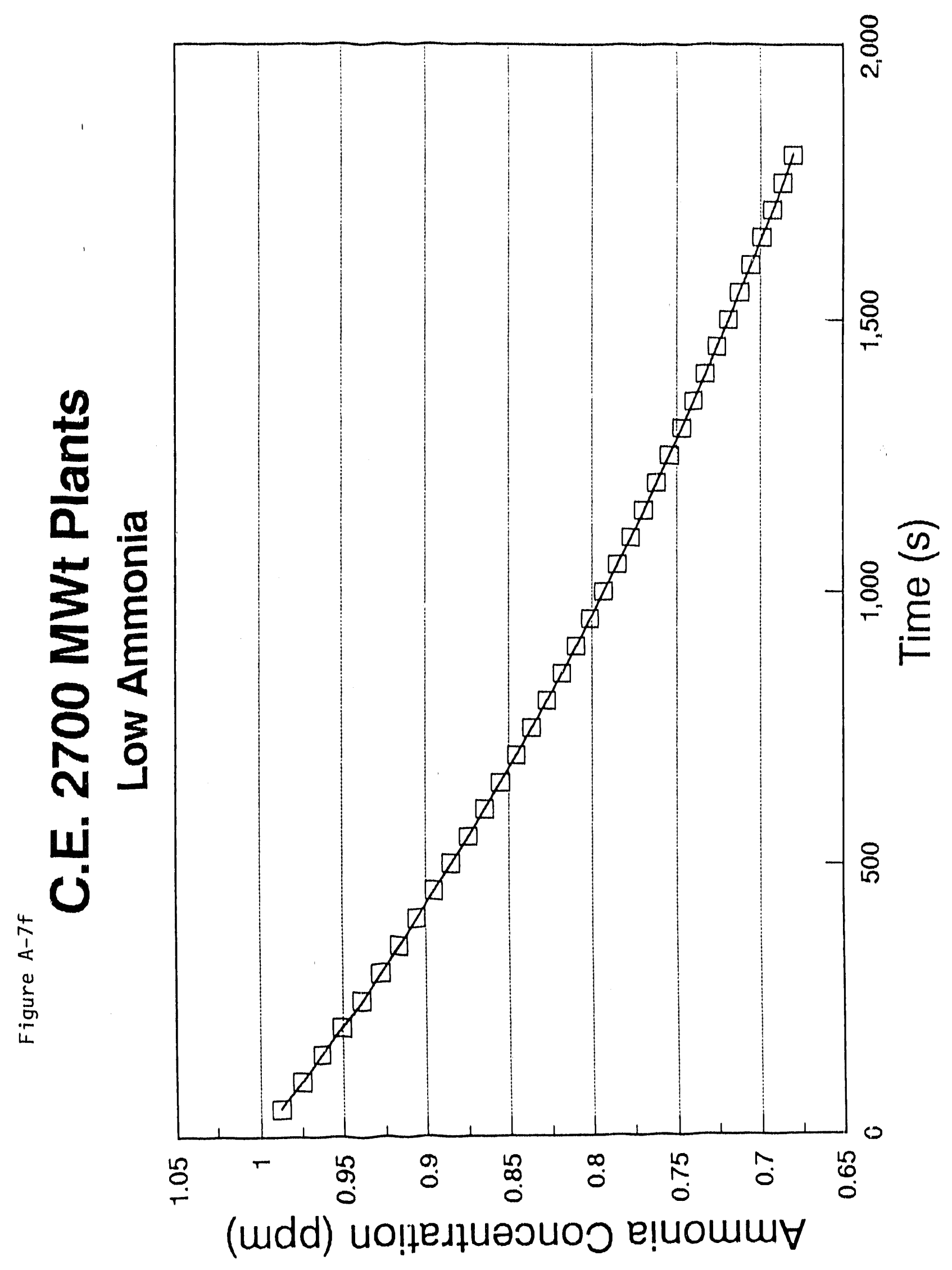

A-55 


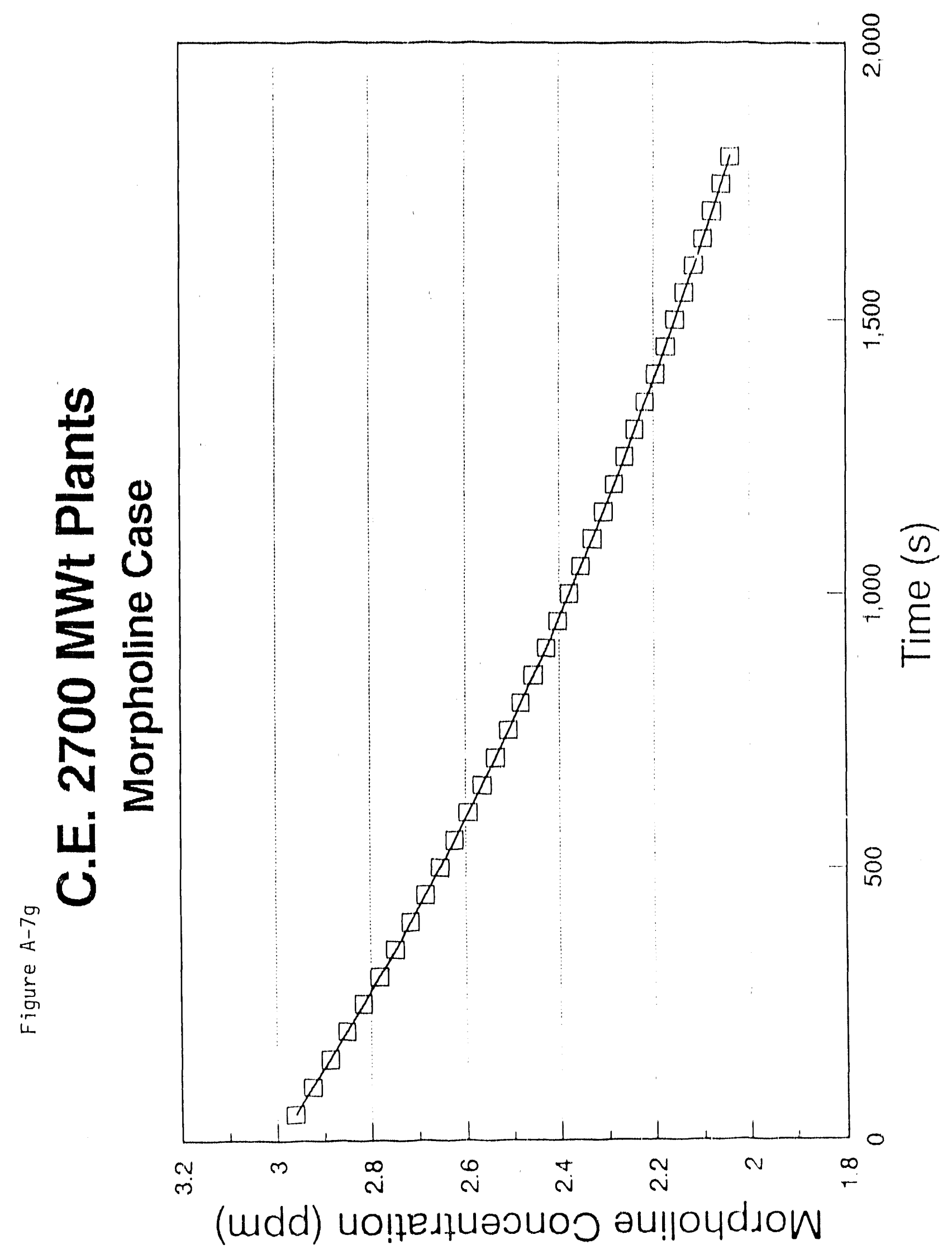

$A-56$ 


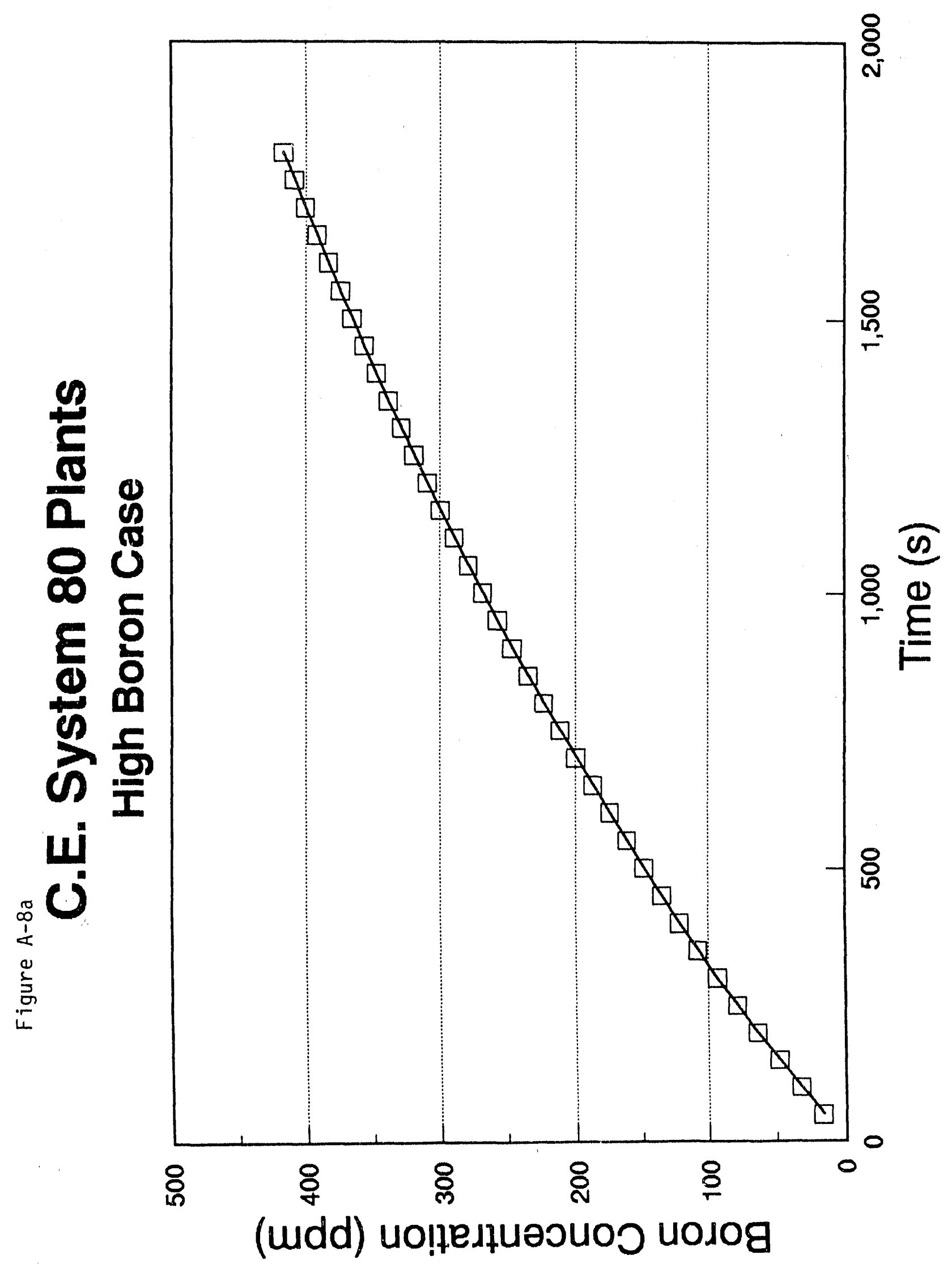

A-57 


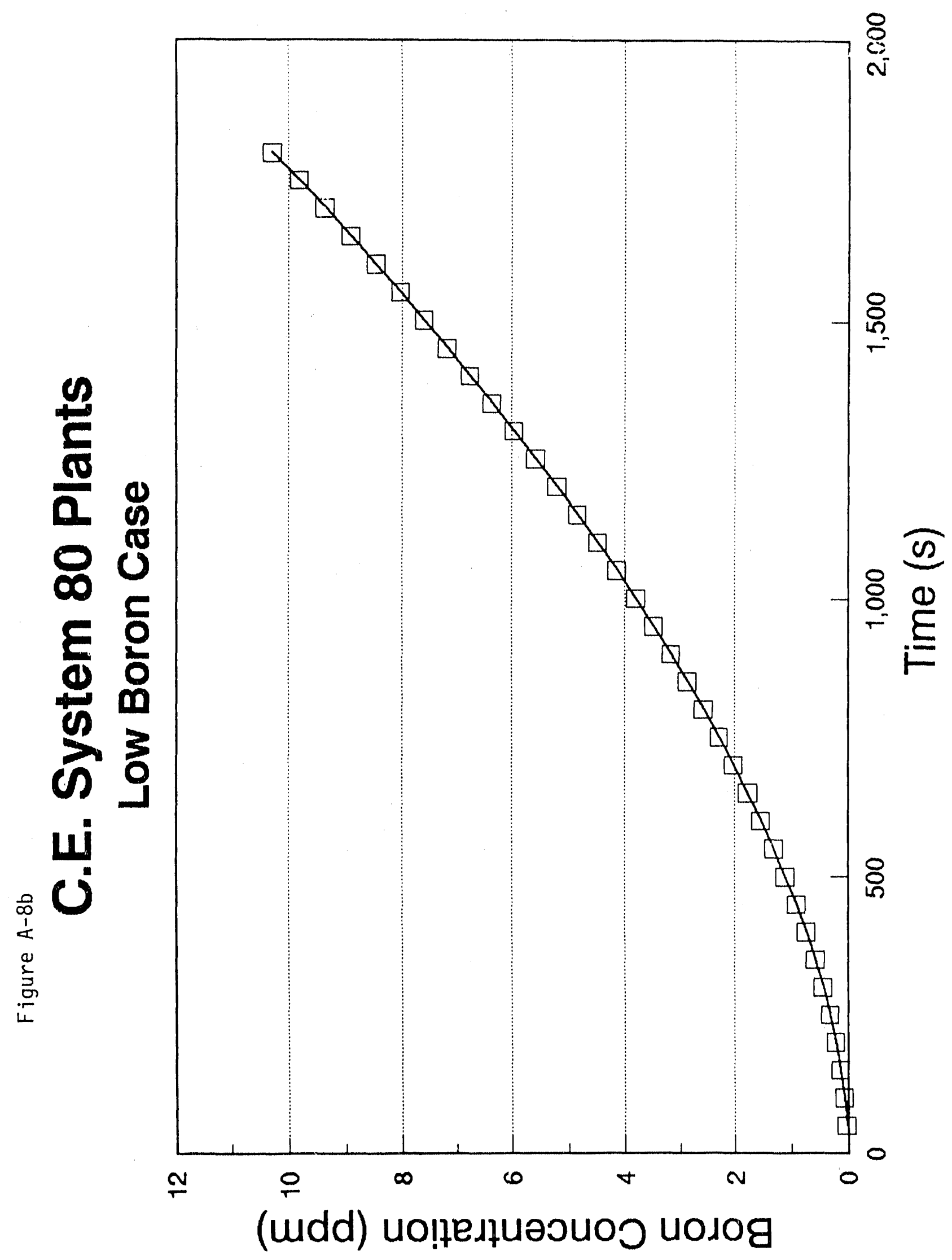




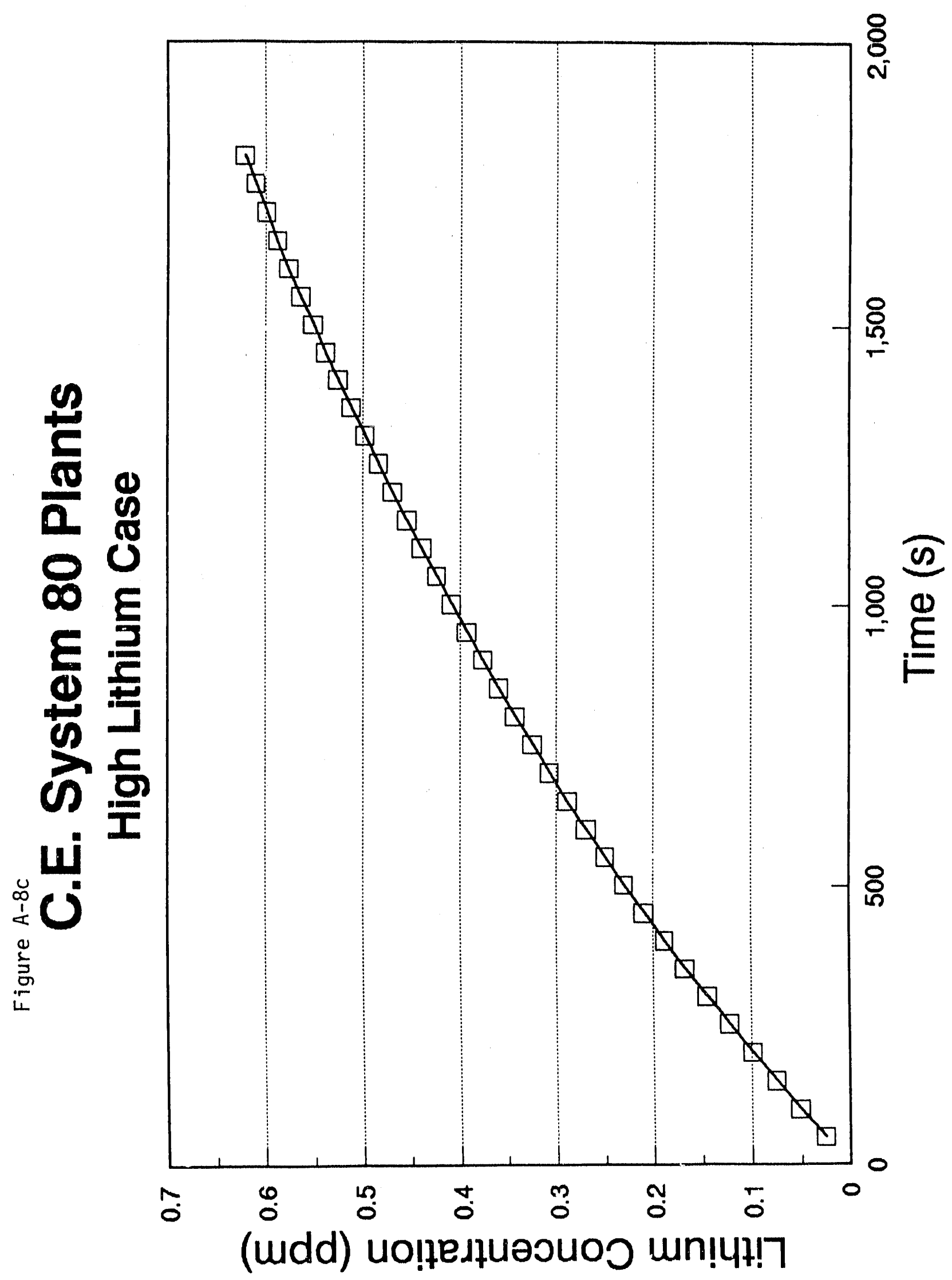




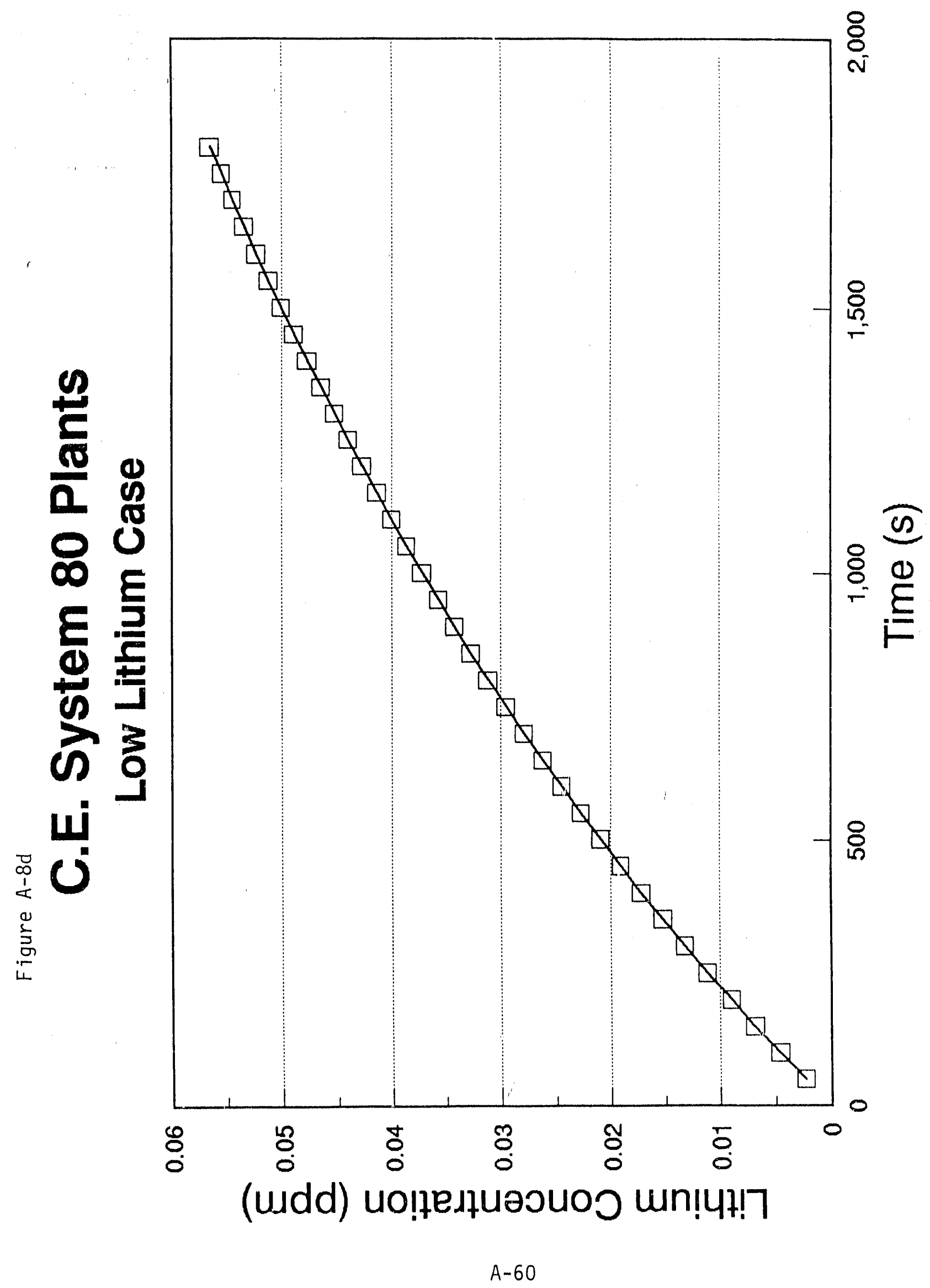




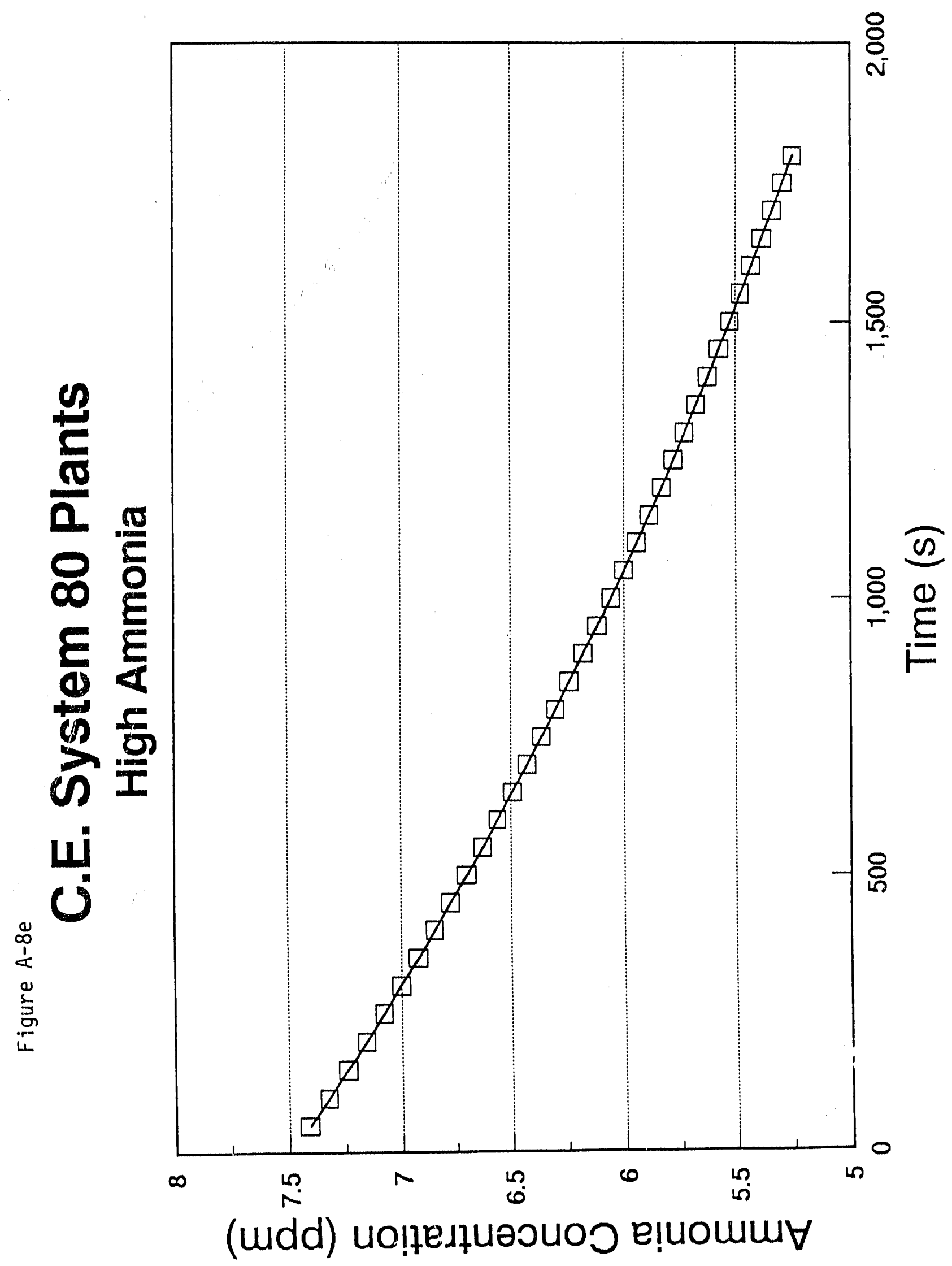

A-61 


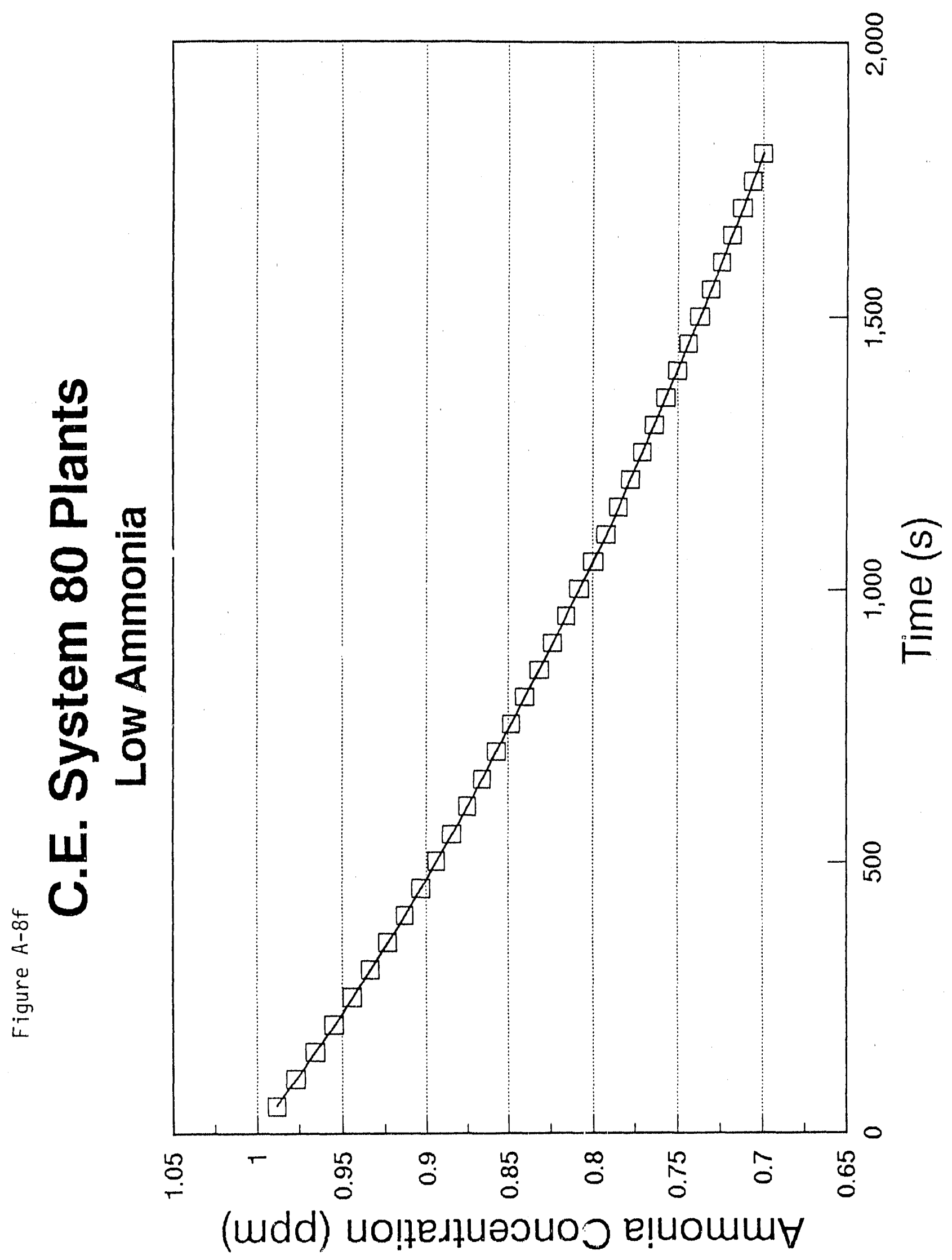

A-62 


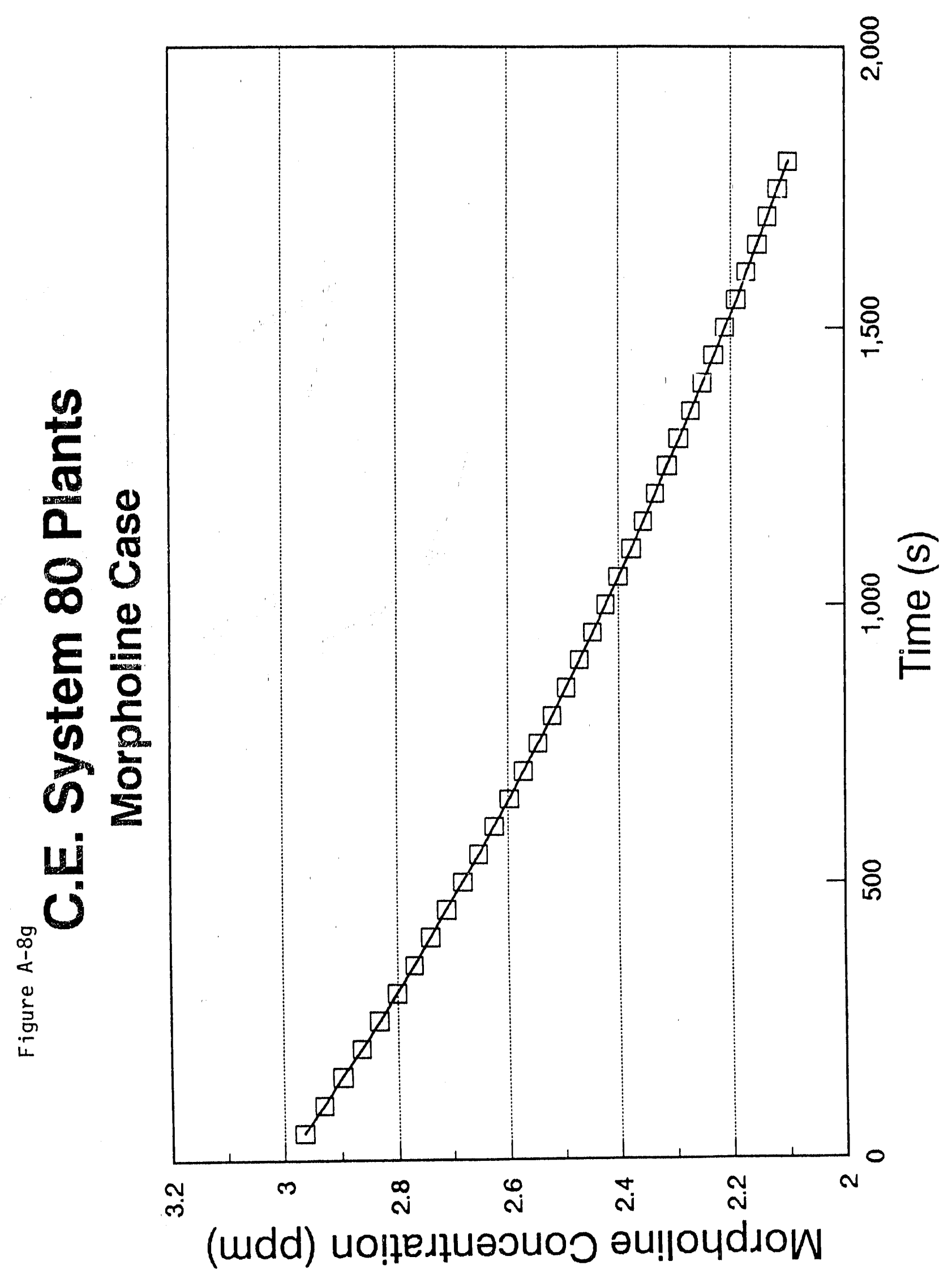




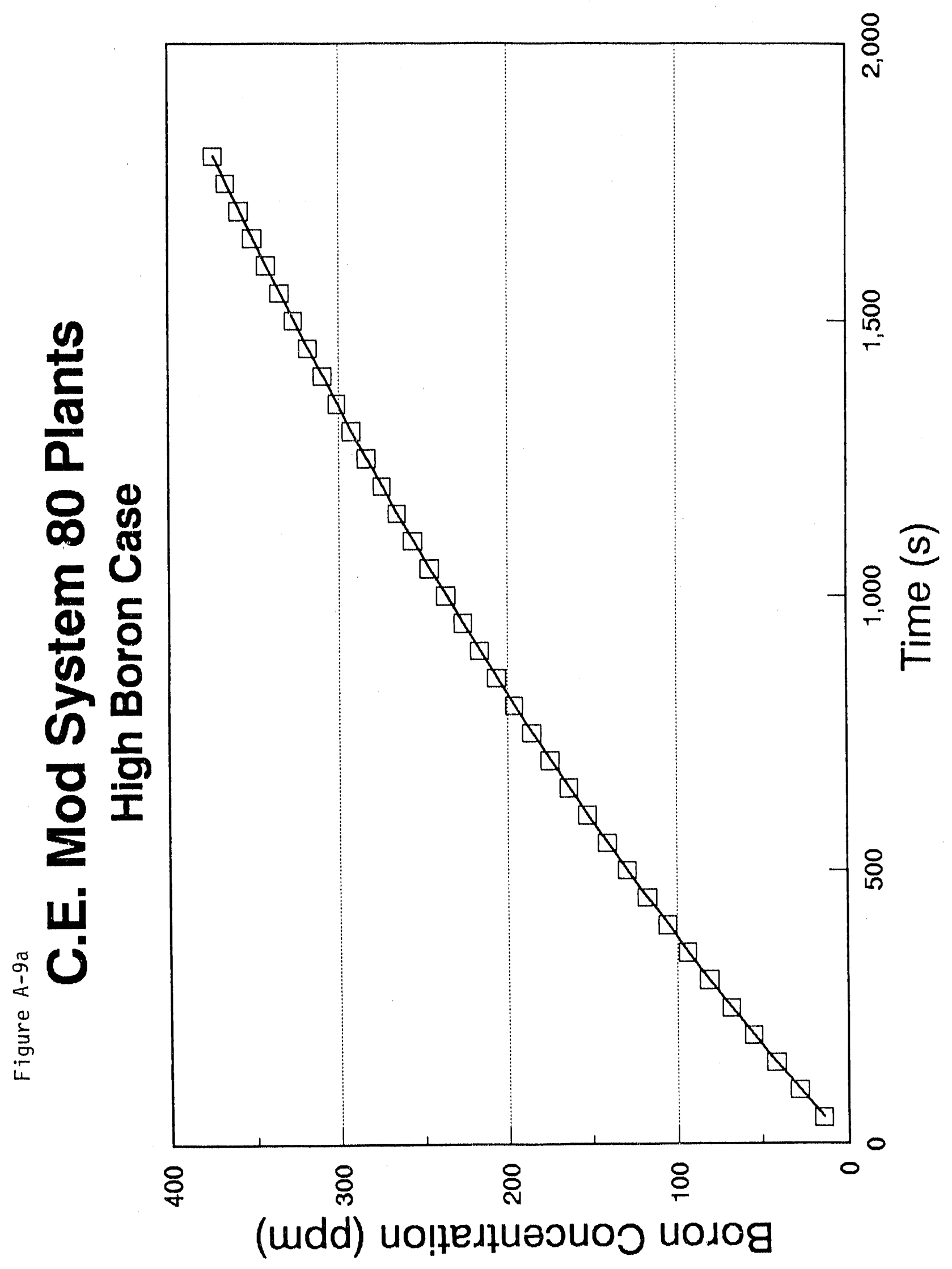




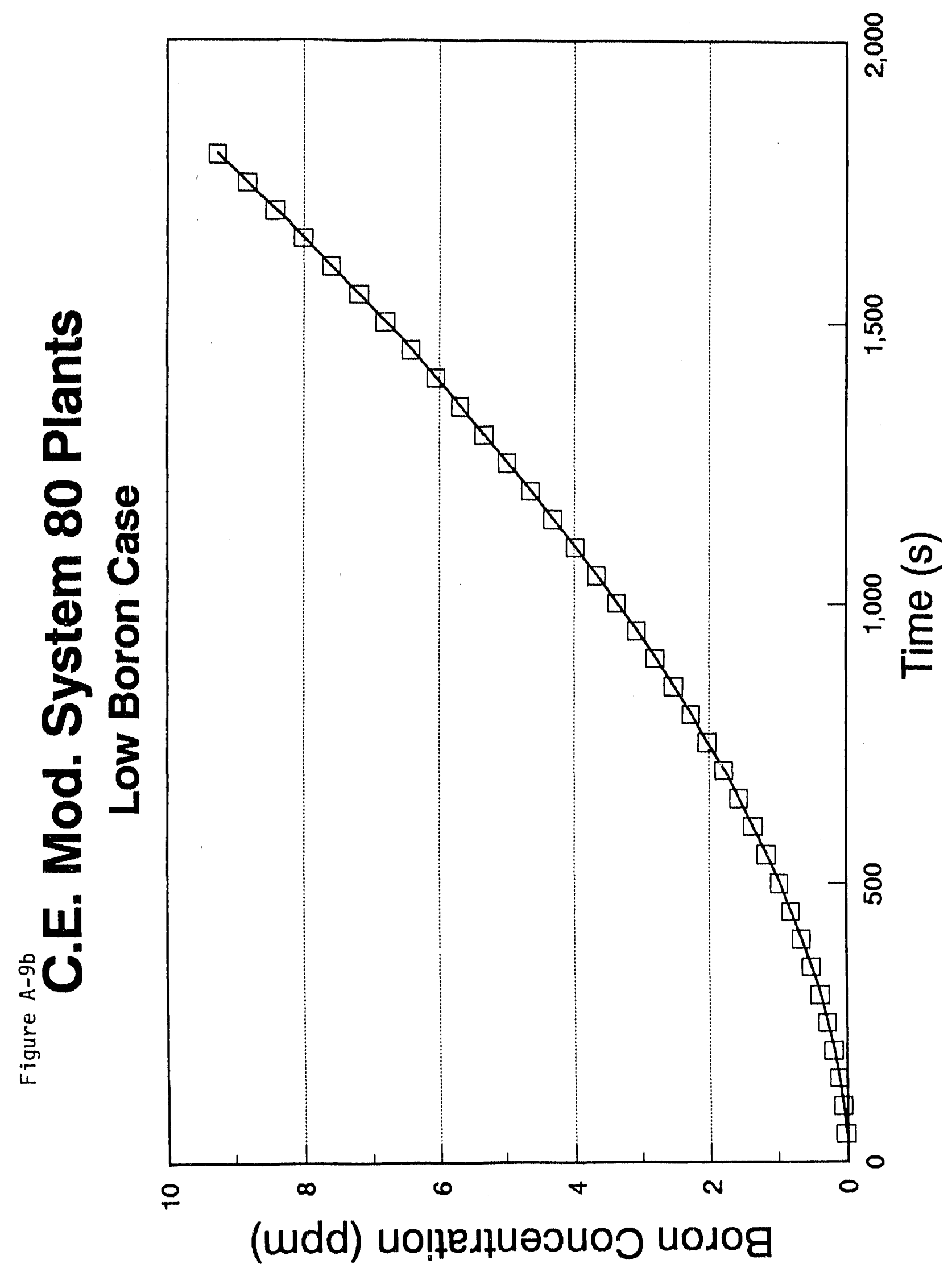




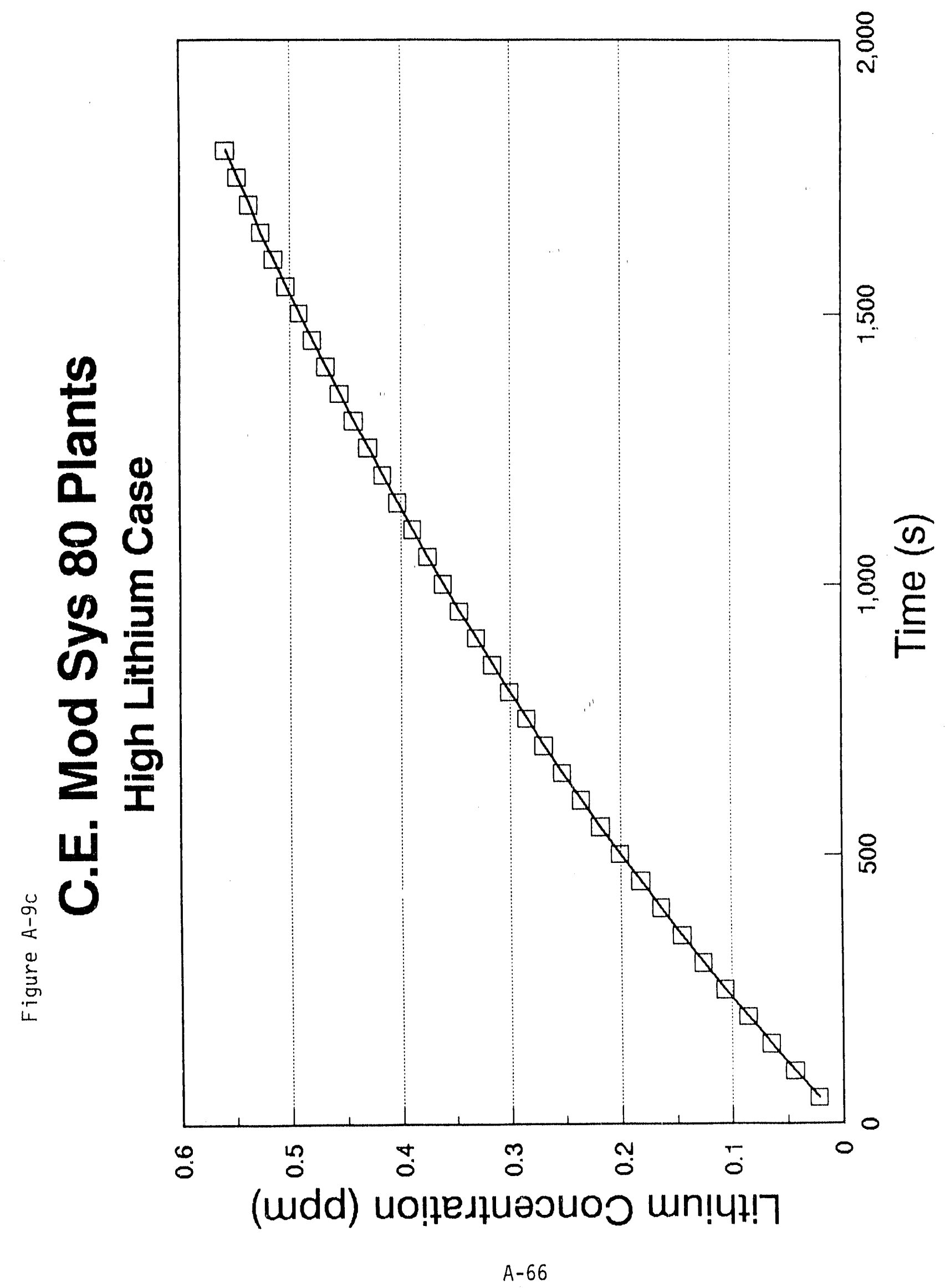




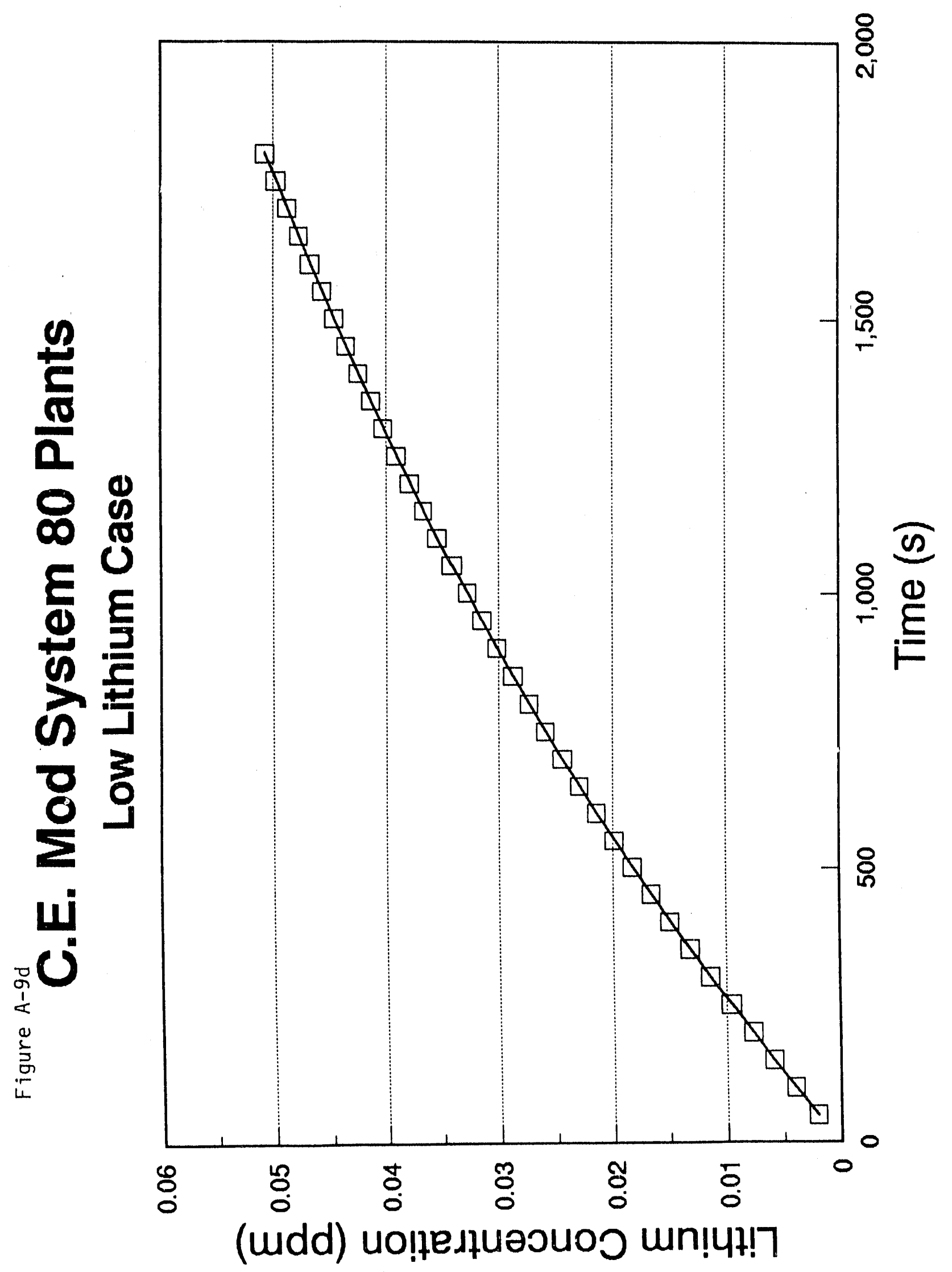




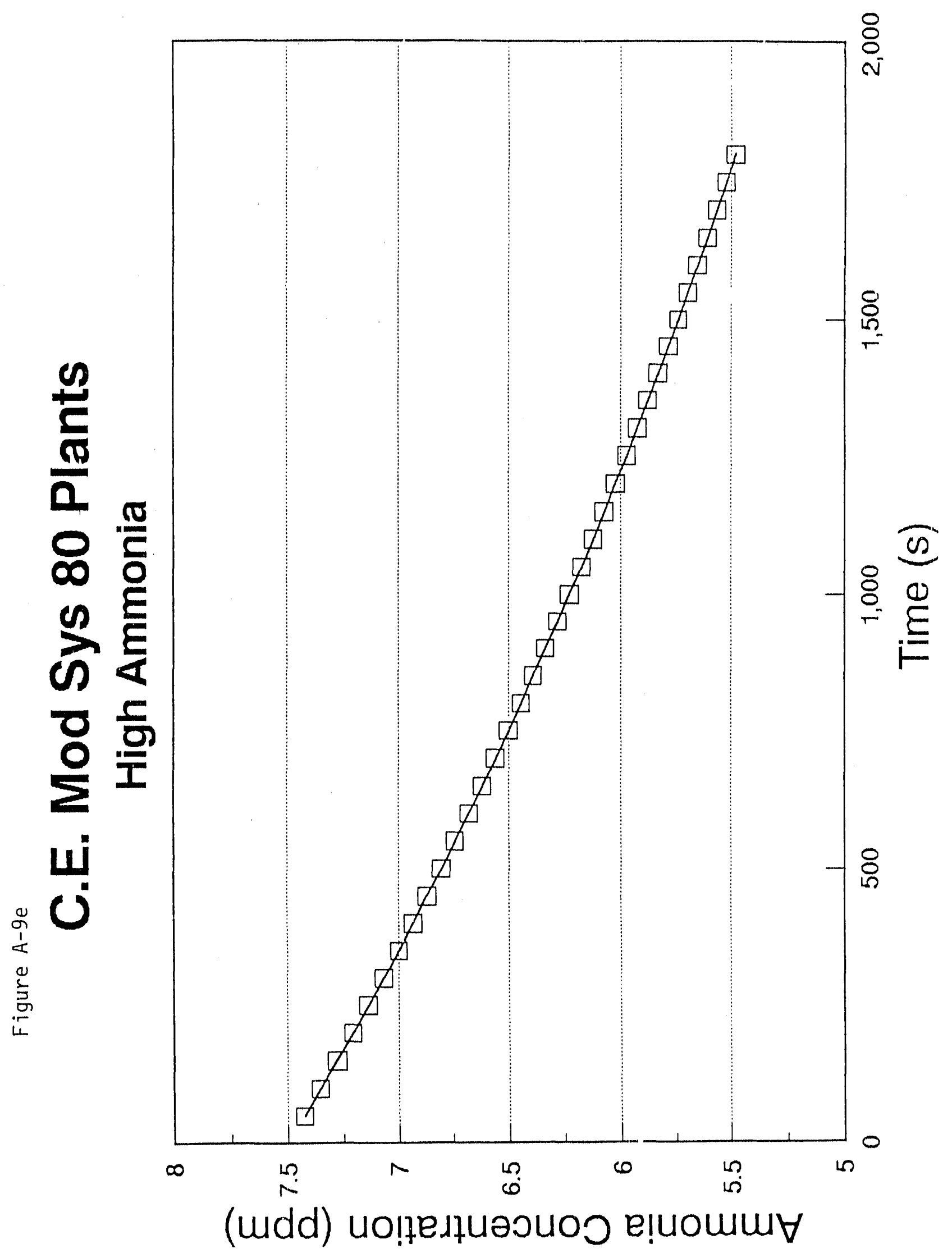




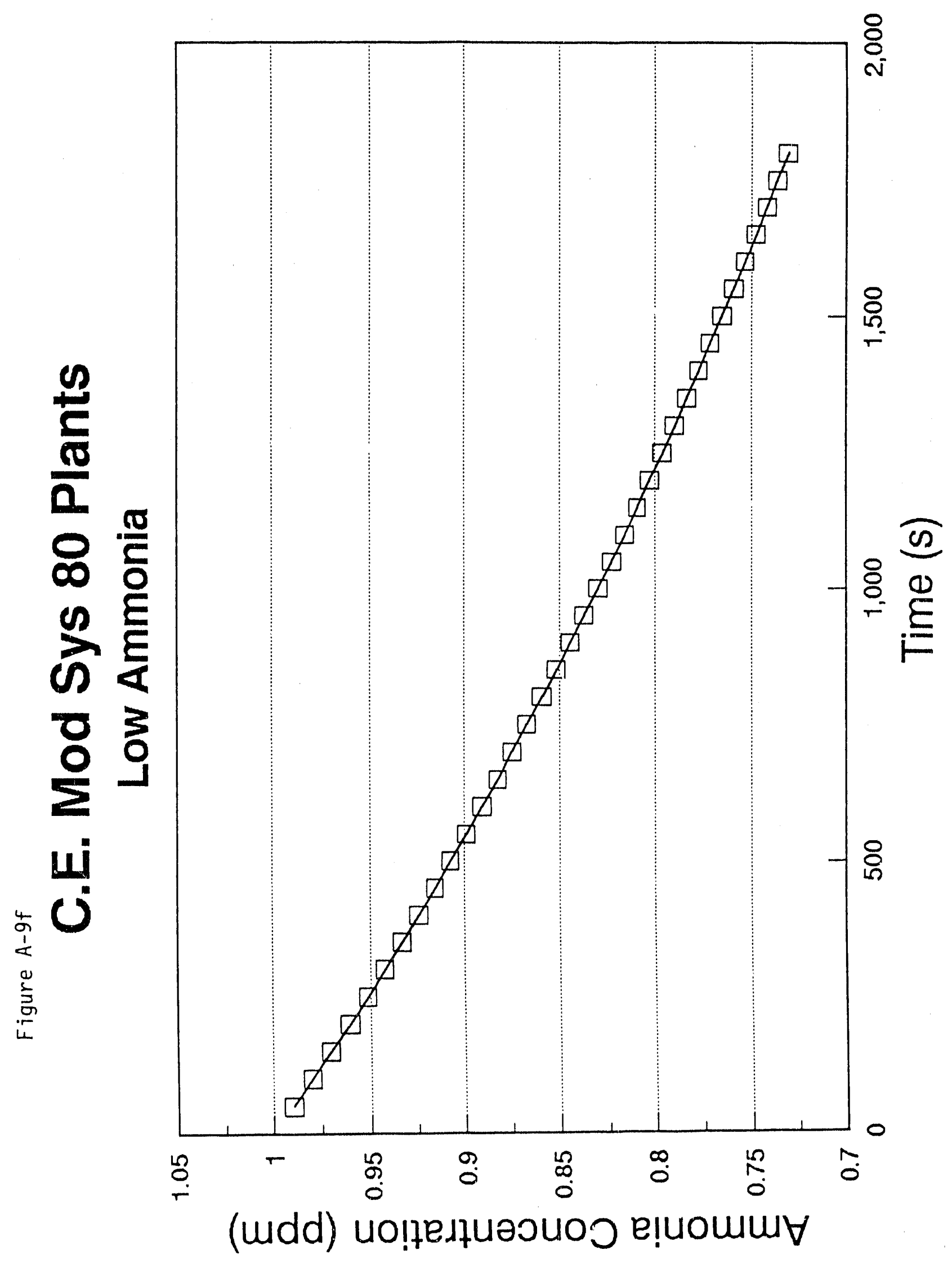




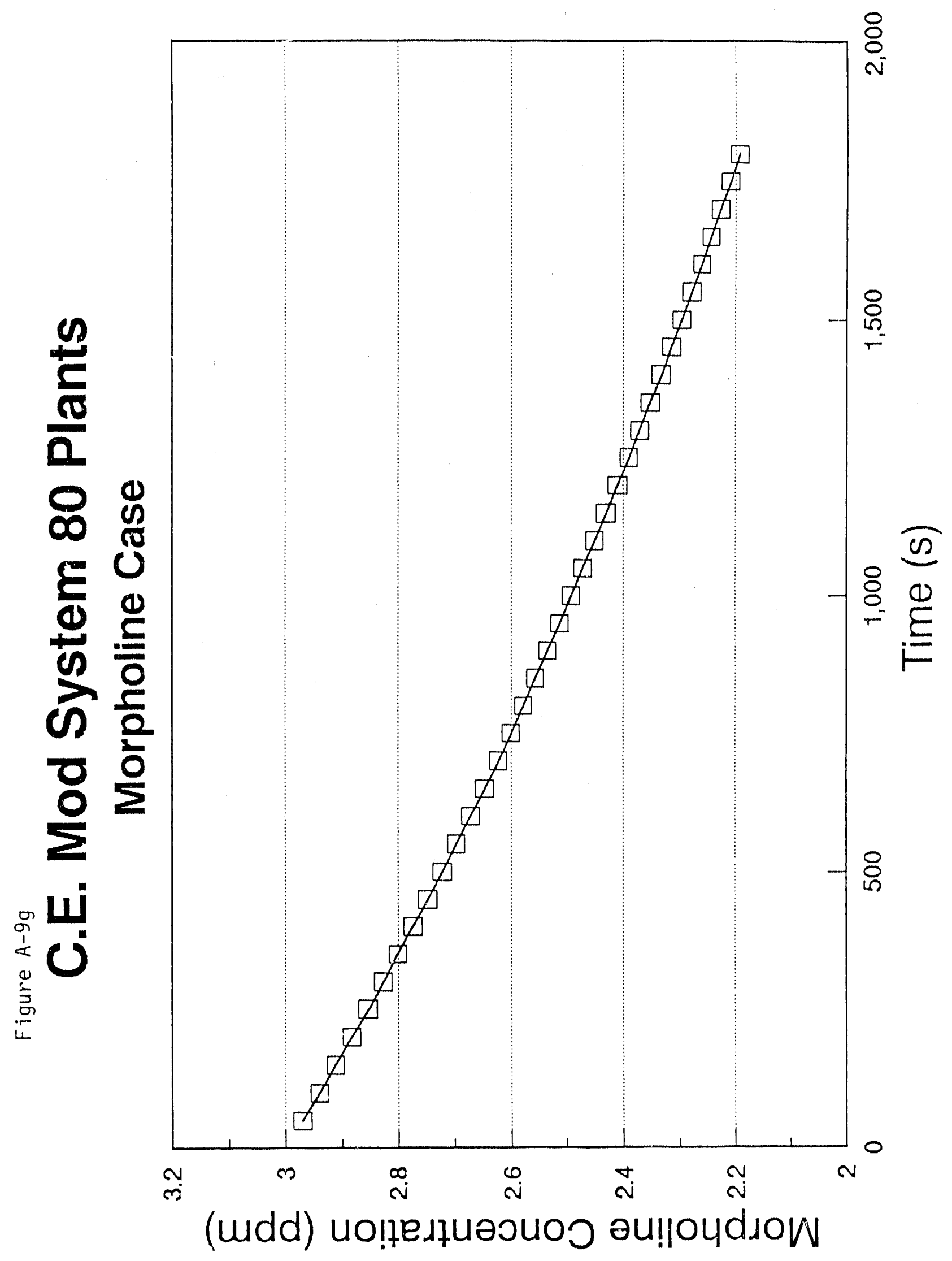

A-70 


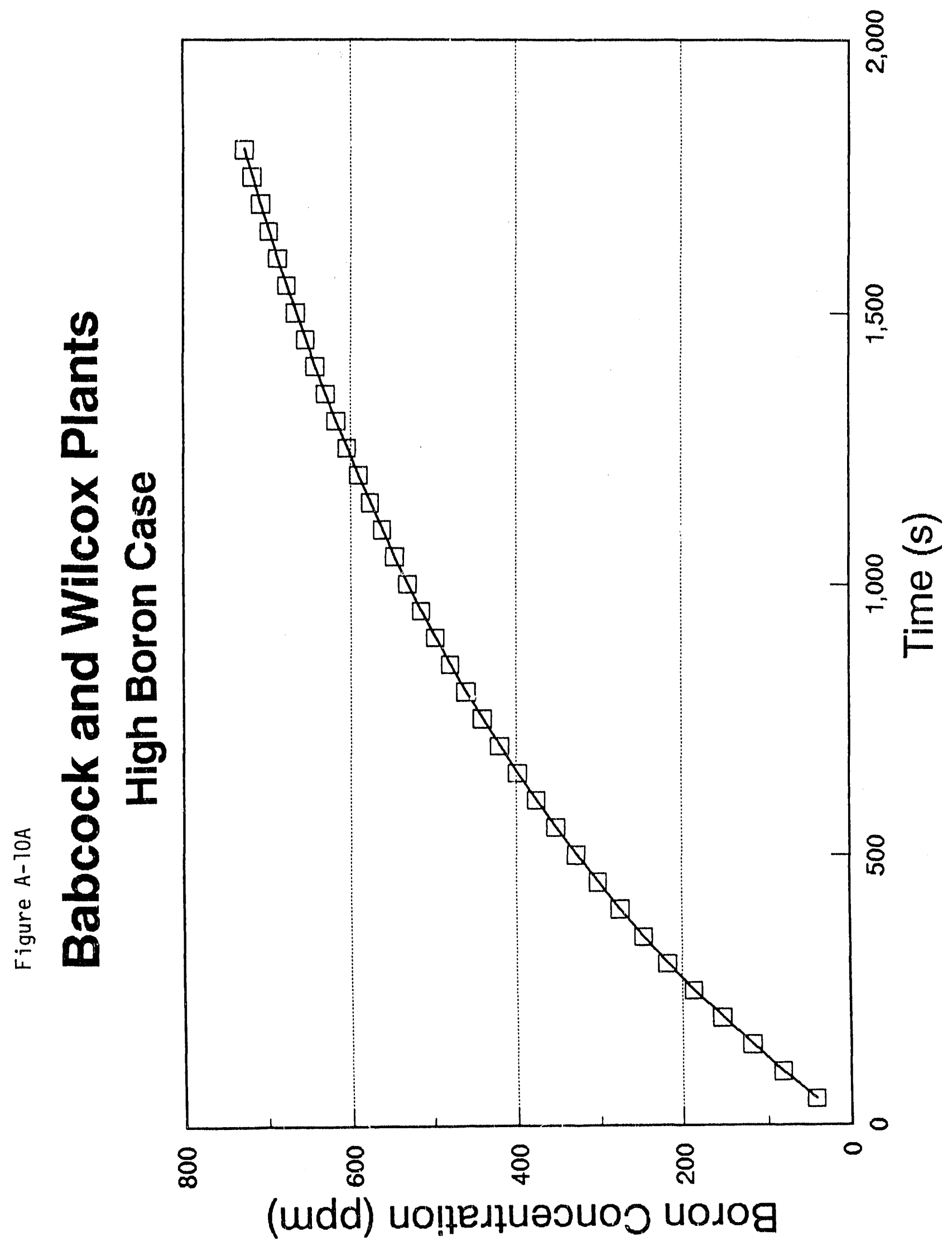




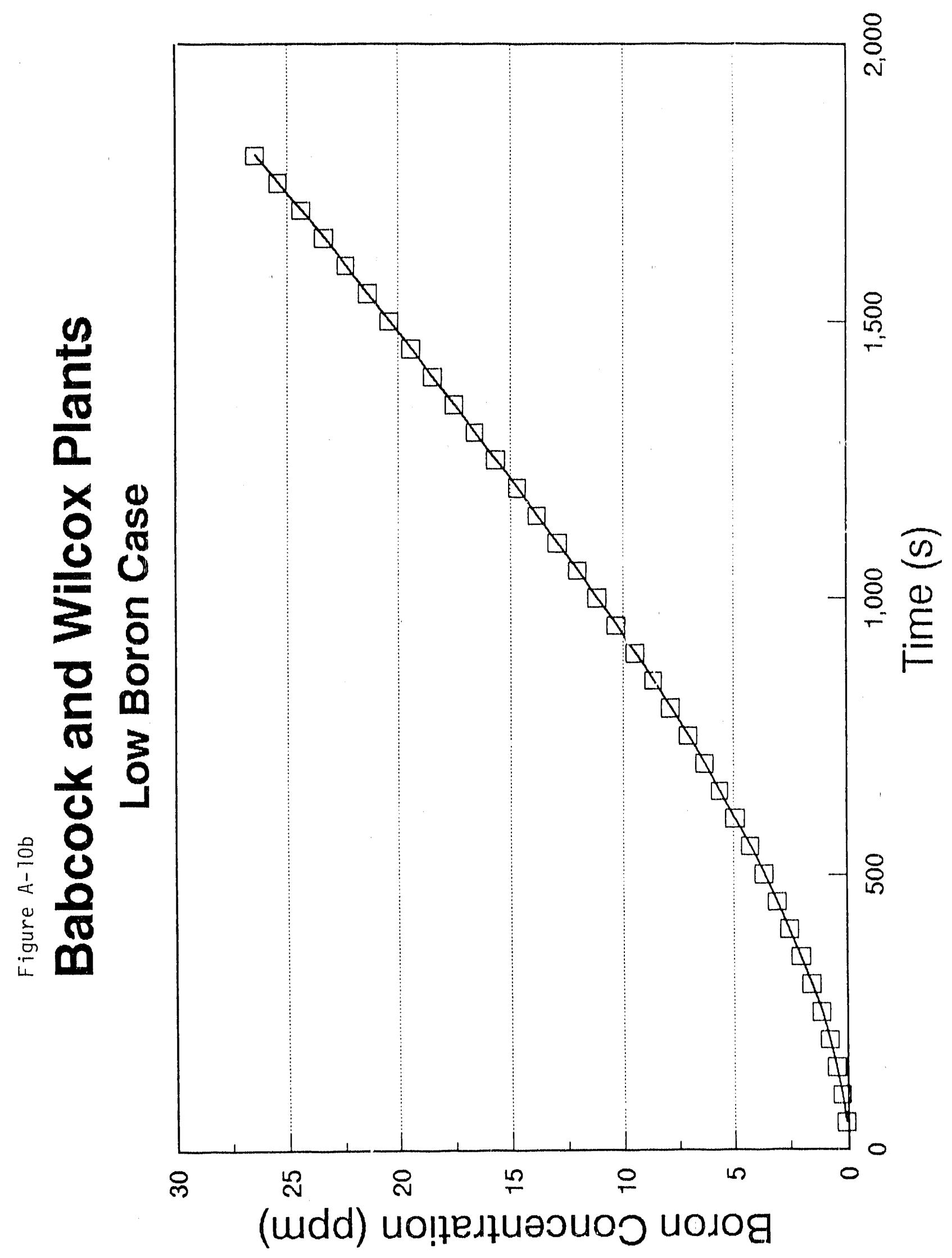

A-72 


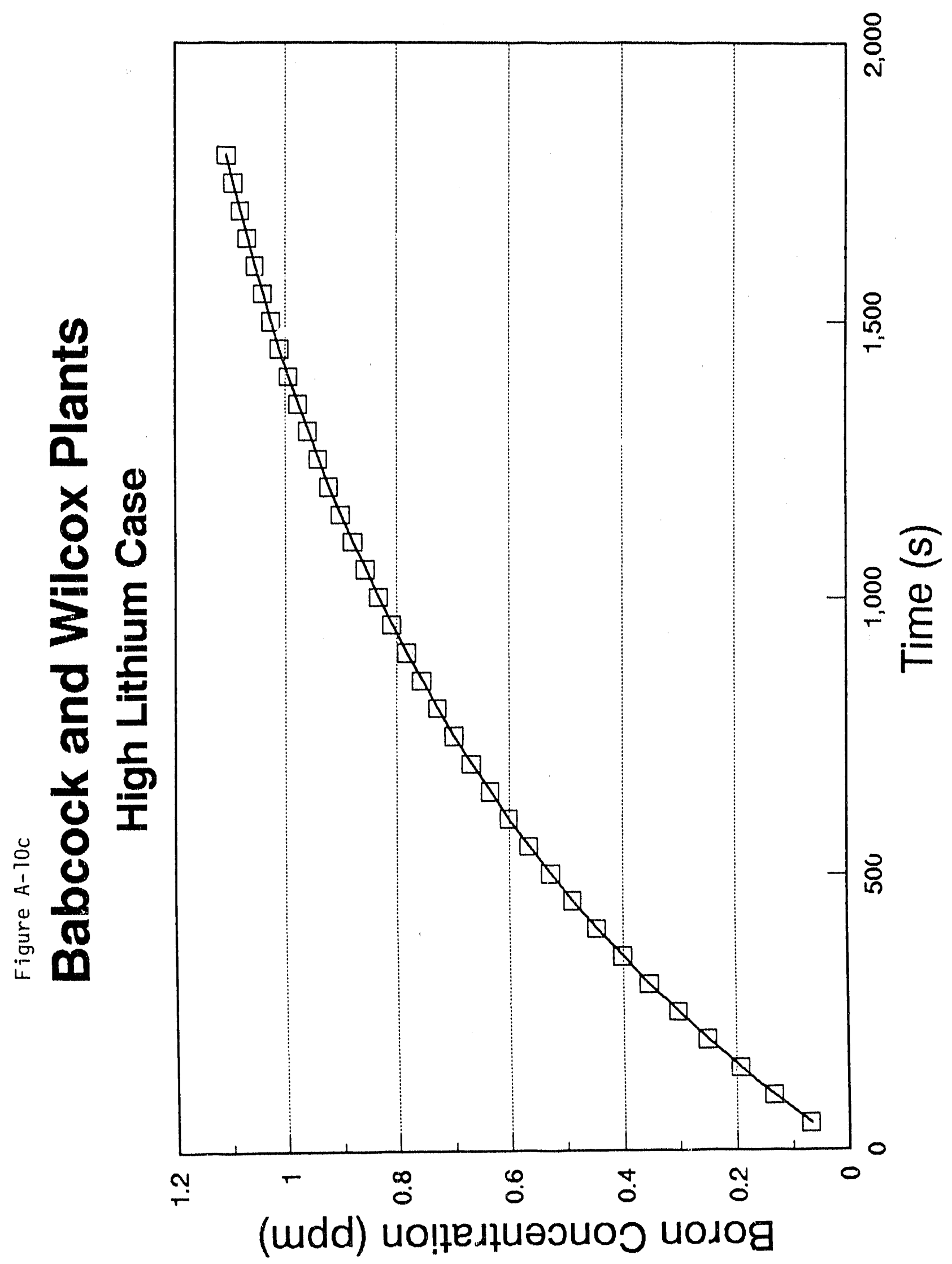

A-73 


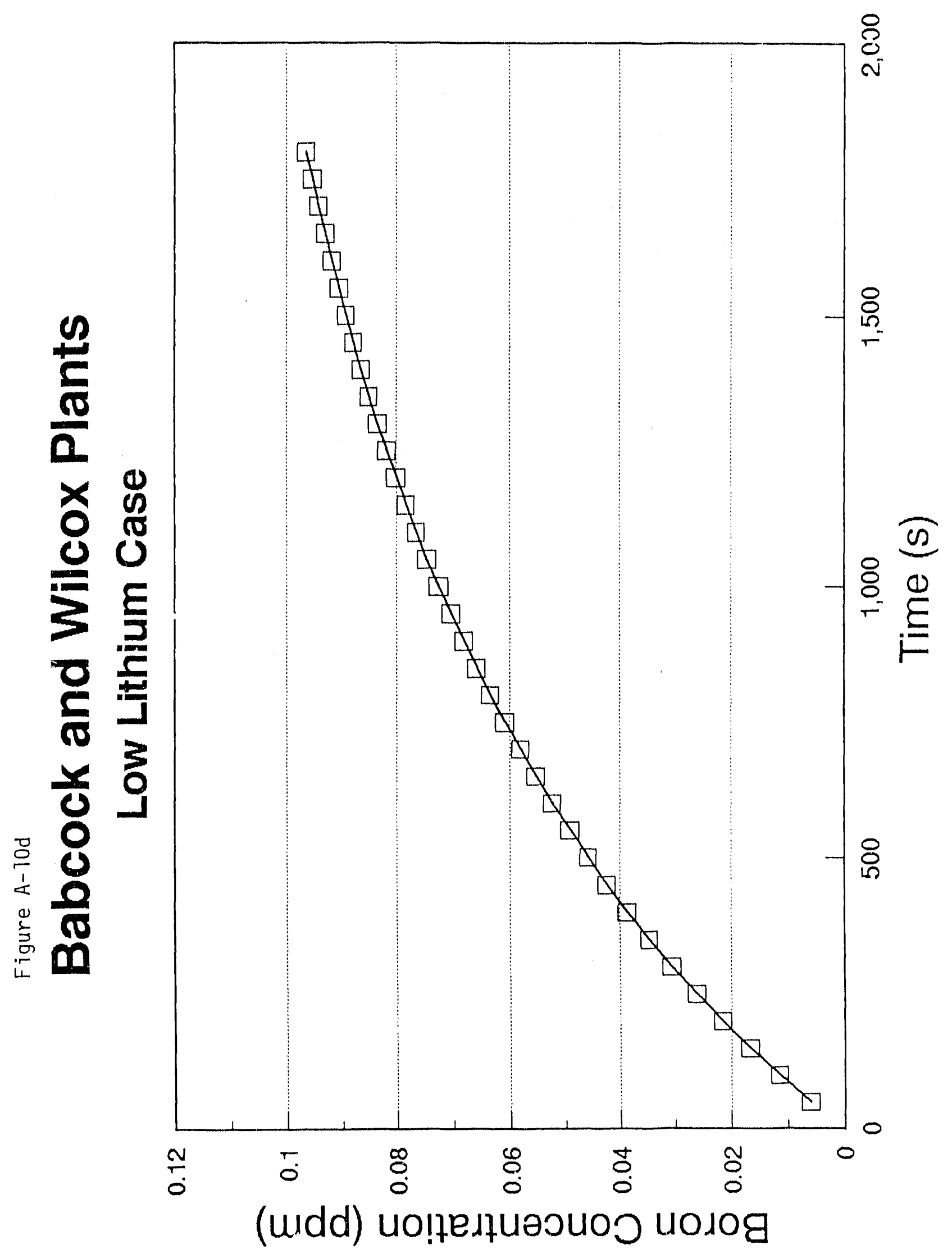




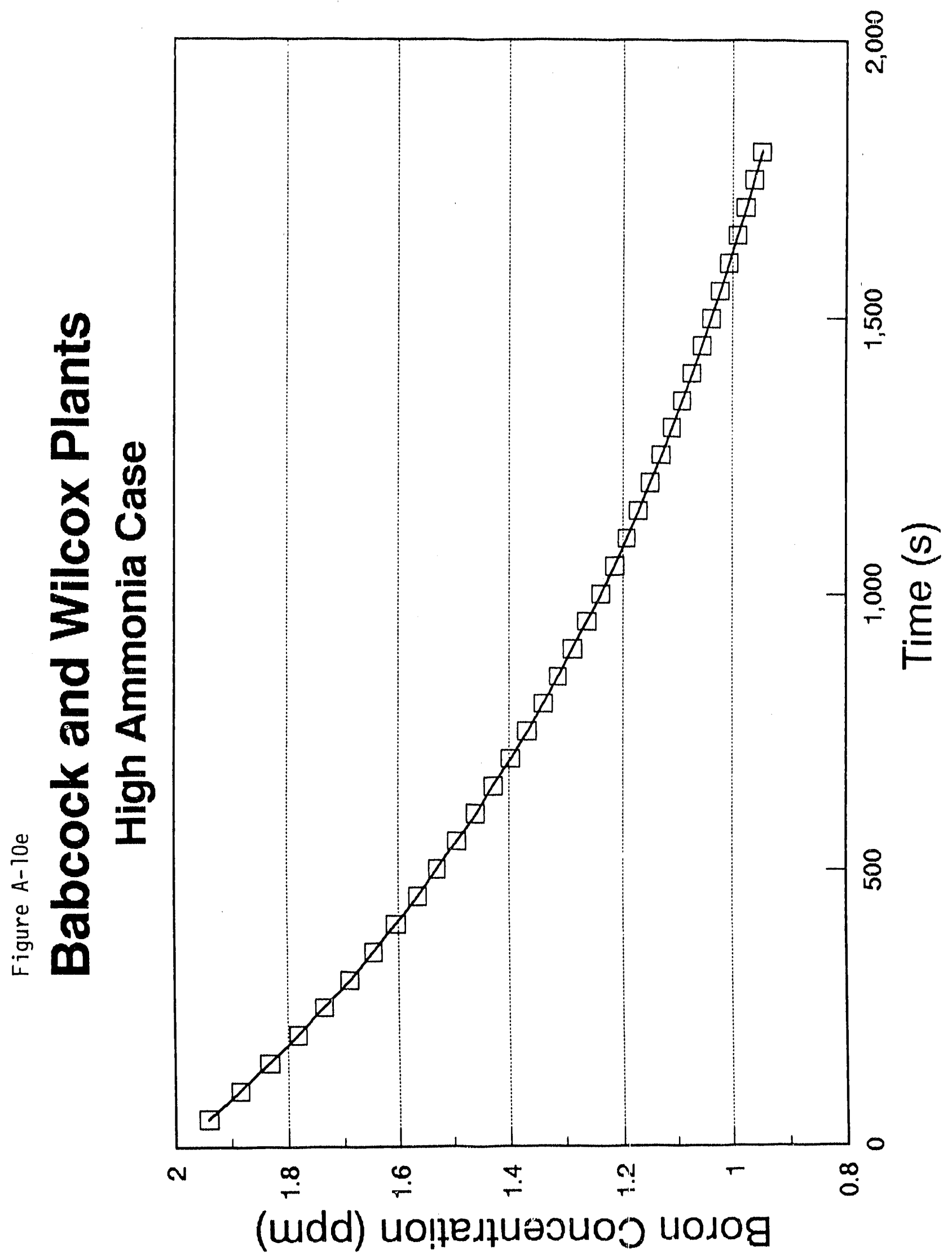

A-75 


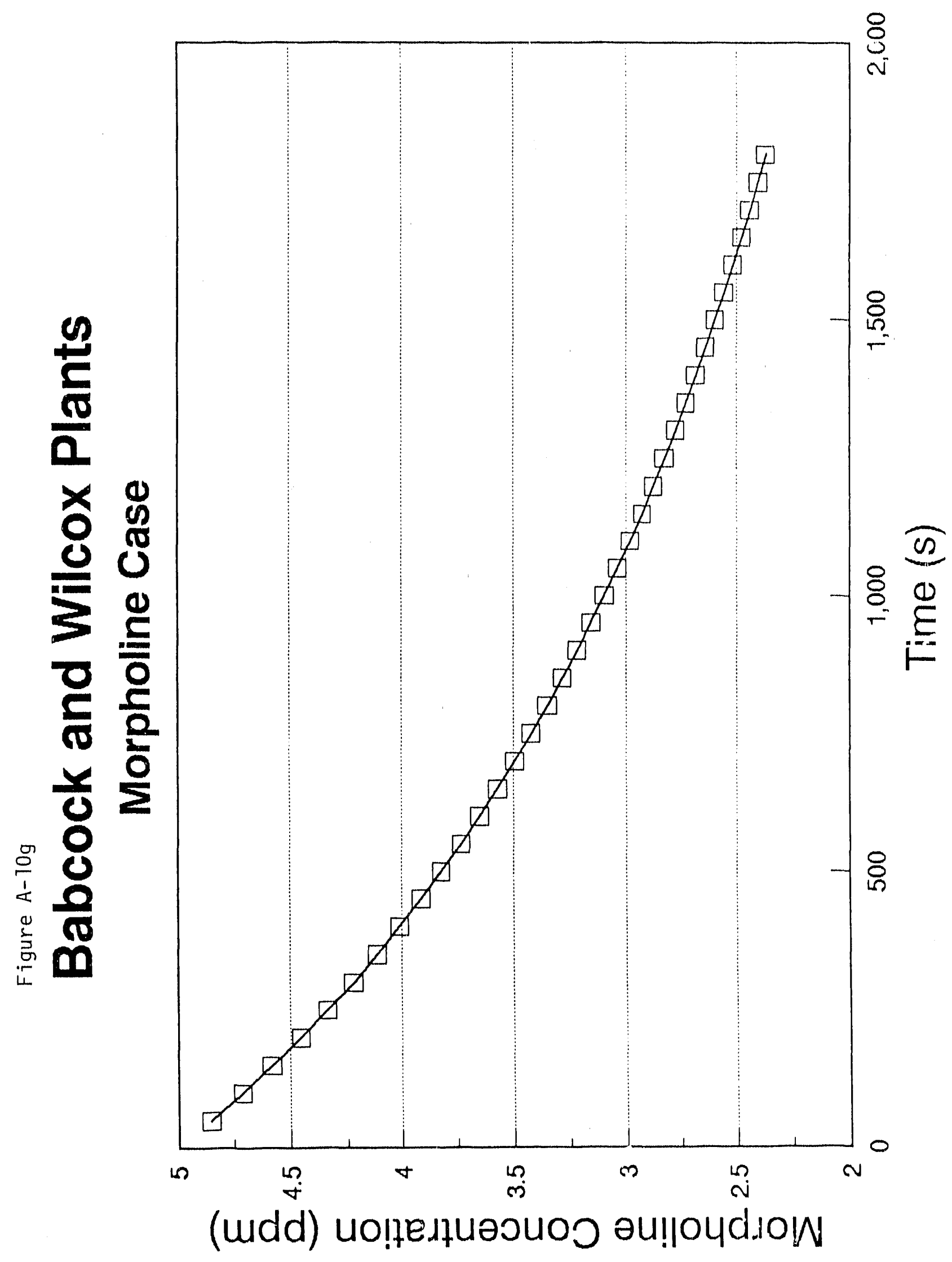

A-76 


\section{APPENDIX B \\ ESTIMATED THERMODYNAMIC PROPERTIES \\ OF MORPHOLINE AND THE \\ AQUEOUS MORPHOLINIUM ION}




\section{APPENDIX B: ESTIMATED THERMODYNAMIC \\ PROPERTIES OF MORPHOLINE AND \\ THE AQUEOUS MORPHOLINIUM ION}

\section{INTRODUCTION}

Morpholine $\left(\mathrm{C}_{4} \mathrm{H}_{9} \mathrm{NO}\right)$ is one of the principal chenicals used for SCS chemistry control. Morpholine is used as a pH control additive. In the SCS applications, morpholine reduces erosion-corrosion in two-phase regions, because it is less volatile than ammonia and provides a higher liquid phase $\mathrm{pH}$ in wet steam regions. One benefit of using morpholine along with ammonia to control SCS pH (noted in U.S. operating plants) is that steam generator sludge accumulations are far lower than would be expected if the $\mathrm{pH}$ were controlled using ammonia alone. Lower sludge accumulations generally lead to less heat exchanger tube corrosion since the chemicals (e.g. chlorine, copper, etc.) tend to concentrate in the sludge and attack the tube walls. Therefore, the use of morpholine has become fairly widespread in U. S. PWRs, bciti in recirculating and once-through steam generators.

When this study was initiated, it was determined that the thermodynamic data for morpholine were not included in the FACT main data base. Therefore, it was necessary to research the applicable data and input them into a user data base in the FACT program. Paul K. Talley and Arthur D. Pelton ${ }^{a}$ were requested to assist in obtaining the data and making them available, in appropriate form, for the calculations. This appendix documents the data researched by Talley and Pelton which have been used in this study. The results of their efforts are the thermodynamic properties for morpholine in the gaseous and liquid states, aqueous morpholine, and the aqueous morpholinium ion. The properties include the enthalpy of formation, absolute

Private communication from Paul K. Talley and Arthur D. Pelton, May 1991. 
entropy of the standard state, and the heat capacity as a function of temperature for each of the states.

\section{Ideal Gas}

The enthalpy of formation and absolute entropy at $298 \mathrm{~K}$ and 1 atmosphere for morpholine as an ideal gas were estimated using the method of Benson et a1. ${ }^{8-1}$ This method permits the establishment of these properties based on the contributions of the various functional groups that make up the compound. Corrections for "ring-strain" and symmetry were based on the structure of the molecule. Reference 1 also contains the heat capacity as a function of temperature for this compound. The following values were thus obtained:

$$
\begin{aligned}
\Delta_{f} H_{g}^{\circ} & =-142.25 \mathrm{~kJ} / \mathrm{mol} \\
S_{g}^{\circ} & =237.8 \mathrm{~J} / \mathrm{mol} \mathrm{K} \\
C_{p, g} & =a+b T+c t^{2}+d T^{3} \quad(\mathrm{~J} / \text { mol.K) }
\end{aligned}
$$

where:

$\Delta_{f} H_{f}^{O}=$ enthalpy of formation

$$
\begin{aligned}
S_{g}^{\circ} & =\text { entropy of formation } \\
C_{p, g} & =\text { heat capacity } \\
a & =-42.8 \\
b & =0.5388 \\
c & =-2.666 \times 10^{-4} \\
d & =4.199 \times 10^{-8}
\end{aligned}
$$




\section{Liquild}

Parameters for the Antoine equation for predicting vapor pressures are also available from Reference 1. A value for the enthalpy of vaporization at the normal bolling point $(401.4 \mathrm{~K})$ was obtained by applying the clausius $\mathrm{Clapeyron}$ equation to these data $\left(\Delta \mathrm{H}_{\text {vap }}=37656 \mathrm{~J} / \mathrm{mol}\right)$. The value was deduced from the enthalpy of the ideal gas at the bolling temperature to obtain the enthalpy of the 1iquid. The liquid heat capacity was estimated using the method of $\mathrm{Shaw}^{\mathrm{B}-2}$ and then used to calculate the standard state enthalpy of formation of the liquid. A similar procedure was used to obtain the standard state absolute'entropy. The data for the liquid phase are:

$$
\begin{aligned}
\Delta H^{O_{1, U}} & =-187.94 \mathrm{~kJ} / \mathrm{mol} \\
S_{1}^{\circ} & =121.44 \mathrm{~J} / \mathrm{mol} \mathrm{K} \\
C_{p, 1} & =192.5 \mathrm{~J} / \mathrm{mol} \mathrm{K}
\end{aligned}
$$

\section{Aqueous Morpholine}

Several references report vapor-1 iquid equilibrium for morpholine and water. A few of these references have been analyzed in the Chemistry Data Series. ${ }^{B-3}$. The heat capacity of aqueous morpholine was assumed to be identical to that of the pure liquid. The activity coeffictent for morpholine in water at infinite dilution $\left(\gamma^{\infty}=1.33\right.$ at $T=373 \mathrm{~K}$ [boiling point of water]), taken from the Chemistry Data Series, is sufficiently small as to be considered as predominately an erithalpy effect. The enthalpy of formation of the liquid was augmented accordingly to obtain that of the aqueous spectes. Since RTIn $\boldsymbol{w}^{\infty}$ is considered to be constant with respect to temperature, the absolute entropy is identical for both liquid and aqueous phases. The thermodynamic parameters shown below have been converted to a 1-molal basis: 


$$
\begin{aligned}
\Delta H_{\text {, aq }}^{\circ} & =187.05 \mathrm{~kJ} / \mathrm{mol} \\
S_{\text {aq }}^{\circ} & =154.8 \mathrm{~J} / \mathrm{mol} \mathrm{K} \\
C_{p_{\text {aq }}} & =192.5 \mathrm{~J} / \mathrm{mol} \mathrm{K}
\end{aligned}
$$

\section{Aqueous Morpholinium}

Data for the free energy, entropy, and heat capacity of formation of the aqueous morpholinium ion $\left(\mathrm{C}_{4} \mathrm{H}_{10} \mathrm{NO}^{+}\right)$from aqueous morpholthe and the hydrogen ion at $298.15 \mathrm{~K}$ were reported by Cobble et a1. ${ }^{\mathrm{B}-4}$ These data were then used to extract the enthalpy of formation. These values were simply added to those of aqueous morpholine to obtain those of the ion. (i.e. to obtain the enthalpy of formation, absolute entropy, and heat capacity at the standard state of the morpholinium ion in an aqueous environment). The values reported below are also given on the basis of a 1 molal aqueous solution:

$$
\begin{aligned}
\Delta H_{\text {f,aq }}^{\circ} & =226.07 \mathrm{~kJ} / \mathrm{mol} \\
S_{\text {aq }}^{\circ} & =186.5 \mathrm{~J} / \mathrm{mol} \mathrm{K} \\
C_{p, a q} & =144.4 \mathrm{~J} / \mathrm{mol} \mathrm{K}
\end{aligned}
$$

\section{Accuracy}

The accuracy of the absolute values of enthalpy and entropy for gaseous morpholine depend upon the accuracy of those estimated for the ideal gas. These estimates are probably good to about $5 \%$ for the ideal gas. Morpholine has a significant dipole moment ( 1.5 debye) and exhibits positive deviations from ideality. Given this, it is reasonable to assume the accuracy of the enthalpy and entropy are within $7-10 \%$. 
The accuracy of the thermodynamic properties of the saturated liquid relative to the ideal gas are about $5 \%$ for temperatures up to $100 \mathrm{~K}$ above and below the boiling point. Calculated saturation temperatures should be within a degree of their true values. However, these data may not be reliable in the vicinity of the critical point $(618 \mathrm{~K})$.

The thermodynamic data for aqueous morpholine relative to the idea gas are also good to within $5 \%$ over a similar temperature range. Although reasonable results for bubble temperatures $( \pm 1 \mathrm{~K}$ ) at 1.01355 bar are obtained for morpholine concentrations up to 20 mole \%, reliable results can be anticipated only at very small concentrations. Since the morpholine concentrations typically found in PWR steam generators and used in this report are of the order of $5 \mathrm{ppm}$, the results are considered to be reliable.

The data for aqueous morpholinium relative to aqueous morpholine are considered to be excellent in view of the reliability of their source. Overa11, the use of these data to predict pH in steam generators was checked by comparing test calculations using the data and the FACT computer program to values of $\mathrm{pH}$ documented in the EPRI guidelines ${ }^{8-5}$. Based on these comparisons, the morpholine data are considered to be reliable and adequate for this study. 


\section{References}

B-1 R. C. Reid, J. M. Prausnitz, and B. R. Poling, The Properties of Gases and Liquids, 4th ed., McGraw-Hill, 1987.

B-2 R. Shaw, "Heat Capacity of Liquids: Estimation of Heat Capacity at Constant Pressure and $25 \mathrm{C}$ Using Additivity Rules, "Journal of Chemical and Engineering Data, Vol 14, pp 461, 1969.

B-3 J. Gmehling and U. Onken, Vapor - Liquid Equilibrium Data Collection : Aqueous - Organic Systems, Chemistry Data Series Vol. 1, Part 1 ,
Dechema, 1977.

B-4 J. W. Cobble, R. C. Murray, P. J. Turner, and K. Chen, High Temperature Thermodynamic Data for Species in Aqueous Solution, EPRI NP.

B-5 PWR Secondary Water Chemistry Guidelines, Rev. 2, EPRI NP-6239, 1988. 
APPENDIX C

WESTINGHOUSE SGTR PROCEDURE

C-1 


\section{APPENDIX C: WESTINGHOUSE S/GTR PROCEDURE}

Several simplifying assumptions were made during the determination of the SCS chemical concentrations. This appendix includes a discussion of the expected thermal and hydraulic response of a typical PWR to an SGTR and an estimation of the effects of the simplifying assumptions on the results of this analysis. This discussion is based on the generic SGTR recovery procedure recommended for Westinghouse-design PWRs. ${ }^{\mathrm{C}-1}$

A typical design-basis SGTR is estimated to last approximately 30 minutes from the time the tube ruptures until the RCS pressure has been equilibrated with that of the SCS in the affected steam generator. By that time, break flow (from RCS to SCS) has ceased and the plant can safely be cooled down to cold conditions so that the steam generator can be repaired. During the 30 minute transient, several operator-controlled recovery actions are performed. The specific recovery actions depend on the size of the break flow, safety injection capacity, any additional failures which might occur, and the ease with which the affected steam generator is identified. Therefore, the exact transient will differ from plant to plant and the description in this appendix is only representative of a guillotine-shear of one steam generator tube in a recirculating steam generator with the $p 1$ ant at full power, reflecting neither the exact times nor the specific phenomena associated with any given SGTR.

Simultaneous with the tube rupture, RCS pressure starts to decrease toward the low RCS pressure reactor trip setpoint. The delay between tube rupture and reactor trip will depend on the magnitude of break flow (flow from the RCS to the SCS through the ruptured tube) relative to the charging pump capacity. In some cases, reactor trip occurs on overtemperature $\Delta T$ (reduced pressure automatically reduces the core $\Delta T$ setpoint) and in others, the operator may manually trip the reactor upon receipt of an alarm. Usually in the case of a complete shear of a tube there would be insufficient time for the operator to react before automatic shutdown occurs. 
The coolant level in the pressurizer will decrease due to the initial mismatch between break flow and charging pump capacity. The level will further decrease due to reactor trip which causes a heat balance mismatch as all steam generators continue to draw heat from the RCS until all main steam valves have shut. The concomitant pressure decrease will cause initiation of safety injection (either automatically or, if the depressurization is slow enough, manually via operator action), which will slow the net mass loss from the RCS, though not the break flow itself. Normal feedwater to all steam generators is terminated and auxiliary feedwater flow is initiated. Operator action is required to adjust auxiliary feedwater flow to the various steam generators to maintain coolant level within the narrow range span. Since the level in the affected steam generator (steam generator with the ruptured tube) will tend to increase much more rapidly than that in the unaffected steam generator(s), the operators should, by this time, be able to identify the transient as an SGTR and isolate the affected steam generator, minimizing additional radioactive iodine release to either the confinement or the environment.

SCS pressure will increase rapidly as the automatic isolation of the turbine (following reactor trip) stops steam flow from the steam generators and traps steam in the steam lines. Normally, automatic steam dump to the condenser will regulate steam pressure in the SCS. However, in some cases, the steam dump will be insufficient and the secondary relief valves will lift, releasing steam to the environment. In the case of loss of offsite power, automatic steam dump to the condensers will not occur and pressure control in the SCS is maintained by the SCS relief valves. The capacity of the secondary relief valves is sufficient to maintain SCS pressure control. If these valves stick open, pressure will not only be maintained, it will decrease and an uncontrolled RCS cooldown could result. Assuming steam dump flow is available, the operators are expected to isolate the affected steam generator and cool down the other steam generators and the RCS to maintain no-load RCS temperature using steam dump flow in the unaffected steam generators. Cooldown is continued until the RCS temperature is approximately $28 \mathrm{~K}$ below that of the affected steam generator. This will ensure that when the RCS is 
depressurized to eliminate the break flow, the RCS will be adequately subcooled and voiding within the RCS will not occur.

After RCS cooldown to $28 \mathrm{~K}$ below the affected steam generator, the RCS is depressurized to eliminate break flow. The preferred method of depressurization is via pressurizer spray, which requires continued reactor coolant pump (RCP) operation. This is the preferred method since it does not involve additional RCS mass loss. However, if the RCPS are not operating or if the pressurizer spray, for some other reason, is not effective, RCS depressurization may be effected via cycling of the pressurizer power operated relief valve (PORV). This is continued until the RCS pressure has equilibrated with that of the affected steam generator SCS pressure at which time the transient has effectively been terminated. The procedure continues with other operator actions until the plant has been brought to a cold shutdown condition. Table $C-1$ contains a summary of the automatic $(A)$ and operator-controlled ( 0 ) actions associated with this procedure. In this table, loss-of-offsite power is assumed to occur shortly after or coincident with the automatic turbine trip, necessitating the use of pressurizer PORVs to depressurize the RCS.

The assumptions used in the analysis documented in the main report are:

1. Makeup flow equals break flow.

2. Mixing in the RCS and SCS is instantaneous and complete.

3. The affected steam generator is isolated at transient initiation.

4. The mass flow of any given chemical from the RCS to the SCS is independent of that for any other chemical.

5. The effect of boron in the SCS at transient initiation is ignored.

6 . The boron concentration in the makeup system is constant.

The effects of these assumptions on the results from this analysis are discussed here. The assumption of equality of break and makeup flows should have very little, if any, effect on the results. Obviously, at the beginning of the transient, break flow will probably exceed makeup flow and the overall RCS mass inventory will decrease. However, as long as the pressurizer remains 
partially till, there will be no voiding in the rest of the RCS and the assumption will be valid. For those cases where the pressurizer does momentarily completely drain, there will be some minor volding in the RCS. However, since the initial RCS and makeup system boron concentrations are nearly equal, this should have only a very minor effect on the break flow boron concentration. There will be a somewhat larger effect on the lithium concentration since the makeup system lithium concentration is zero. Nonetheless, the efiects of voiding are sti11 judged to be minor due to the short time in which the pressurizer is expected to be drained.

The second assumption is that both the RCS and the SCS are instantaneously and completely mixed during the transient. This assumption was required to avoid a detailed transient mixing analysis to determine the actual mixing. The effects of this assumption can be divided into those effects on the RCS and those, on the SCS. In the RCS, as the transient continues and the makeup flow mixes with the RCS, the concentrations of the various RCS chemicals ( $\mathrm{LHOH}$ and $\mathrm{H}_{3} \mathrm{BO}_{3}$ ) decrease. The effect is most evident with the $\mathrm{LiOH}$ since the makeup system concentration of $\mathrm{LHOH}$ is zero. The effect is less important for $\mathrm{H}_{3} \mathrm{BO}_{3}$ since the assumed concentrations of this specie in the RCS and makeup system are nearly equal (1400 ppm in the RCS and $1200 \mathrm{ppm}$ in the makeup system). As long as the RCPs are operating, this is judged to be an accurate assumption. Even if the RCPs are shut off, the break flow itself provides significant mixing potential, though the degree of, and the time for mixing will result in some stratification of the two fluids. Incomplete mixing will result in a higher concentration of both species in the break flow (therefore, higher concentration in the SCS) than assumed in this analysis. Since the effect is greater for $\mathrm{LiOH}$ than for $\mathrm{H}_{3} \mathrm{BO}_{3}$, the actual SCS coolant will be more alkaline than assumed. Iodine vapor concentration is enhanced for acidic conditions so this analysis is conservative in it results in an upper bound of the expected iodine concentration in the vapor state. Incomplete mixing in the SCS could result in $10 \mathrm{cal}$ ized regions of high boron concentration (or low alkaline concentration) which could cause higher iodine concentrations in the vapor spaces. However, there would be other localized regions with smaller iodine concentrations which would tend to counteract the 
higher concentrations resulting in an average vapor concentration near that calculated using this assumption.

The third assumption is that the affected steam generator is isolated at transient initiation and all chemicals which flow into the SCS remain there. In an actual SGTR, this probably will not occur unt 11 somewhat later in the transient. However, one of the first operator actions is to isolate the affected steam generator so that excessive radloactive release is prevented. Therefore, the effect of this assumption should be small. The chemicals entering the SCS with the break flow are non-volatile in nature. Therefore, while some of the masses of these species will be in the vapor state, most will remain in the aqueous state and will be unaffected by continued steaming until the steam generator is isolated. The volatile SCS chemicals will be lost as steaming occurs. However, as long as feedwater flow exists, these will be replenished. Thus, the masses of these species $\left(\mathrm{NH}_{3}\right.$ and $\left.\mathrm{C}_{4} \mathrm{H}_{10} \mathrm{NO}\right)$ will be maintained with the feedwater injection. Some differences in dilution may occur if the feedwater flow is affected by the break flow, but these chemicals play a lesser role in the aqueous $\mathrm{pH}$ as discussed in the main report.

The assumption of independent chemical mass flow shouldn't be affected by the SGTR procedure and is judged to be sufficientiy accurate for this analysis. Neglecting the initial condition boron concentration in the SCS is likewise judged to be acceptable since the initial concentration is very small compared with the boron concentration due to injection from the RCS (a few ppm compared to several hundred ppm).

The assumption of constant boron concentration in the makeup system is considered to be accurate for this analysis. Makeup flow will most likely occur from a single source during the relatively short duration of an SGTR.

In summary, the assumptions made to simplify the analys is of SCS pH during an SGTR are judged to be either sufficiently accurate for the analysis or to result in a conservative bound on the iodine expected to be in the SCS vapor space and potentially released to the environment. 


\section{REFERENCES:}

C-1 Steam Generator Tube Rupture, Procedure E-3, Basic Revision, September 1,1981 . 
Table C-1: Typical SGTR Sequence of Events

1. Reactor trip - RCPs will shut down if offstte power is not avallable (A)

2. Turbine trip (A)

3. Loss of offsite power - if this occurs, RCPs stop operating, requiring pressurizer PORV operation to depressurtze RCS and resulting in incomplete mixing in the RCS (A)

4. Steam generator safety valves open $(A)$

5. Safety injection actuated (A)

6. Auxiliary feedwater actuated (A)

7. Main steamline valves closed $(0)$

8. Steam dump from unaffected steam generators - continued unti1 RCS temperature is $28 \mathrm{C}$ below no-load temperature $(0)$

9. Pressurizer PORV opened - continued unt 11 RCS pressure has equitibrated with that of the affected steam generator, terminating break flow (0) 


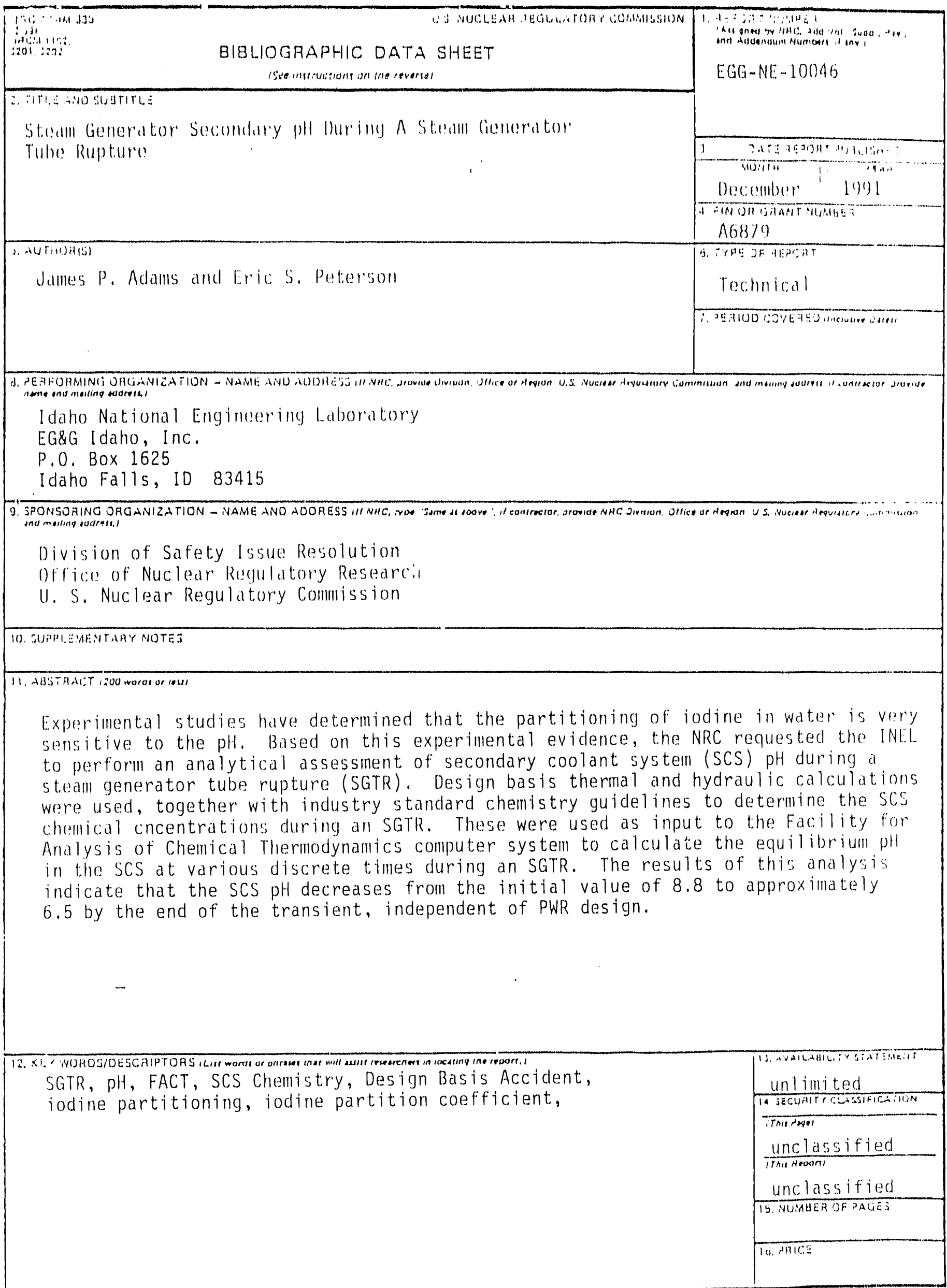



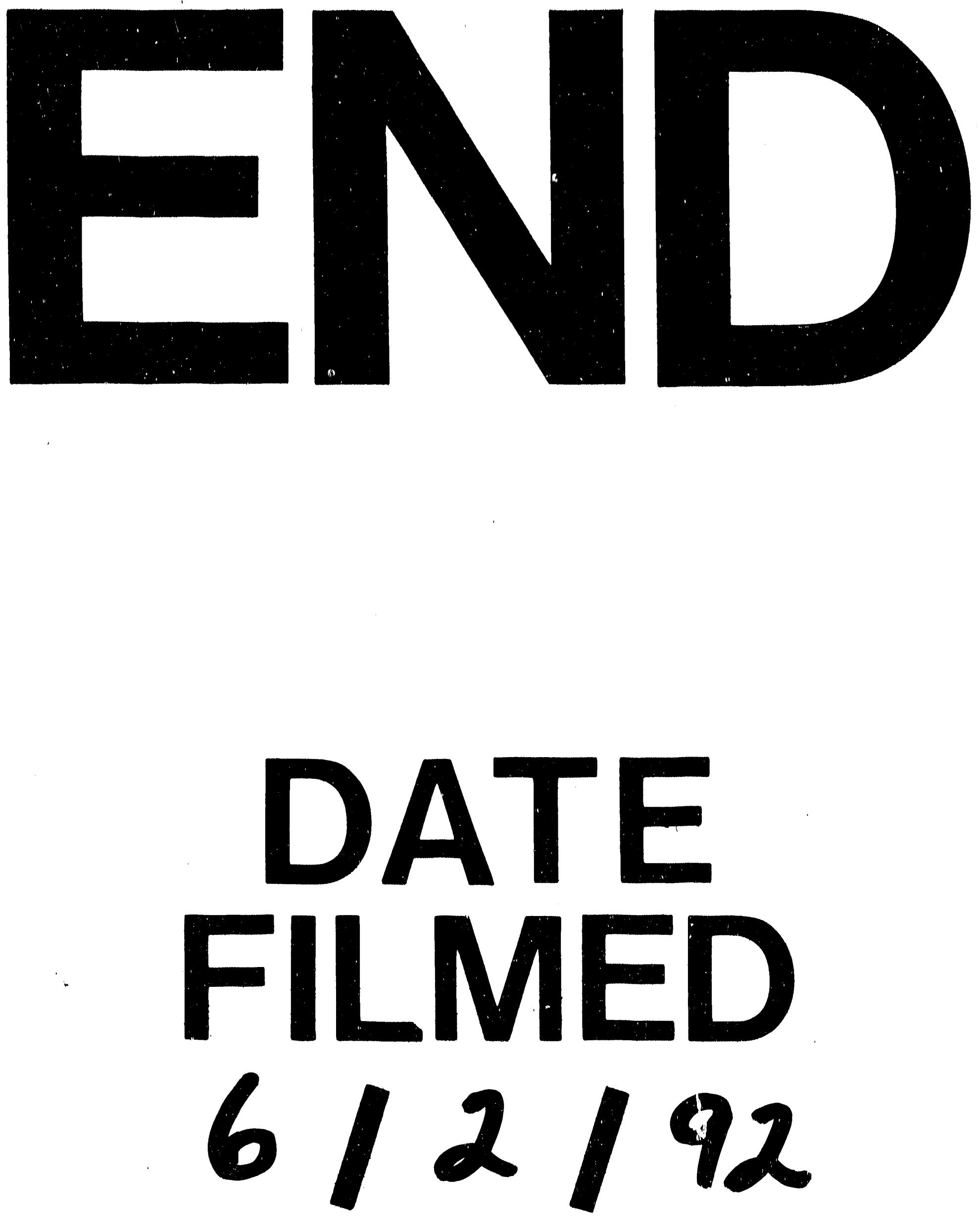
